\title{
Das Achilleis-Fragment
}

\subsection{Zwischen den Zeiten}

Die Achilleis ist nicht nur eine der unbekanntesten Dichtungen Goethes, sondern der deutschen Literaturgeschichte überhaupt. ${ }^{1}$ Als eines der wenigen unvollendeten Werke Goethes hat ihr fragmentarischer Status seit jeher als Begründung für das geringe Interesse sowohl von Seiten des Publikums wie auch der Literaturwissenschaft gedient. Bereits ihre Veröffentlichung steht noch im Schatten von Hermann und Dorothea - im Gegensatz zum äußerst erfolgreichen Idyllen-Epos wird dem Fragment über den antiken Helden kaum Beachtung geschenkt. ${ }^{2}$ Bezeichnenderweise führen auch weder die Münchner noch die Hamburger Gesamtausgabe Kommentare von Zeitgenossen über die Achilleis auf, während zu Hermann und Dorothea doch zahlreiche Dokumente präsentiert werden. Das Fragment hat weder auf die bürgerliche Leserschaft noch auf die Philologie eine große Wirkung ${ }^{3}$ und wird, wenn überhaupt, dann meist negativ aufgenommen. Dabei dreht sich die Auseinandersetzung mit dem Gedicht im Kern stets um die Frage nach der Nähe bzw. Entfernung der Achilleis zum homerischen Epos, ${ }^{4}$ also ihrer geistigen Zugehörigkeit entweder zur Antike oder zur Moderne und inwiefern ihr diese überhaupt zugutekommt.

Daran wird bereits deutlich, dass die Zuweisung von kulturellen Artefakten zu bestimmten Zeitstufen und die daran hängende Wertehierarchie auch nach 1800 noch ein vorerrschendes literaturwissenschaftliches Paradigma bilden. Die ungeklärte Zeitzugehörigkeit der Achilleis - noch Mitte des 20. Jahrhunderts beruft sich die Achilleis-Forschung auf die Dichotomie von homerisch-unhomerisch, ohne eine eindeutige Zuweisung zu leisten ${ }^{5}-$

1 Vgl. Dreisbach, Elke: Goethes Achilleis. Heidelberg: Winter 1994 (= Beiträge zur Neueren Literaturgeschichte, Folge 3, Bd. 130). S. 1.

2 Vgl. ebd. S. 62; Liggieri: Warum gelingt uns das Epische so selten? Ein Blick hinter Goethes Achilleis. S. 177 und Schadewaldt, Wolfgang: Goethes Achilleis. In:Ders.(Hrsg.): Goethestudien. Natur und Altertum. Zürich und Stuttgart: Artemis 1963. S. 301-395, hier S. 302.

3 Vgl. MA 6.1. S. 1099.

4 Vgl. Dreisbach: Goethes Achilleis. S. 63.

5 Vgl. Reinhardt, Karl: Tod und Held in Goethes Achilleis (Vortrag vor der Leipziger GoetheGesellschaft, Okt. 1944). In: Becker, Carl (Hrsg.): Tradition und Geist. Gesammelte Essays zur Dichtung. Göttingen: Vandenhoeck\&Ruprecht 196o. S. 283-308 und Schadewaldt: Goethes Achilleis. S. 301-395. 
macht aber gleichwohl deutlich, wie beschränkt und unzureichend die AntikeModerne-Dialektik als Ordnungs- und Bewertungsstrategie tatsächlich ist. Mit Blick auf Goethes Formdenken und der darin so zentral gestellten Zeitlichkeitsvorstellung der Gleichzeitigkeit lässt sich darüber hinaus vermuten, dass gerade die doppelte Zugehörigkeit zu Antike und Moderne die besondere Bedeutung der Achilleis ausmacht.

Dieser These soll im Folgenden nachgegangen werden, indem die Spannungsverhältnisse, die die Achilleis zweifellos bestimmen, auf die zeitgenössischen Problemerfahrungen der frühen Moderne hingewendet und als gezielte ästhetische Verfahrensweisen ausgestellt werden. Inwiefern die Achilleis die Probleme moderner Epik in zugespitzter Form ausstellt und so einen besonderen Zugang zu Goethes Eposverständnis eröffnet, soll zunächst entlang einer kurzen Rekapitulation ihrer Entstehungsgeschichte verdeutlicht werden. Im Weiteren soll dann - mit Verweisen auf den gattungspoetologischen Austausch mit Schiller auf der einen und einem Blick auf den engen entstehungsgeschichtlichen Bezug zum Faust auf der anderen Seite ein explizites Hybridisierungsprogramm für die Achilleis aufgespürt werden. Wie zu zeigen sein wird, versucht Goethe die entgegengesetzten Poetologien des Epischen und des Tragischen bewusst füreinander fruchtbar zu machen. Damit verfolgt er wohl einen hohen ästhetischen Anspruch, der sich allerdings deutlich vom klassizistischen Einheitsgebot abhebt. Denn während schon die Verbindung von Idylle und Epos, die in Hermann und Dorothea erprobt wurde, nicht unbedingt konform war mit der Forderung nach reinen Gattungen, ihr aber aufgrund der Wesensverwandtschaft der Formen immerhin eine gewisse Legitimität zugestanden werden konnte, ist die zu überwindende Diskrepanz zwischen Epos und Tragödie ungemein größer, ja $z u$ groß, um auf eine klar umrissene Gattung zurückführen zu können. Unter diesem Blickwinkel bestätigt sich der grundsätzlich experimentelle Status von Goethes EposProjekt und manifestiert sich darüber hinaus gerade auch ein veränderter, dynamischer Gattungsbegriff, wie er weiter oben vorgestellt wurde. ${ }^{6}$ Die Achilleis kann so trotz ihrer Fragmentarität als autonome Dichtung angesehen werden und erlangt gerade in ihrer Brüchigkeit spezifische Relevanz für die Moderne.

In einer vergleichenden Lektüre mit dem Faust-Drama soll dann schließlich auf die Schwierigkeiten und Möglichkeiten hingeführt werden, die sich Goethe durch sein Hybriditätsprogramm offenbaren. Ein besonderes Augenmerk gilt auch hier den sich manifestierenden ästhetischen Eigenzeiten,

6 Vgl. Kap. 3.2: Mediale Beschleunigung und die Verzeitlichung der Form und 3.3: Goethes explorative Epistemologie als Gegenmodell zum Empirismus. 
ihren Potenzialen und Funktionen. Zum einen kann daran aufgezeigt werden, wie in der modernen Tragödienform Beschleunigung als fatale Zeitsignatur der Moderne reflektiert wird. Und zum anderen soll nachverfolgt werden, inwiefern temporalen Gestaltungsstrukturen im Prozess der Moderne nicht nur gattungsbestimmende Bedeutung zukommt, sondern sich darüber gerade verschiedene Gattungen miteinander verbinden und zu neuen Formen fügen lassen. Letztlich kann der Achilleis aber auch insofern besondere Bedeutung beigemessen werden, als sie den Geltungsverlust normativer, absoluter Gattungsbegriffe nicht mehr allein auf der Ebene der Form reflektiert, sondern auch als eine Krise der Stoffe ausweist. Goethes Fragment soll hier als Werk aufgezeigt werden, an dem sich die Ablösung spezifischer Verfahrensweisen, wie eben dem Epischen, nicht nur von rein äußerlichen Formgesetzen, sondern auch von den ihnen traditionell zugewiesenen Gegenständen exemplarisch einsehen lässt. Der Stoff und seine Bearbeitung scheinen nämlich nur auf den ersten Blick beide ganz und gar von der Antike bestimmt. Tatsächlich verbindet die Achilleis auf der Ebene des Dargestellten das Problem moderner Epik mit der prekären Subjektkonzeption der Moderne und erweist sich damit als höchst selbstreflexive, sentimentalische Dichtung.

\subsubsection{Bemerkungen zur Forschungsgeschichte}

Sowohl die zeitgenössische Rezeption wie auch die spätere Forschung beurteilen das Fragment als epigonale ${ }^{7}$, gescheiterte ${ }^{8}$ und unbedeutende Dichtung am Ende von Goethes Epos-Projekt. ${ }^{9}$ Im Veröffentlichungsjahr befindet Karl August Böttiger gegenüber Friedrich Rochlitz, Goethes Werk fließe „im Ganzen“ „weder tief noch anmutig“ und tadelt besonders die antikisierenden Elemente als störende Künstlichkeit: „Es ist und bleibt effeoetae senectutis debilitas darin sichtbar. ${ }^{40}$ Auch Franz Grillparzer beurteilt das Fragment 1817 negativ, bemängelt seinerseits aber gerade die Entfernung von der antiken Vorlage:

7 Vgl. Martin, Dieter (Hrsg.): Das deutsche Versepos im 18. Jahrhundert. Studien und kommentierte Gattungsbibliographie. S. 296.

8 Vgl. Dietrich, Wolfgang: Die Geheimnisse, Achilleis, Das Tagebuch. S. 268-29o, hier S. 268.

$9 \quad$ Vgl.MA 6.1. S.1099. Allein die Tatsache, dass Goethe keine Hexameter-Epen mehr schreibt, kann jedoch nicht als Beweis für den endgültigen Interessensabbruch am epischen Erzählen ausreichen. Wie gezeigt wurde, ist der Hexameter nicht das zuverlässige Alleinstellungsmerkmal mehr, andere Merkmale verdrängen dieses Formelement zunehmend. Zudem zeugen nachfolgende Projekte wie Die Unterhaltungen, Die Wahlverwandtschaften, Wilhelm Meisters Wanderjahre und sogar Dichtung und Wahrheit von weiterführenden, experimentierfreudigen Bemühungen um ein modernegemäßes Erzählen im Spannungsfeld zwischen Epos und Roman (Novelle, Idylle) (Märchen, Biographie). 
Überhaupt ist es höchst traurig, dass G.(oethe) sich kein großes episches Sujet gewählt hat, er oder Niemand wäre der Mann gewesen es auszuführen, doch im strengen, dem Antiken sich nähernden Stile, eine romantische Behandlung dürfte ihm schwer geworden sein. Die erste Hälfte der Achilleis spricht für meine Meinung, in der zweiten Hälfte ist er freilich sehr aus dem Ton gefallen. ${ }^{11}$

Selbst Friedrich August Wolf hat der Achilleis gegenüber wohl eine ebenfalls ablehnende Haltung eingenommen, wie aus einem späteren Brief von Carl Friedrich Zelter hervorgeht. Dieser schreibt am 18. Februar 1826 an Goethe:

Am Ende sehen die Herren alle einander ähnlich und auch unser Selige (sc. Wolf) hätte nicht ungern von den Andern gefordert, was Er allein wollte gethan [sic] haben. Ich erinnere mich recht gut seiner Miene über Deinen neuen Gesang zur Ilias. Was er aber auch damit sagen wollte oder nicht: Den Gedanken hat er Dir nicht vergeben; er hat ihn beneidet wie ein Kaufherr der einen neuen Laden neben sich entstehen sieht. - Wie konntest Du Dir auch das herausnehmen! Hätte Er aber das Stück im Winkel einer Bibliothek selbst entdeckt, so hättest Du Deine Freude daran erleben sollen. ${ }^{12}$

An anderer Stelle schreibt Zelter:

[...] kurz vorher hatte ich die Ilias wieder ganz durchgelesen und zwar mit Hinsicht auf die Achilleis, welche ich darauf folgen ließ. Dabey hatte sich bey mir die alte Frage wieder hervorgethan [sic]: ob dieser Eine Gesang wohl, der Anfang einer Fortsetzung des Trojanischen Krieges, einen Folgeplan erwarten lasse, was bey einem so tiefen Studium des Homers sich denken lässt. Dabey fiel mir unser Wolf wieder ein, der mir seine hundert Hexameter für Dich übergeben wollte, und über den Gesang der Achilleis etwas leicht hinwegfuhr, indem ich ihm sagte: wenn ich soviel Griechisch wüsste als Er, so würd' ich mir das größere Verdienst erwerben die Achilleis in schöne Griechische Hexameter zu übetragen; worauf er denn wie natürlich den Laien ablaufen ließ und die Antwort bis heute schuldig geblieben ist. ${ }^{13}$

Inwiefern Wolfs Urteil über Goethes Achilleis tatsächlich auf Missgunst beruht, wie Zelter hier behauptet, lässt sich aufgrund einer fehlenden Überlieferung erster Hand nicht abschätzen. Es kann aber davon ausgegangen werden, dass Wolf sich nach außen hin wohl negativ über Goethes Fragment geäussert hat. Damit erschöpft sich die Überlieferung der zeitgenössichen Ressonanz auch

\footnotetext{
11 Grillparzer, Franz: Sämtliche Werke, hrsg. v. A. Sauer. II. Abteilung, Bd. 7. Wien, Leipzig: Cottasche Buchhandlung 1914. S. 106.

12 Goethe, Johann Wolfgang; Zelter, Carl Friedrich: Briefwechsel zwischen Goethe und Zelter in den Jahren 1799-1823, mit Einleitung und Erläuterungen hrsg. v. Ludwig Geiger, Bd. 2. Leipzig: Reclam 1902. S. $382 \mathrm{f}$. 
schon beinahe. F. W. Riemer zitiert die weitere Äußerung eines allerdings nicht näher bekannten Philologen der Epochenschwelle, in der die Kritikpunkte der frühen Rezeption noch einmal prägnant nachvollziehbar werden:

Dass aber, wie ein anderer von der Gilde behauptet, Goethes Absicht gewesen sei: es solle kein Vers in der Achilleis stehen, den Homer nicht könnte geschrieben haben - während in der That [sic] fast keiner darin stehe, den er geschrieben haben könnte - widerlegt sich durch das was G.(oethe) von der Kühnheit seines Versuchs und über die klare Einsicht der Unerreichbarkeit eines hohen Vorbildes bemerkt. Und dann: wo hätte denn G.(oethe) diese gesagt?14

Positive Reaktionen kommen allein aus Goethes privatem Umfeld, etwa von Charlotte von Schiller, der es gelingt, in der Verschränkung antiker und moderner Elemente eine Erneuerungsleistung zu erkennen: „Die Achilleis habe ich [...] mit Wehmuth wieder begrüßt, wie einen alten Freund, der aber

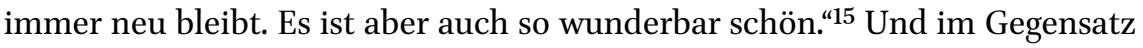
besonders zu Böttiger schätzt Carl Ludwig Knebel gerade die Authentizität sprich das Antike der Achilleis:

[...] und ich erfreute mich aufs neue über das herrliche Gedicht. Nicht jedem ist's erlaubt nach Corinth zu reisen, sagten die Alten. Du hast den Weg dahin auf mehr als eine Weise gefunden und wir finden immer neuen Vorrath [sic] in deinen Schriften, uns wieder zu ergötzen. ${ }^{16}$

Mehrheitlich wird die abgebrochene Achilleis also ungünstig beurteilt, ${ }^{17}$ neben der offenkundigen Fragmentarität wird ihr auch die wahlweise als übersteigert oder gescheitert wahrgenommene Annäherung an das antike Epos zum Verhängnis - zu unzugänglich und zu komplex sei das Gedicht auf der einen Seite und auf der anderen zu unselbständig und unbedeutend..$^{18}$ Bereits die frühe Philologie versucht das Fragment aus dem Blickwinkel der gattungstheoretischen Äußerungen des Briefwechsels zu beurteilen. Wie der verhalten positive Kommentar Zelters andeutet, wird die Achilleis von Anfang an in

14 Riemer, Friedrich Wilhelm: Mittheilungen über Goethe. Aus mündlichen und schriftlichen, gedruckten und ungedruckten Quellen, Bd. 2. Berlin: Duncker und Humblot 1841. S. $523 \mathrm{f}$.

15 Charlotte von Schiller an Goethe, 14.6.1808, zitiert nach Dreisbach: Goethes Achilleis. S. 62.

16 Knebel an Goethe, 7.11.1814, zitiert nach ebd.

17 Vgl. Schadewaldt: Goethes Achilleis. S. 301-395, hier S. 302.

18 Vgl. Liggieri: Warum gelingt uns das Epische so selten? Ein Blick hinter Goethes Achilleis. S. 177 . 
einem unmittelbaren Bedeutungszusammenhang mit der grundsätzlichen Gattungsdebatte über epische und dramatische Dichtung wahrgenommen:

Der Briefverkehr mit Schiller regt mich ganz eigens auf, und wie Ihr hier nebeneinander steht wird mir der verschiedene allgemeine Antheil [sic] wieder lebendig. Ihr beide kommt mir gegeneinander vor wie Einer der in Wechseln und Einer der baar zahlt. Du zweifelst fast dass ein Episches zwischen Hektors Tod und der Griechen Abfahrt inne liege und - machst eine „Achilleis“, die gleich einer stillen Wolke, von Zünftern an goldenen Rändern bestrichen, sich elastisch zusammenzieht und, ihren Kern verbergend, davongehoben wird. ${ }^{19}$

Goethes Gattungsgespräch mit Schiller scheint demnach wie kein anderes Werk einen legitimen literaturwissenschaftlichen Zugang zur Achilleis zu eröffnen und Aufschluss über ihre Gattungskonformität zu geben; ${ }^{20}$ und so setzt sich die Literaturwissenschaft auch standardmäßig auf der Gattungsebene mit dem Text auseinander. 1836 behandelt Georg Gottfried Gervinus die Achilleis erstmalig in seiner Abhandlung Über den Göthischen Briefwechsel, die sich, wie der Titel deutlich macht, aber vor allem dem 1828/1829 erschienenen Schiller-Goethe-Briefwechsel widmet. ${ }^{21}$ Gervinus beschränkt sich hierbei auf das Auflisten sämtlicher Bemerkungen Schillers und Goethes, die sich auf die Achilleis beziehen; auf die Dichtung selbst geht er nur insofern ein, als er sie im Vergleich mit den gattungstheoretischen Erörterungen als gescheiterten Nachahmungsversuch des homerischen Epos abqualifiziert. ${ }^{22} \mathrm{Er}$ problematisiert damit in erster Linie die Form der Achilleis, die nicht episch bzw. antik genug sei. Die ihm nachfolgende Forschung übernimmt sowohl Gervinus' Herangehensweise - das Messen an einer vermeintlich normativen Gattungspoetologie und das gleichzeitige Ausblenden der eigentlichen Textgrundlage - als auch gezwungenermaßen sein Urteil. ${ }^{23}$ Bis in die Hälfte

19 Zelter an Goethe, 14.3.1827. In: Goethe; Zelter: Briefwechsel, Bd. 3. S. 480.

$20 \quad$ Vgl. Dreisbach: Goethes Achilleis. S. 2.

21 Vgl. Gervinus, Georg Gottfried: Über den Göthischen Briefwechsel. Leipzig: Engelmann 1836 .

22 Vgl. ebd. S. 82 f.

23 Cholevius handelt die Achilleis in seiner Geschichte der Poesie nach ihren antiken Elementen mit einem einzigen Satz ab: „Das Gedicht vermischt Antikes und Modernes auf eine unleidliche Weise. Namentlich widersprechen die geistvollen Reden der Götter und Heroen in jeder Zeile der Einfalt der Homerischen Zeiten, in denen uns doch die Tatschen festhalten." Cholevius, Carl Leo: Geschichte der deutschen Poesie nach ihren antiken Elementen. Theil 1 und 2. Leipzig: Brockhaus $1854-1856$, 2. Theil. S. 313. Von Michael Bernays erscheint 1868 ein Aufsatz, der sich hauptsächlich mit der Frage nach Wolfs Einfluss auf die Achilleis auseinandersetzt. Darin geht er davon aus, dass Wolfs Thesen Goethe überhaupt erst zur epischen Produktion ermutigt haben und das Epos nur dank Wolf wiederholbar wird in der Moderne. Gleichzeitig macht Bernays Goethe den Vorwurf, 
des 2o. Jahrhunderts beschränkt sich die Literaturwissenschaft größtenteils darauf, die Achilleis einerseits gegen das antike Epos Homers, andererseits die gattungstheoretischen Überlegungen des Briefwechsels abzugleichen und dabei in erster Linie nach Gründen für den Abbruch der Dichtung zu suchen. Fragen nach der gattungspoetologischen Eindeutigkeit des Epischen und der Zugehörigkeit der Achilleis zu dieser Gattung werden dabei aber völlig außer Acht gelassen.

Erst um 1940 erhält die Diskussion neue Impulse und zwar von Seiten der Altphilologie, die der Achilleis gegenüber grundsätzlich positiver eingestellt ist, aber gleichfalls auf die Beurteilungsdialektik homerisch-unhomerisch zurückgreift. Exemplarisch dafür darf wohl Humphry Trevelyans Studie von

sich wie ein Antiker zu gebaren und dadurch den eigenen künstlerischen Impetus zu verhindern. „Dieser mühselige Versuch einer Wiedergeburt des homerischen Epos musste an der inneren Unmöglichkeit des Unternehmens scheitern“, lautet seine Schlussfolgerung, die damit die Bedeutung von Wolfs historisch-kritischer Altphilologie aber eigentlich im Unklaren lässt. Bernays, Michael (Hrsg.): Goethes Briefe an Friedrich August Wolf. Berlin: Reimer 1868. S. 33. Diese Perspektive übernimmt auch Friedrich Strehlke in seinem Aufsatz von 1870. Es sei Goethes Absicht gewesen, „von jeder modernen Zuthat [sic] abzusehen und die homerische Dichtungsweise vollständig zu reproduzieren." Dieses Ziel habe er aber nicht erreichen können und deshalb das Projekt aufgegeben. Strehlke, Friedrich: Über Goethes Elpenor und Achilleis. In: (Hrsg.): Goethes Werke. Nach den vorzüglichsten Quellen revidierte Ausgabe, Theil 5: Reineke Fuchs, Achilleis, Nachtrag lyrischer Gedichte, hrsg. und mit Anm. begleitet von Friedrich Strehlke. Berlin: Gustav Hempel 1870. S. 1-16.11 ff. Auch Otto Lücke gelangt zu dem Schluss, dass es Goethe nicht gelungen sei, „uns in die antike Welt hineinzuversetzen“, worin das Scheitern der Achilleis allerdings genau besteht, erläutert er nicht weiter. Lücke, Otto: Goethe und Homer. In: Kühlewein, Hugo (Hrsg.): Jahresbericht über die königliche Klosterschule zu Ilfeld. Nordhausen: Kirchners Buchdruckerei 1884. S. 1-51. In dieser frühen Forschungsphase findet sich allein bei Wilhelm Scherer eine positive Beurteilung: „[J]ene fünfhundert Verse“, schreibt dieser über Goethes Fragment, "gehören zu dem Schönsten, was er hervorgebracht." Scherer, Wilhelm: Geschichte der Deutschen Literatur, hrsg. v. Heinz Amelung. Berlin: Verlag von Th.Knaur Nachf. 1883. S. 576. Erst Heinrich Düntzer eröffnet am Ende des 19. Jahrhunderts eine alternative Perspektive auf Goethes Verhältnis zum homerischen Epos und damit auch auf die Achilleis. In dem er darauf hinweist, dass zwischen den Erörterungen des Briefwechsels mit Schiller und der Ausführung fast ein ganzes Jahr liegt und die Dichtung deshalb wohl aus einer andren "Stimmung" entstanden sei, führt er die Achilleis einer eigenständigen Interpretation zu. Als Goethe mit der Ausführung begonnen habe, „hatte er die sklavische Nachbildung Homers, an die er kaum einmal flüchtig hatte denken können, entschieden aufgegeben; sein Gedicht sollte sich frei und innerlich selbständig neben die Ilias stellen“. Düntzer, Heinrich (Hrsg.): Goethes Werke (= Deutsche NationalLiteratur. Historisch-kritische Ausgabe, Bd. 86: Hermann und Dorothea, Achilleis, Der ewige Jude, Reineke Fuchs). Berlin, Stuttgart: W. Spemann 1882-1897. S. 115 ff. Dieser Versuch, die Dichtung aus der Beurteilung als gescheiterte Nachahmung zu lösen und als Neuschöpfung zu betrachten, bleibt in der Literaturwissenschaft allerdings noch lange Zeit unbeachtet, vgl. Dreisbach: Goethes Achilleis. S. 5 . 
1941 genannt werden. ${ }^{24}$ Otto Regenbogen erkennt dann jedoch, dass „Goethe, freilich in einer gewandelten Welt [...] auch hier als Homeride dichtet [...], auch hier am Homerischen Faden weiterspinnt. [Hervorhebung M.E.]“. Regenbogen argumentiert zwar etwas vage, verweist aber erstmals deutlich auf eine Vorstellung der Kontinuität anstelle der unüberwindbaren Gegensätzlichkeit von Antikem und Modernem. ${ }^{25}$ Nach Kern ${ }^{26}$ und Morris ${ }^{27}$ unternimmt Wolfgang Schadewaldt 1963 den dritten ausführlichen Versuch, die Achilleis unter Einbezug der Paralipomena zu rekonstruieren - und zwar nicht nur den ersten Gesang, sondern die ganze geplante Dichtung. Auch Schadewaldt geht auf das Verhältnis von Goethes Achilleis und Homers Ilias ein, im Gegensatz zu vorhergehenden Untersuchungen beschreibt er dieses nun allerdings als ein gegenseitiges Durchdringen und ununterscheidbares Vermischen: „Antikes und Modernes, Griechisches und Abendländisches“, stellt er fest, würden sich "gegenüberstehen und vereinigen“. ${ }^{28}$ Eine eindeutige Bestimmung dessen, was an der Achilleis modern oder antik bzw. homerisch oder eben unhomerisch ist, gelingt durch diese Argumentation freilich nicht. Dafür führen aber das Aufdecken von Uneindeutigkeit in Goethes Werk und das Eingestehen von Unsicherheit bei dessen Interpretation gerade auf die spezifische Modernität des Textes. Insofern liefert Schadewaldt wichtige Vorarbeit für die hier angestrebte Neuperspektivierung von Goethes epischen Werken als Versuchen eines modernen Erzählens. Diesen innovativen Ansatz unterläuft er jedoch wieder, wenn er bei der Suche nach Gründen für den fragmentarischen Status der Dichtung wenig glaubwürdig argumentiert, „dass des Düsteren in seinem [Goethes] Plan der Achilleis so viel war, dass er es produktiv dichterisch nicht ausgehalten hätte“. ${ }^{29}$ Schadewaldts Hinführen auf die nicht auflösbaren Ambivalenzen der Achilleis als ihre eigentliche Signatur erweist sich für die unmittelbar folgende Forschung dann auch nicht als produktiv. ${ }^{30}$

24 Vgl. Trevelyan, Humphry (Hrsg.): Goethe and the Greeks. Cambridge: Cambridge University Press 1942.

25 Vgl. Regenbogen, Otto: Über Goethes Achilleis (1942). In: Dirlmeier, Franz (Hrsg.): Kleine Schriften. München: Beck 1961. S. 495-520.

26 Kern, Otto: Goethes Achilleis. In: Vossische Zeitung, Sonntagsbeilage Nr. 23 und Nr. 24 (1904). S. 180-183 und S. 189-192.

27 Morris, Max: Goethes Achilleis. In: Chronik des Wiener Goethe-Vereins Nr. 7/8 und Nr. 9/10 (1901). S. 26-35 und S. 38-44.

28 Schadewaldt: Goethes Achilleis. S. 301-395, insb. S. 390-395.

29 Ebd. S. 39o.

30 Fast 20 Jahre später erscheint überhaupt erst der nächste Beitrag, der Schadewaldts Position scharf ablehnt: Friedrich Sengle hält die Achilleis für ein „missglücktes Experiment", das gar keiner eigenen Untersuchung wert sei. Mit Verweisen auf Goethes Selbstaussagen versucht Sengle, das Fragment als „Nachahmung Homers“ aufzuzeigen, dass 
Mitte der goer Jahre regt Elke Dreisbachs Dissertation die literaturwissenschaftliche Beschäftigung mit der Achilleis dann allerdings neu an und etabliert für die ihr nachfolgende Forschung eine deutliche Hinwendung zum Text selbst. ${ }^{31}$ Sie leistet detaillierte Analysen von Goethes Handschrift, der angebrachten Korrekturen und der Erstausgabe, sowie eine sehr sorgfältige

überhaupt nur im „direkten Wettstreit mit dem antiken Epiker“ betrachtet werden könne. Sengle, Friedrich: Goethes Ikarus-Flug. Zur Forcierung des Homerisierens im AchilleisPlan. In: Ders. (Hrsg.): Neues zu Goethe. Essays und Vorträge. Stuttgart: Metzler 1989. S. 69-85. David Constantine, Wolfgang Dietrich und Dieter Martin folgen der Interpretation, dass es sich bei der Achilleis um ein gescheitertes Nachahmungsprojekt handle, mehr oder weniger unkritisch, vgl. Constantine, David: Achilleis and Nausikaa. Goethe in Homer's World. In: Oxford German Studies 15 (1984). S. 95-111; Dietrich: Die Geheimnisse, Achilleis, Das Tagebuch. S. 268-29o und Martin: Das deutsche Versepos im 18. Jahrhundert. Studien und kommentierte Gattungsbibliographie. Damit steht die Forschung in den 8oer und frühen goer Jahren des 20. Jahrhunderts wieder am gleichen Punkt wie am Ende des 19. Jahrhunderts.

31 Sowohl Thomas Gärtner, der sich auf das Motiv der Hoffnung beschränkt, als auch Benedikt Jessing befassen sich in ihren Aufsätzen aus dem Jahr 2009 fast ausschließlich textanalytisch mit dem ausgeführten ersten Gesang, vgl. Gärtner, Thomas: Das Motiv der Hoffnung in Goethes Achilleisfragment. In: Goethe Jahrbuch 126 (2009). S. 174-181 und Jessing, Benedikt: Zwischen Antikisierung und Moderne: Goethes Achilleis. S. 249-264. Auch für Liggieris Monographie von 2010, die unter Berücksichtigung der Gattungsdebatte nach den Schwierigkeiten des Epischen fragt, erweisen sich Dreisbachs Ergebnisse als wegweisend. In seiner Folgerung, dass das Moderne der Achilleis hauptsächlich in der Art liege, wie Goethe die metaphysische Welt-Einrichtung gestaltet habe, orientiert er sich maßgeblich an ihren Forschungsresultaten, vgl. Liggieri: Warum gelingt uns das Epische so selten? Ein Blick hinter Goethes Achilleis. S. 137-176 und 182. Einen besonderen Blickwinkel auf das Werk eröffnet dann Lars Friedrich in seinem Aufsatz zur semiotischen Bedeutsamkeit der Achilleis. Er liest das Fragment als symbolisches Gefüge und arbeitet daran heraus, wie in der Gattungsdebatte der Epochenschwelle, besonders bei Goethe und Schiller, die epische Darstellung hinter die epische Erzählung zurücktritt und sich auf den Ursprung des Zeichens begibt, vgl. Friedrich, Lars: Zeichenbaustellen. Goethes Achilleïs. In: Harst, Joachim; Mendicino, Kristina (Hrsg.): Sêma: Wendepunkte der Philologie. Würzburg: Königshausen \& Neumann 2013. S. 65-82. Ebenfalls 2013 schreibt Christoph Meid einen höchst beachtenswerten Aufsatz über die Achilleis, in dem dieser statt der Paralipomena Goethes Beziehung zu Homer stärker in den Blick nimmt und die Vielstimmigkeit der Dichtung nicht nur als deren besondere Eigentümlichkeit, sondern überhaupt als den Charakter von Goethes Epos ausmacht. Er erkennt die Achilleis als von vornherein gefährdetes Projekt, dessen ästhetischen Widerstände Goethe mal produktiv nutzen kann und die mal zu Verzweiflung und Überforderung führen. Gerade in diesem unauflösbaren Spannungsverhältnis zwischen kreativer Neuschöpfung und Nachschöpfung verortet Meid gleichwohl das Reizvolle wie auch das Befremdliche der Achilleis und liefert damit einen wertvollen Anknüpfungspunkt für die hier angestrebte Lektüre, vgl. Meid, Christoph: Goethes Achilleis - Versuch eines modernen Epos in der Nachfolge Homers. In: May; Zemanek (Hrsg.): Annäherung - Anverwandlung - Aneignung. Goethes Übersetzungen in poetologischer und interkultureller Perspektive. S. 83-101. 
Auswertung der Paralipomena. Vielfältige Bezüge zwischen Schemata, Gesamtplan und dem ausgeführten Text werden aufschlussreich herausgearbeitet und führen zu neuen Erkenntnissen. Die antiken Formen, legt Dreisbach dar, würden in der Achilleis eine ganz andere Funktion übernehmen, als in Goethes übrigen epischen Versuchen, sie dienten hier nämlich nicht der Imitation der Ilias, sondern vielmehr dazu, gerade die Andersartigkeit und Fremdheit der antiken Epik aufzuzeigen. Obwohl Dreisbach bemüht ist, auf der poetologischen und ästhetischen Eigenständigkeit der Achilleis zu beharren, entkommt sie der Suche nach Gründen für das Fragment nicht und schlussfolgert, dass das Scheitern der Achilleis auf die ästhetische Einheit und Abgeschlossenheit des antiken Epos zurückverweise. ${ }^{32}$ Damit gelingt ihr, wenn auch nicht die Überwindung des klassizistischen Paradigmas, so zumindest die Lösung aus der daran haftenden Wertematrix, nach der alles Antike zwar als ästhetisch vorzüglich aber künstlerisch uninspiriert, das Moderne hingegen als ästhetisch disparat, dafür schöpferisch eigenständig beurteilt wird. Die Altphilologie versucht die Dialektik von Antikem und Modernem also noch einmal fruchtbar zu machen für den Text. Letztlich vermag sie die Achilleis aufgrund eines einseitigen Fokus auf die Bindung an die antike Vorlage aber nur als gescheitert aufzuzeigen. Dieser Forschungsmeinung will die vorliegende Untersuchung im Folgenden eine alternative Perspektive zur Seite stellen, indem sie die formale - und wie zu sehen sein wird auch stoffliche - Hybridität der Achilleis als ihre besondere ästhetische Qualität in den Blick nimmt.

\subsection{Gattungsreflexion: Die Achilleis als hybride Komposition aus Epischem und Tragischem}

Im Achilleis-Projekt scheinen die Fragen nach einer klaren Gattungsdifferenzierung und der Umsetzbarkeit einer epischen Poesie in der Moderne besonders eng ineinander zu greifen. Wie bereits die skizzierte Rezeptionsgeschichte gezeigt hat, ist die Entstehung der Achilleis nicht zu trennen von der Gattungsdiskussion mit Schiller und der grundsätzlichen Frage, welche Stoffe wie zu bearbeiten sind. Nicht zufällig findet sich der erste Hinweis auf ein mögliches Epos über den griechischen Helden in demselben Brief, mit dem Goethe Ende 1797 den Aufsatz Über epische und dramatische Dichtung an Schiller übersendet: „ob nicht zwischen Hectors Tod und der Abfahrt der Griechen von der Trojanischen Küste, noch ein episches Gedicht inne liege?“33,

32 Vgl. Dreisbach: Goethes Achilleis. S. 222.

33 Goethe an Schiller am 23.12.1797, BW. S. 537. 
fragt er hier rhetorisch. Ab Frühling 1798 nimmt dann die gattungstheoretische Besprechung der Achilleis bereits lange vor ihrer Ausführung sehr viel Platz im Briefwechsel der Dichterfreunde ein. Erst ein Jahr später schreibt Goethe den ersten und einzigen Gesang seiner Achilleis nieder, danach bricht die Arbeit jedoch ab. ${ }^{34}$ Bezeichnenderweise ebbt gleichzeitig auch das Interesse am Epischen und überhaupt der Poetik der Gattungen ab - im Briefwechsel mit Schiller stellt die Gattungsfrage ab 1800 keinen wesentlichen Gegenstand mehr dar und andere Themen rücken nun in den Fokus. ${ }^{35}$ Wie im Folgenden deutlich werden wird, steht die Achilleis neben der gattungstheoretischen Reflexion aber auch in unmittelbarer Verbindung mit Goethes wohl berühmtesten und erfolgreichsten Werk überhaupt, der Faust-Dichtung. Inwiefern die gegenseitige Befruchtung dieser beiden Werke, die auf den ersten Blick nicht gegensätzlicher sein könnten, einer deutlichen Hybridisierungpragmatik folgt und nicht nur die Erneuerung des Epischen, sondern auch des Tragischen vorantrieben, soll hier zunächst in ihrem entstehungsgeschichtlichen Zusammenhang sichtbar gemacht und anschließend vertieft werden.

\subsubsection{Goethes Faust, die Tragödie der Moderne und die Vermischung der Formen}

Goethe veröffentlicht von seinem Faust-Projekt, das ihn fast sein ganzes Leben lang begleitet, ${ }^{36} 1790$ das Brüchstück Faust, ein Fragment in seinen gesammelten Schriften. ${ }^{37}$ Danach bleibt die Arbeit jahrelang liegen, bis Goethe Schiller am 22. Juni 1797 überraschend ${ }^{38}$ mitteilt: „Da es höchst nöthig [sic] ist dass ich mir, in meinem jetzigen unruhigen Zustande, etwas zu thun [sic] gebe, so habe ich mich entschlossen an meinen Faust zu gehen [...]."39 Damit fällt die Wiederaufnahme der Tragödie mitten in Goethes epische Phase, zwischen die Beendigung von Hermann und Dorothea und die intensivierte Ilias-Lektüre auf der Suche nach einem neuen epischen Stoff. Die produktive Beschäftigung mit dem Faust dauert bis Anfang Juli und bricht dann aber erneut ab. „Faust ist die Zeit zurückgelegt worden“, meldet Goethe Schiller, „die nordischen Phantome

34 Erst Jahre später wird er die Achilleis erneut erwähnen: „Verschiedene romantische Sujets überlegt. Verwandlung der Achilleis in einen Roman." Eintrag vom 10.8.18०7, WA III, 3 . S. 255. 1808 wird das Fragment im Rahmen der von Cotta besorgten Gesamtausgabe überhaupt erst veröffentlicht, vgl. FA I, 8. S. 1135 .

35 Vgl. Dreisbach: Goethes Achilleis. S. 11.

36 Vgl. Die Entstehung. In: Goethe, Johann Wolfgang: Faust. Der Tragödie erster und zweiter Teil. Urfaust, hrsg. v. Erich Trunz. München: Beck 2010. S. 477-481.

37 Vgl. Goethe über seinen Faust und Quellen zur Entstehungsgeschichte In: Ebd. S. 426.

38 Schiller antwortet am 23.6.1797: „Ihr Entschluss, an den Faust zu gehen, ist mir in der That überraschend, besonders jetzt, da Sie Sich zu einer Reise nach Italien gürten.", BW. S. 410. Goethe an Schiller, 22.6.1797, BW. S. 409. 
sind durch die südlichen Reminescenzen auf einige Zeit zurückgedrängt worden, doch habe ich das ganze als Schema und Uebersicht sehr umständlich durchgeführt". ${ }^{40}$ Wenn Goethe im Dezember 1797 dann versucht, die sich über das ganze vorhergehende Jahr erstreckende gattungspoetologische Debatte in einem Aufsatz zu bündeln, dann geschieht das nicht zufällig genau in dem Moment, als sich ihm mit der Achilleis ein neues episches Projekt offenbart und die Arbeit am Faust immer noch im Raum steht. ${ }^{41}$ In diesem Nebeneinandertreten von moderner Faust-Tragödie und antike-inspiriertem Achilleis-Epos wird nämlich gerade der Vergleich von Homers Ilias mit Sophokles' dramatischen Tragödien wieder aufgenommen und insofern die Ausgangslage für Goethes Gattungsgespräch mit Schiller reflektiert. ${ }^{42}$

Im darauffolgenden Jahr unterbricht Goethe am 9. April seine erneute IliasLektüre ${ }^{43}$ nach dem gleichen Muster: „Faust wieder vorgenommen.44 ${ }^{44}$ Direkt an seine früheren Worte anknüpfend erklärt er in einem Brief an Charlotte Schiller: „Vor die schöne homerische Welt ist [...] ein Vorhang gezogen und die nordischen Gestalten, Faust und Companie, haben sich eingeschlichen. ${ }^{45}$ Am Faust arbeitet Goethe nun bis Anfang Mai rege weiter, so dass er Schiller am fünften des Monats mitteilen kann: „Meinen Faust habe ich um ein gutes weiter gebracht.“46 Auch diese produktive Faust-Phase bricht nun aber plötzlich ab und Goethe wendet sich erneut der Ilias $\mathrm{zu}$, am 11. Mai vermerkt das Tagebuch: „Die Ilias wieder vorgenommen. ${ }^{47}$ Erst im Frühling des folgenden Jahres führt Goethe den ersten Gesang seiner Achilleis aus, zwischen dem

40 Goethe über seinen Faust und Quellen zur Entstehungsgeschichte des Faust. S. 428 f.

41 Vgl. Friedrich: Zeichenbaustellen. Goethes Achilleïs. S. 65-82, hier S. 65 .

42 Vgl. Goethe an Schiller, 23.12.1797: „Ich habe mich seit einigen Tagen dieser Criterien beym Lesen der Ilias und des Sophokles bedient, [...]., BW. S. 535 .

43 29. März 1798: „Schema zur Äneis. In der Ilias gelesen. [...].“ 31. März 1798: „Die Ilias. Verschiedne Schriften aus der Bibliothek die sich darauf beziehen. Schemata und Auszüge.“ 1. April 1798: „Fortsetzung der Arbeit an der Ilias. [...].“ 2. April 1798: „Wood über Homer. Schema fortgesetzt. [...]“” 3. April 1798: „Le Chevalier Ebene von Troja und dahin einschlagende Betrachtungen. [...] Mittag zu Schiller, wo viel über die neuen epischen und tragischen Unternehmungen gehandelt wurde. [...].“ 11. Mai 1798: „Die Ilias wieder vorgenommen.“ 12. Mai 1798: „Ilias fortgesetzt. [...].“ 13. Mai 1798: „Früh Ilias fortgesetzt. [...].“ 14. Mai 1798: „Früh Ilias. [...].“ 15. Mai 1798: „Früh Ilias fortgesetzt. [...].“ 16. Mai 1798: „Ilias fortgesetzt. [...].” 17. Mai 1798: „Ilias fortgesetzt. [...].“ 21. Mai 1798: „Das Schema der Ilias geendigt. Vorbereitung zu andern Arbeiten. Gegen Abend bey Schiller, den Humboldtischen Aufsatz über das Epische Gedicht angefangen. Alsdenn noch viel über die Ilias sowohl im ganzen als in den Theilen." WA III, 2. S. 200-208.

44 Goethe über seinen Faust und Quellen zur Entstehungsgeschichte des Faust. S. 428.

45 WA IV, 13. S. 116.

46 Goethe an Schiller, 5.5.1798, BW. S. 65 o.

47 WA III, 2. S. 207. 
10. März und dem 5. April 1799 schreibt er die $65_{1}$ Verse fast 10 Monate nach seinen theoretischen Überlegungen nieder. ${ }^{48}$ Am 15. Mai wird das Gedicht zum vorläufig letzten Mal im Tagebuch erwähnt: „Verschiedne Correcturen [...] theils [sic] an der Achilleis." 49 Obwohl die beiden gründlich ausgearbeiteten Schemata demonstrieren, dass die Konzeption des Werks weit fortgeschritten war, ${ }^{50}$ brechen damit die Arbeit an der Achilleis und überhaupt die Bemühungen um das Epische ab, ohne dass Goethe sogleich ein neues Projekt in Angriff nehmen würde. ${ }^{51}$ Am 11. April 18oo nimmt er jedoch, angeregt von Cotta und Schiller, ${ }^{52}$ die Arbeit am Faust wieder auf und setzt diese bis September erfolgreich fort. Zu Beginn des Jahres 1801 bricht die Produktivität ab, ${ }^{53}$ erst im Frühling 1806 wird Goethe das vorläufig letzte Arrangement zum Druck geben, ${ }^{54}$ welches dann verzögert durch die Kriegswirren von 18o6/1807 zur Ostermesse im Jahr 1808 erscheinen wird. ${ }^{55}$ Die entscheidende Arbeit

48 Erst im Februar 1799 wird die Achilleis überhaupt erst wieder erwähnt, vgl. dazu den Tagebucheintrag vom 17. Februar 1799: „[...] Abends Achilleis besprochen.“, Tagebucheintrag vom 10. März 1799: „Schema der Achilleis. Anfang der Ausführung“ und Tagebucheintrag vom 5. April 1799: „Achilleis, Schluss des ersten Gesangs“. WA III, 2. S. 235, 236 und 241.

49 WA, III, 2. S. 249.

50 Vgl. MA 6.1. S. 1103-1114. Goethe erarbeitet 1798 zunächst einen einheitlichen Gesamtentwurf und 1799 ein zweites Schema, welches mehr Details enthält, einzelne Gesänge skizziert und insgesamt stärker auf die konkrete Ausführung ausgerichtet ist. Der Abschluss dieses Schemas wird auf den 10. Mai datiert, während die Ausführung des ersten Gesanges bereits am 5 . April zu einem Ende gekommen ist. Damit geht die Planung deutlich über die Ausführung hinaus. Dazu vgl. auch Dreisbach: Goethes Achilleis und Meid: Goethes Achilleis - Versuch eines modernen Epos in der Nachfolge Homers. S. 83-101, hier S. 83 .

$5^{1} \quad$ Vgl. Dreisbach: Goethes Achilleis. S. 11.

52 Schiller schreibt am 24. März 1800 an Cotta: „Nun noch einen guten Rat. Ich fürchte, Goethe lässt seinen Faust, an dem schon so viel gemacht ist, ganz liegen, wenn er nicht von außen und durch anlockende Offerten veranlasst wird, sich noch einmal an diese große Arbeit zu machen und sie zu vollenden [...] Sie können ihn, da bin ich überzeugt, durch glänzende Anerbietungen dahin bringen, dieses Werk in diesem Sommer auszuarbeiten [...]." Tatsächlich gelingt dieses Vorhaben, das bezeugt wiederum Goethe in einem Brief an Schiller vom 11. April 180o: „Cottas Freiheit ist mir sehr angenehm. Ich habe einen Brief von ihm über Faust, den Sie mir wahrscheinlich zugezogen haben; wofür ich aber danken muss, denn wirklich habe ich auf diese Veranlassung das Werk heute vorgenommen und durchdacht.“ Im Tagebuch heisst es dann am 11. April: „Brief von Cotta. Faust angesehen.“ - 13. April: „Faust" - 14. April „Faust“ - in ähnlicher Weise immer wieder Tagebuchnotizen bis zum 5. September. Goethe: Faust. Der Tragödie erster und zweiter Teil. S. 431.

53 Zwischen dem 18. März 1801 und dem 30. September 1805 sind weder in den Tagebüchern noch in den Briefen Goethes Erwähnungen des Faust zu finden, vgl. ebd. S. 433 f.

54 Tagebucheintrag vom 25.4.18o6: „Faust letztes Arrangement zum Druck.“ WA III, 3. S. 126.

55 Vgl. Goethe: Faust. Der Tragödie erster und zweiter Teil. S. 434. 
am Faust wird also einmal im Sommer 1797 und einmal im Frühsommer 1798 durch Goethes Homer-Studium sowie die Achilleis-Arbeit unterbrochen, oder fällt vielmehr damit zusammen, wie die aufgeführten Äußerungen deutlich machen. In den Jahren 1797 bis 1800 hat Goethe demnach die Gestalten des Achilles und des Faust - und mit ihnen die Erzähl- und Darstellungsweisen des Tragischen und des Epischen - gleichzeitig „in seiner Seele gehegt" ${ }^{46}$ und wechselweise an dem einen wie dem anderen Gedicht geplant und gearbeitet.

Für die Entstehung des Achilleis-Epos erweist sich damit die Auseinandersetzung nicht mit der Idyllenform wie bei Hermann und Dorothea, sondern explizit mit der Poetologie des Tragischen als besonders ergiebig. Darauf, dass das Epische und das Tragische in einer durchaus komplexen gattungspoetologischen Beziehung zueinander stehen, wurde bereits an anderer Stelle der vorliegenden Untersuchung hingedeutet. ${ }^{57}$ Darüberhinaus hat sich allerdings ebenfalls abgezeichnet, dass die Diskussion um epische und dramatische Dichtung keine eindeutige Abgrenzung zwischen der dramatischen Darstellung und der spezifischen Form der Tragödie leistet, geschweige denn auf die Besonderheiten explizit moderner Tragik eingeht. Dabei führt die durch die Querelles des Anciens et des Modernes angestoßene Debatte über moderne und antike Kunstformen sehr wohl auch zu einer Befragung der Tragödie und ihrer jeweiligen Besonderheiten in der Antike und der Moderne. ${ }^{58}$

Grundvoraussetzung für die kritische Auseinandersetzung mit der Antike ist eine klare Differenzierung zwischen der antiken Form des Tragischen und einem spezifisch modernen Verständnis dieser Formensprache. ${ }^{59}$ Diese Distinktion ist gerade für Schiller und seine Erneuerung der Tragödie, in deren Zentrum die moderne conditio humana steht, von größter Bedeutung. Ausgehend von der Frage nach dem Vergnügen an tragischen Gegenständen erörtert er 1791 die Bedingungen und Zuständigkeiten des Tragischen und verbindet dabei die traditionell affekttheoretische Orientierung der Gattungstheorie mit seiner Philosophie des Erhabenen. ${ }^{60}$ Damit schließt er einerseits an Lessings bürgerliches Trauerspiel und dessen Ersetzung des klassisch-

\footnotetext{
$5^{6}$ Schadewaldt: Fausts Ende und die Achilleis. S. 283-30o, hier S. 288.

57 Vgl. S. $121 \mathrm{ff}$. in diesem Buch.

$5^{8}$ Vgl. Jauss, Hans Robert: Schlegels und Schillers Replik auf die ,Querelles des Anciens et des Modernes. In: Ders. (Hrsg.): Literaturgeschichte als Provokation (= Edition Suhrkamp, 418). Frankfurt a. M.: Suhrkamp 1970. S. 67-106.

59 Vgl. Jessing: Zwischen Antikisierung und Moderne: Goethes Achilleis. S. 249-264, hier S. 249 .

6o Vgl. Schiller, Friedrich: Über den Grund des Vergnügens an tragischen Gegenständen. In: Ders.: Sämtliche Werke, Bd. 5. S. $35^{8-372 .}$
} 
aristokratischen Helden durch ein bürgerliches Individuum ${ }^{61}$ an und setzt sich mit seiner Fokussierung auf die ästhetische Dimension des Tragischen gleichwohl davon ab. Ausgangspunkt für Schillers Theorie des Erhabenen, und damit auch für seine Konzeption der Tragödie, ist Kants dualistische Anthropologie. Diese beschreibt das Wesen des Menschen als innere Zerrissenheit zwischen Vernunft und Sinnlichkeit, Natur und Geist, Notwendigkeit und Selbstbestimmung. Das besondere Potenzial des Erhabenen sieht Schiller nun im Gegensatz zum Schönen gerade darin, diese „Disharmonie“62 nicht zu überspielen, sondern sie vielmehr aufzudecken und darüber hinaus mit den Vorstellungen von Freiheit und Selbstbestimmung in Verbindung zu bringen. In der Konstellation des Erhabenen wird die Dialektik von Sinnlichkeit und Vernunft nämlich durch die Gewissheit überboten, dass „unsere vernünftige Natur" gerade dann, wenn die physische Natur in ausweglose Bedrängnis gerät, „ihre Überlegenheit, ihre Freiheit von Schranken fühlt" und sich als „unbezwingliche Burg unserer moralischen Freiheit "63 formiert. ${ }^{64}$

Der unhintergehbare Schicksalszwang der aristotelischen Tragödie wird hier vom Streben des modernen Individuums nach Selbstbestimmung und moralischer Autonomie abgelöst. Mit dieser Durchsetzung moralischer Unabhängigkeit gegen die physische Natur steht im Zentrum von Schillers Tragödienkonzeption eine Figur der Selbstentzweiung. So überführt er nicht nur den Kern des Tragischen in eine Dialektik, sondern setzt darüber hinaus auch antike und neuzeitliche Tragödie in ein dialektisches Verhältnis. Aus diesem Blickwinkel kann nämlich gerade sichtbar gemacht werden, dass das moderne, reflektierende Subjekt und die antike Tragödie als Gegenstand dieser Reflexion, die mythisch begründete Wirklichkeit des Tragischen und das in der Neuzeit von dieser Wirklichkeit getrennte Individuum kraft dialektischer Dynamik auseinander hervorgehen. ${ }^{65}$ Insofern werden in Schillers Konzeption des Tragischen die traditionell wirkungsästhetischen Zielsetzungen mit einer reflexiv-philosophischen Gattungsbegründung komplementiert. Dadurch nimmt er allerdings eine entscheidende Wertung und Hierarchisierung zwischen antiker und moderner Tragödie vor, repräsentieren sie doch zwei ganz voneinander abgetrennte Entwicklungsstadien des menschlichen Bewusstseins. Während der neuzeitlichen Tragödie die Projektion von Selbstbestimmung

61 Vgl. Lamping, Dieter (Hrsg.): Handbuch der literarischen Gattungen. Stuttgart: Kröner 2009. S. 148 f. (Drama).

62 Schiller, Friedrich: Über das Pathetische. In: Ders.: Sämtliche Werke, Bd. 5. S. 520.

63 Ebd. S. 489.

64 Vgl. Galle, Roland: Tragisch/Tragik. In: Barck; Fontius et al. (Hrsg.): Ästhetische Grundbegriffe: Historisches Wörterbuch in sieben Bänden, Bd. 6. S. 117-171, hier S. 153 f.

65 Vgl. ebd. S. 151. 
und Mündigkeit eingeschrieben wird, steht ihre antike Vorlage für blinde Schicksalsergebenheit. Für Schiller ist die antike Tragödie

eine Erscheinung ihrer Zeit, die nicht wiederkommen kann, und das lebendige Produkt einer individuellen bestimmten Gegenwart einer ganz heterogenen Zeit zum Maßstab und Muster aufdringen, hieße die Kunst, die immer dynamisch und lebendig entsteht und wirken muss, eher töten als beleben. Unsere Tragödie, wenn wir eine solche hätten, hat mit der Ohnmacht, der Schlaffheit, der Charakterlosigkeit des Zeitgeistes und mit einer gemeinen Denkart zu ringen, sie muss das Gemüt erschüttern, zu heben, aber nicht aufzulösen suchen. Die Schönheit ist für ein glückliches Geschlecht; aber ein unglückliches muss man erhaben zu rühren suchen. [Hervorhebungen M.E. $]^{66}$

Neben der Bestimmung des Erhabenen als gleichwohl notwendige Wirkung und Ziel des modernen, sentimentalischen Dichters beharrt Schiller hier prominent auf der Einsicht unhintergehbarer historischer Differenz. Der Tragödienbestimmung liegt damit die rigide und grundsätzliche Abrichtung auf ein lineares Zeitgefüge zugrunde, welches die Gattungsgeschichte als eine kontinuierliche Traditionsentwicklung strukturiert, ${ }^{67}$ in der die jeweils zeitlich verfassten Ausprägungen in einem strengen Abfolgeverhältnis stehen.

Im Unterschied zu Schiller, der sich mit seiner Tragödienkonzeption von der Antike abwendet und ganz dem modernen Zeitgesetz des Fortschritts verschreibt, steht für Goethe gerade die Vermittlung zwischen den unterschiedlichen Zeiten und was daraus für die Gegenwart gewonnen werden kann, im Vordergrund. In der Denkfigur der Gleichzeitigkeit des Ungleichzeitigen lassen sich nicht nur die einzelnen Gattungen in ein wechselseitiges Wirkungsverhältnis setzen, sondern auch ihre jeweiligen Zeitsignaturen. Dieses auf Komplementarität ausgerichtete Formdenken versucht sich Goethe nicht nur für das Epische und die Achilleis, sondern gerade auch für die Tragödie zunutze zu machen, gerät damit aber auch immer wieder in produktionsästhetische Schwierigkeiten. An die behutsame Frage nach der Möglichkeit einer epischen Bearbeitung des eigentlich tragischen Achilles-Stoffs schließt Goethe ein „oder nicht?" an und gibt gleich selbst die Antwort: „ich vermute fast das letzte.“68

66 Schiller an Professor Johann Wilhelm Süvern, 26.7.180o. In: Schiller, Friedrich: Werke und Briefe in zwölf Bänden, Bd. 12. S. $5^{22}$.

67 Vgl. Jessing: Zwischen Antikisierung und Moderne: Goethes Achilleis. S. 249-264, hier S. $249 \mathrm{f}$.

68 Goethe an Schiller, 23.12.1797: „ob nicht zwischen Hektors Tod und der Abfahrt der Griechen von der Trojanischen Küste, noch ein episches Gedicht inne liege? ich vermuthe fast das letzte [...].“ BW. S. 537 . 
Damit wird die Aufgabe des Projekts nahegelegt, bevor es überhaupt in Angriff genommen wurde.

Dass Goethe der Achilleis nun aber doch keine Absage erteilt, sondern weiter der Frage nach einer epischen Behandlung nachgeht, geht auf Schillers Beschreibung der Beziehung zwischen dem Epischen und dem Dramatischen als eine grundsätzliche Hybridität bzw. gegenseitige Wechselwirkung zurück:

Die Tragödie in ihrem / höchsten Begriffe wird also immer zu dem epischen Character hinaufstreben und wird nur dadurch Dichtung. Das Epische Gedicht wird eben so zu dem Drama herunterstreben und wird nur dadurch den poetischen Gattungsbegriff ganz erfüllen; just das, was beide zu poetischen Werken macht, bringt beide einander nahe. Das Merkmal, wodurch sie specifiziert [sic] und einander entgegen gesetzt werden, bringt immer einen von beiden Bestandtheilen des poetischen Gattungsbegriffs ins Gedränge, bei der Epopee die Sinnlichkeit, bei der Tragödie die Freiheit, und es ist also natürlich, dass das Contrepoids gegen diesen Mangel immer eine Eigenschaft seyn [sic] wird, welche das specifische [sic] Merkmal der entgegengesetzten Dichtart ausmacht. Jede wird also der andern den Dienst erweisen, dass sie die Gattung gegen die Art in Schutz nimmt. Dass dieses wechselseitige Hinstreben zu einander nicht in eine Vermischung und Grenzverwirrung ausarte, das ist eben die eigentliche Aufgabe der Kunst, deren höchster Punkt überhaupt immer dieser ist, Charakter mit Schönheit, Reinheit mit Fülle, Einheit mit Allheit pp zu vereinbaren. ${ }^{69}$

Auch wenn Schiller grundsätzlich vor dem Ausarten der Formenvermischung warnt, stößt er hier den Gedanken an, dass eine gewisse gegenseitige Durchdringung der Wesensmerkmale der Formen für die moderne Dichtung zugelassen werden kann, ja sogar zugelassen werden muss. Damit legitimiert er nicht nur das Verfahren der gegenseitigen Integration, sondern führt auch auf die Idee einer gelingenden Verbindung von Gegensätzen als besonderen ästhetischen Gewinn. Dass Goethe in der Abweichung vom reinen, idealischen Formanspruch dann ebenfalls neue Gestaltungsmöglichkeiten und darüber hinaus die Qualifikation einer Dichtung für die neue Zeit erkennt, geht klar auf diesen Impuls Schillers zurück. ${ }^{70}$ Daran lässt sich nicht nur nachvollziehen, wie stark die Entstehung der Achilleis in den grundsätzlichen Gattungsfragen verwurzelt ist, sondern zeigt sich auch, auf welchem produktiven Höhepunkt sich der geistige Austausch zwischen Schiller und Goethe in den Jahren 1797 bis 1799 befindet.

Wann immer Goethe Zweifel an seinem Vorhaben hegt oder in Widersprüche gerät, sorgt Schiller mit seinem fortwährenden Eingreifen für Orientierung

$69 \quad$ Schiller an Goethe, 26.12.1797, BW. S. 542 f.

$70 \quad$ Vgl. Dreisbach: Goethes Achilleis. S. 23. 
und Klärung. So etwa Mitte Mai des Jahres 1798, als Goethe während er Arbeit an der Achilleis erneut die Ilias herbeizieht und aus dieser Lektüre aber nicht nur Inspiration, sondern gerade auch Verunsicherung über das eigene Vorgehen erfährt:

Das Studium [der Ilias] hat mich immer in dem Kreise von Entzückung, Hoffnung, Einsicht und Verzweiflung durchgejagt. Ich bin mehr als jemals von der Einheit und Untheilbarkeit [sic] des Gedichts überzeugt, [...]. Die Ilias erscheint mir so rund und fertig, man mag sagen was man will, dass nichts dazu noch davon gethan [sic] werden kann. Das neue Gedicht das man unternähme [sic] müsste man gleichfalls zu isoliren [sic] suchen und wenn es auch, der Zeit nach, / sich unmittelbar an die Ilias anschlösse. ${ }^{71}$

„Das wichtigste bey [sic] meinem gegenwärtigen Studium“, schließt Goethe aus dieser Beobachtung, ,ist[,] dass ich alles subjective [sic] und pathologische aus meiner Untersuchung entferne“, womit er zwischenzeitlich auf eine streng normative Imitationsprogrammatik zurückzukommen scheint:

Soll mir ein Gedicht gelingen, das sich an die Ilias einigermasen [sic] anschlißet; so muss ich den Alten auch darinne folgen worin sie getadelt werden, ja ich muss mir zu eigen machen was mir selbst nicht behagt; dann nur werde ich einigermaßen sicher seyn [sic] Sinn und Ton nicht ganz zu verfehlen. Mit den zwei wichtigen Puncten [sic], dem Gebrauch des göttlichen Einflusses und der Gleichnisse, glaube ich im reinen zu seyn [sic], wegen des letzten habe ich wohl schon etwas gesagt. Mein Plan erweitert sich von innen aus und wird, wie die Kenntniss wächst, auch antiker. [Hervorhebung M.E.] ${ }^{72}$

Schiller eröffnet dem Freund aber erneut eine alternative Perspektive: „Das was Ihnen im Homer missfällt“, nimmt er Goethes Gedanken auf, „werden Sie wohl nicht absichtlich nachahmen, aber es wird, wenn es sich in Ihre Arbeit einmischt für die Vollständigkeit der Versetzung in das Homerische Wesen und für die Aechtheit [sic] Ihrer Stimmung beweisend seyn [sic]“. ${ }^{.73}$ An Goethes wiedererlangte Überzeugung von der formalen Einheit der Ilias und die daran anschließende Folgerung, dass ein neues episches Gedicht also ebenfalls als in sich geschlossenes Ganzes zu gestalten wäre, schließt sich Schiller zunächst an und bekräftigt: „es [hat] wohl seine Richtigkeit, dass keine Ilias nach der Ilias mehr möglich ist“ ${ }^{\star 74}$ Und gleichzeitig rät er:

71 Goethe an Schiller am 16.5.1798, BW. S. 659.

72 Goethe an Schiller am 12.5.1798, BW. S. 656.

73 Schiller an Goethe, $15 \cdot 5 \cdot 1798$, BW. S. 658.

74 Schiller an Goethe, $18.5 \cdot 1798$, BW. S. 661. 
auch wenn es wieder einen Homer und wieder ein Griechenland gäbe, so glaube ich Ihnen nichts besseres wünschen zu können, als dass Sie Ihre Achilleis, so wie sie jetzt in Ihrer Imagination existiert, bloß mit sich selbst vergleichen, und beim Homer bloß Stimmung suchen, ohne Ihr Geschäft mit seinem eigentlich zu vergleichen. ${ }^{75}$

Daraus spricht zunächst Schillers Wissen um die historische Verfasstheit und damit die unwiederholbare Einzigartigkeit des homerischen Epos - „keinem Vernünftigen kann es einfallen, in demjenigen, worin Homer groß ist, irgend einen Neuern ihm an die Seite stellen zu wollen"76 - und gleichzeitig hält er an der Relevanz der Antike fest, indem er sie als immer noch produktive Quelle von Werten und Inspiration ausweist. ${ }^{77}$ Schiller liefert damit noch einmal die ausschlaggebenden Orientierungs- und Haltepunkte, die Goethes Zweifel vorläufig auszuräumen vermögen: „Zu dem ersten Blatt Ihres lieben Briefes kann ich nur Amen sagen“, bekundet dieser erleichtert, „denn es enthält die Quintessenz dessen was ich mir wohl auch zu Trost und Ermunterung zurief“". ${ }^{78}$ Aus gutem Grund wird Goethe später festhalten: „Es ist nicht gut, dass der Mensch allein sei $[. .$.$] und besonders nicht, dass er allein arbeite, vielmehr bedarf er$ der Teilnahme und Anregung, wenn etwas gelingen soll. Ich verdanke Schillern die ,Achillleis" und viele meiner Balladen, wozu er mich getrieben. "79 Damit gesteht er dem Dichterfreund nicht nur wesentlichen Einfluss auf sein Denken und Schreiben zu, sondern weist die Achilleis auch explizit als ein gemeinschaftliches Werk mit einem schwierigen Entstehungsprozess aus.

Diese ausführliche, abstrakt-reflexive Vorarbeit im Austausch mit Schiller bezeichnet Dreisbach als ganz und gar untypisch für Goethe, wobei sie sich auf eine rückblickende Äußerung Goethes gegenüber Eckermann aus dem Jahr 1823 bezieht. ${ }^{80}$ Wie die bisherigen Ausführungen der vorliegenden Studie allerdings aufgezeigt haben, greifen die üblichen Vorgehensweisen und als gegeben angesehenen Strukturen nicht mehr in den 179oer Jahren, sie werden

75 Schiller an Goethe, $18.5 \cdot 1798$, BW. S. 661.

76 Schiller: Über naive und sentimentalische Dichtung. S. 718 .

77 Vgl. Liggieri: Warum gelingt uns das Epische so selten? Ein Blick hinter Goethes Achilleis. S. 84 .

78 Goethe an Schiller, 19.5.1798, BW. S. 663 .

79 Gespräch mit Eckermann vom 7.3.183o. In: Korn, Eugen (Hrsg.): Goethes Gespräche. Paderborn: Salzwasser 2012. S. 243.

80 „Dagegen war es ganz gegen meine Natur, über das, was ich von poetischen Plänen vorhatte, mit irgend jemanden zu reden, selbst nicht mit Schiller. Ich trug alles still mit mir herum, und niemand erfuhr in der Regel etwas, als bis es vollendet war." Gespräche mit Goethe, 16.11.1823. In: Eckermann, Johann Peter: Gespräche mit Goethe in den letzten Jahren seines Lebens, hrsg. v. Fritz Bergemann (= insel taschenbuch 500). Frankfurt a. M.: Insel 1981. S. 66 f.; vgl. auch Dreisbach: Goethes Achilleis. S. 12. 
vielmehr hinterfragt, wenn nicht gar aufgegeben. Auf die Erschütterung der sozialen, kulturellen und epistemologischen Systeme um 1800 reagiert Goethe in seinen naturwissenschaftlichen Schriften mit dem Entwurf einer neuen, alternativen Denk- und Verfahrensweise, ${ }^{81}$ die sich gerade für die Entstehung der Achilleis als besonders zuträglich erweist: Wenn Goethe sich im Nachhinein bei Schiller für die Achilleis bedankt, klingt darin deutlich die wissenschaftstheoretische Vorstellung einer interagierenden, durch gegenseitige Mitteilung, Erinnerung und Widerspruch zu tieferer Erkenntnis gelangenden Arbeits- und Denkgemeinschaft an, die Goethe in seinem Aufsatz über den Versuch ausgebreitet hat. ${ }^{82}$ Inwiefern die methodischen und epistemologischen Einsichten, die Goethe im Zusammenhang mit seiner Morphologie gewinnt, konstitutiv sind für das Achilleis-Fragment und überhaupt die Restitution des Epischen, soll nun im Folgenden auf der Darstellungsebene weiterverfolgt werden.

\subsubsection{Zur ästhetischen Bedeutung des Fragmentarischen}

Die aufgezeigte Entstehungsgeschichte macht deutlich, dass die Achilleis nicht nur in unmittelbarem Zusammenhang mit der Gattungsdiskussion des Briefwechsels zum einen und Goethes Antikenauseinadersetzung zum anderen steht, sondern auch unauflösbar verbunden ist mit der FaustTragödie. Besprechung und Ausführung des Fragments erweisen sich dabei als langwieriger, komplexer und zuweilen auch abwegiger Prozess. Diese Inkonsistenzen hat die frühere Forschung als Schwäche, Verwirrtheit oder gar Verirrung Goethes bzw. als grundsätzliche und von vorneherein bestehende Problematik der Achilleis interpretiert. ${ }^{83}$ Das Projekt ist aber gerade deshalb auch von besonderer Bedeutung, weil es Goethes Hin- und Herschwanken zwischen verschiedenen Positionen und Formen als geistige Beweglichkeit beleuchtet und neben einen alternativen Denk- und Kreationsprozess auch ein dezidiert anderes Verständnis von Gattung als lebendige, veränderliche Diskursformation ohne klare Grenzen oder Hierarchie sichtbar macht. Die Methoden des Wiederholens, Sammelns, Ausbreitens, Vergleichens und immer wieder neu Anordnens, wie sie im Aufsatz Über den Versuch skizziert werden, ${ }^{84}$ treten in diesem Zusammenhang als potente, alternative Verfahrensweisen im Sinne einer poetischen techné hervor, die sogar krasse

\footnotetext{
81 Vgl. S. 91 ff. in diesem Buch.

82 Vgl. Kap. 3.3: Goethes explorative Epistemologie als Gegenmodell zum Empirismus.

83 Vgl. Sengle: Goethes Ikarus-Flug. Zur Forcierung des Homerisierens im Achilleis-Plan. S. $69-85$, hier S. 82 .

84 Vgl. Kap. 3.3: Goethes explorative Epistemologie als Gegenmodell zum Empirismus.
} 
Gegensätzen wie das Epische und das Tragische miteinander in Beziehung setzt und dadurch bewusst füreinander fruchtbar macht. Das entspricht freilich nicht der desparaten Abwehrbemühung im Sinne einer konservativen Verweigerungshaltung, wie sie der klassizistischen Programmatik eingeschrieben ist, sondern bedeutet vielmehr die prekäre Sicherung gefährdeter poetologischer Formen und weist gleichzeitig auf die Unzulänglichkeit normativer Zugriffsbemühungen hin.

Geht man auf dem Hintergrund der explorativen Epistemologie an den Text heran, erscheint auch seine Unabgeschlossenheit nicht länger als Defizit, sondern vielmehr als das, was ihn gerade besonders anschlussfähig macht. Dass Goethe mit dem ersten Achilleis-Gesang ein Teilwerk veröffentlicht, das klar unabgeschlossen ist, kann unter Rückbezug auf den Versuch als Vermittler und Lenker durchaus als Bemühung gedeutet werden, das Fragment als legitime Form des Unfertigen, des Versuchs für die Literatur der Moderne fruchtbar zu machen. ${ }^{85}$ Im Gegensatz zur bildenden Kunst hat Goethe in der Literatur nicht nur eine fragmentarische Disposition entdeckt, sondern gerade darin auch ihr Potenzial erkannt, über die Totalität organischer Schönheit hinauszugehen. „Literatur ist das Fragment der Fragmente“, definiert er in seinen Betrachtungen im Sinne der Wanderer, „das wenigste dessen, was geschah und gesprochen worden, ward geschrieben, vom Geschriebenen ist das wenigste übriggeblieben“. ${ }^{86}$ Sicherlich zielt Goethe mit dieser Überlegung auf die Unvollständigkeit der antiken Literaturüberlieferung, allem voran der homerischen Epen, die die klassizistische Ideologie zu verdecken versucht. Darüber hinaus privilegiert er hier allerdings die Literatur als einzige der Künste dazu, auch dann noch den Sinn des Schönen in sich aufzubewahren, wenn sie das Ideal unmittelbar-sinnlicher Ganzheit verfehlt. ${ }^{87}$

Der Gedanke einer notwendig fragmentarischen Gestalt des Ästhetischen lässt sich seit der Frühromantik als Grundkonstante der modernen ästhetischen Theorie verfolgen und speist sich aus dem zunehmenden Widerspruch zwischen Autonomisierung und Dynamisierung der Kunst auf der einen Seite und der Trivialisierung sowie dem Fragwürdigwerden des Mehrwerts der Kunst auf der anderen. ${ }^{88}$ Dem Ideal einer einheitlichen, in sich geschlossenen Kunst ist das Fragment nicht länger verpflichtet und doch reflektiert es die ästhetischen Vorstellungen von Ganzheit und Totalität

\footnotetext{
85 Vgl. S. 98 f. in diesem Buch.

86 Goethe, Johann Wolfgang: Kunsttheoretische Schriften und Uebersetzungen., Bd. 18. S. 556 .

87 Vgl. Ostermann, Eberhard: Der Begriff des Fragments als Leitmetapher der ästhetischen Moderne. In: Athenäum. Jahrbuch für Romantik 1 (1991). S. 189-205. S. 193.

88

Vgl. ebd. S. 189 .
} 
immer noch latent mit. ${ }^{89}$ Damit ist dem Fragmentarischen ein doppeltes Zeitlichkeitsmoment eingeschrieben: Zum einen verweist es dezidiert auf die spezifische Historizität jeglicher Dichtung, anstatt sie der zeitlosen Kunst zu überführen. Und zum anderen bringt es doch noch jene Idee der ganzen, zeitlosen Dichtung zur Geltung, allerdings mit Blick auf eine von der Geschichte nicht verschonten Kunst. Diese Spannungen zwischen Zeitbezug und Zeitenthobenheit, Partialität und Totalität spielen für die modernespezifischen Neuorientierung des Epischen eine besonders tragende Rolle und werden von Goethe nicht nur reflektiert, sondern gerade auch fruchtbar gemacht. ${ }^{90}$ In der epischen Wechselbeziehung von Teil und Ganzem, Historizität und Überzeitlichkeit liegt nämlich das Potenzial begründet, über den Traditionsbruch hinweg zwischen Gegenwart und Vergangenheit, Ideal und Realität zu vermitteln. Auch wenn dem Fragment bei Goethe nicht die gleiche ästhetische Bedeutung zukommt, wie ihm von der Frühromantik beigemessen werden wird, so leistet er mit seinem am Epischen exerzierten modernen Formdenken doch wichtige Vorarbeit dafür.

Damit wird nicht behauptet, Goethe habe die Achilleis absichtlich unvollendet gelassen, es soll aber eine Aufmerksamkeitsverschiebung weg von der Frage nach Gründen für den Abbruch, hin auf die Frage nach der möglichen ästhetischen Bedeutsamkeit der formalen Unabgeschlossenheit erreicht werden. Denn ob nun als Defizit oder Leistung bewertet, in beiden Fällen erzeugt die Fragmentarität der Achilleis ein ihre Relevanz begründendes Moment, in dem sie ihr Korrelat - das Ganze - stets mit ins Spiel bringt, wenn auch im Hintergrund schwebend. Goethes Auffassung von Totalität ist zu diesem Zeitpunkt, wie Helmut Pfotenhauer erläutert, ein Ganzes, das durch die Erfahrung des Partialen durchgegangen ist, dem es abgerungen werden muss. ${ }^{91}$ Während Schiller das Fragmentarische zwar als Aspekt des Sentimentalischen registriert, für die Idee der Kunst aber als irrelevant taxiert, ${ }^{92}$ hat sich Goethe

89 Vgl. ebd. S. 19 o.

$90 \quad$ Vgl. S. $126 \mathrm{ff}$. in diesem Buch.

91 Vgl. Pfotenhauer, Helmut: Zerstückelung und phantasmatische Ganzheit. Grundmuster ästhetischer Argumentation in Klassizismus und Antiklassizismus um 1800 (Winckelmann, Moritz, Goethe, Jean Paul). In: Agazzi, Elena (Hrsg.): Der fragile Körper. Zwischen Fragmentierung und Ganzheitsanspruch. Göttingen: V\&R unipress 2005. S. 121-131, hier S. 128 .

92 Auch Schiller hatte bereits erkannt, dass das Ideal ästhetischer Vollkommenheit in der Moderne nur noch annäherungsweise zu erreichen sei. Die sentimentalische Kunst, die eine „Kunst des Unendlichen“ ist, bleibt hinter der naiven Kunst der Begrenzung zurück. Dieser defizitäre Status könnte auch als Ausdruck ästhetischer Überlegenheit und eines Zu-Sich-Selbst-Kommens des Ästhetischen gelesen werden und davon profitiert die Dichtung, die sich als Produkt der Einbildungskraft von der einengenden 
von der Vorstellung totaler ästhetischer Ganzheit als sinnfälligem Paradigma historischer Versöhnung offenbar bereits ein Stück weit abgelöst. Auf dem wenn auch begrenzten Gebiet der Literatur weist er dem Fragmentarischen nicht nur einen Platz zu, sondern macht es hier vielmehr produktiv. Und zwar nicht allein für die Erneuerung des Epischen, sondern wie die Bezüge zwischen Achilleis und Faust deutlich machen, auch für die Tragödie: „Ich werde sorgen dass die Theile anmuthig [sic] und unterhaltend sind und etwas denken lassen", schreibt Goethe an Schiller über seinen Faust, „bey dem ganzen, das immer ein Fragment bleiben wird, mag mir die neue Theorie des epischen Gedichts zu statten kommen. [Hervorhebungen M.E.]". ${ }^{93}$

Entgegen Schlegels Behauptung, dass Goethe „keine Idee von romantischer Ganzheit" ${ }^{\text {"94 }}$ gehabt habe, manifestiert sich nun gerade am Epos-Projekt und besonders an der Achilleis sehr wohl ein goethescher Begriff von der fragmentierten Einheit. Allerdings stehen bei Goethe die Vorstellungen von sinnlich-organischer Ganzheit und reflektiert-historischer Partialität nicht in einem radikalen Ausschlussverhältnis, sondern gerade wegen ihrer Komplementarität in einer Wechselbeziehung - oder anders gesagt: in einer Gleichzeitigkeit des Ungleichzeitigen. Das Ganze ist überhaupt nur noch als Fragment zu haben, zudem soll es gleichzeitig unmittelbar-intuitiv - „anmutig und unterhaltend " - wirken, also dem Zeitgeschmack entsprechen, und doch die geistige Reflexionstätigkeit fördern - „etwas denken lassen“. Die grundsätzlichen Spannungsverhältnisse, die Goethes Epos-Projekt prägen, werden hier der tragischen Form in solchem Maße zuträglich, dass Goethe den Faust sogar als „rhapsodisches Drama“95 bezeichnet. In der Vorstellung einer fraktalen Ganzheit, wie sie weiter oben als spezifische Errungenschaft des Gattungsdiskurses über das Epische aufgezeigt werden konnte, ${ }^{96}$ können also auch die engen Grenzen der Tragödienform überschritten werden.

Norm sinnlich-plastischer Vollkommenheit emanzipiert. Dennoch hält Schiller an der uneingeschränkten Gültigkeit des ganzheitlichen Ideals fest, weil die Legitimität des Ästhetischen für ihn davon abhängt, dass der autarke, von allen historischen Einflüssen gereinigte schöne Schein als Gegenbild der entfremdeten Wirklichkeit und zugleich als Vor-Schein zukünftiger geschichtlicher Vollendung fungiert, vgl. Ostermann: Der Begriff des Fragments als Leitmetapher der ästhetischen Moderne. S. 192.

Goethe an Schiller, 27.6.1797, BW. S. 415 .

94 Zitiert nach Ostermann: Der Begriff des Fragments als Leitmetapher der ästhetischen Moderne. S. 194.

95 Goethe an Schiller, 11.4.1798, BW. S. 635 .

96 Vgl. S. $172 \mathrm{ff}$. in diesem Buch. 


\subsection{Das Problem moderner Epik als eine Krise der Stoffe}

In der Achilleis greifen also Reflexion und Produktion, theoretischer Gattungsdiskurs und die konkrete Ausführung epischer Dichtung in bisher ungekanntem Maße ineinander. Dem Fragment kommt innerhalb von Goethes Epos-Projekt allerdings auch insofern besondere Bedeutung zu, als daran deutlich wird, wie die Problematik moderner Epik zusehends über die bloße Frage der Form hinausgeht. Nach der erfolgreichen Fertigstellung des Wilhelm MeisterRomans im August 1796 und dem idyllischen Epos Hermann und Dorothea im März 1797 ist Goethe fest entschlossen, sich auch fernerhin im epischen Fach zu betätigen. Im unmittelbaren Anschluss an Hermann und Dorothea fasst er den Plan, unter dem Titel Die Jagd ein weiteres Versepos zu schreiben. ${ }^{97}$ Dazu kommt es allerdings nicht, und zwar aufgrund formaler Schwierigkeiten: „Der Plan meines zweyten [sic] Gedichts [die Jagd] hat diesen Fehler [es fehlt ein retardierendes Motiv]“, schreibt er an Schiller, „und ich werde mich hüten bis wir hierüber [die Retardation als Haupteigenschaften des Epos] ganz im klaren sind auch nur einen Vers davon niederzuschreiben“. ${ }^{98}$ Erst 1826 wird Goethe auf die Geschichte einer unerhörten Begegnung zwischen einem Jahrmarktlöwen und einer fürstlichen Jagdgesellschaft zurückgreifen und den Stoff nun aber als novellistische Prosaerzählung gestalten. Im Herbst 1797 konzipiert er auf seiner Schweiz-Reise erneut ein Epos, diesmal scheint ihm die Wilhelm Tell-Legende geeignet für eine epische Bearbeitung. Noch im Frühling darauf schreibt er zuversichtlich an Heinrich Meyer: „Meine beiden epischen Gegenstände, sowohl Tell als Achill, haben Schillers großen Beifall." ${ }^{\text {“99 Aber auch }}$ dieses Vorhaben wird nie umgesetzt. Es ist schließlich Schiller, der den TellStoff in seinem berühmten gleichnamigen Drama aufnimmt. Die Haltung, auf deren Hintergrund die epischen Versuche anvisiert und dann doch wieder aufgegeben werden, beschreibt Goethe folgendermaßen:

Ich habe jetzt keine interessantere Betrachtung als über die Eigenschafften der Stoffe in wie fern sie diese oder jene Behandlung fordern. Ich habe mich darinnen so oft in meinem Leben vergriffen, dass ich endlich einmal ins Klare kommen möge um wenigsten künftig von diesem Irthum [sic] nicht mehr zu leiden. [Hervorhebung M.E] ${ }^{100}$

Vgl. Briefwechsel im Juni 1797, Goethe an Schiller, 22.6. und Schiller an Goethe, 26.6., BW. S. 409, 412 und Schadewaldt: Fausts Ende und die Achilleis. S. 283-30o, hier S. 286 f.

$98 \quad$ Goethe an Schiller, 19.4.1797, BW. S. 376.

99 Goethe an Heinrich Meyer, 23.3.1798, zitiert nach HA 2. S. 759.

100 Goethe an Schiller, 22.4.1797, BW. S. 379. 
Die Gründe für das Fallenlassen der Pläne zur Jagd und zu Wilhelm Tell sind demnach nicht allein auf der Ebene der Darstellung zu verorten, vielmehr erweist sich jetzt auch schon die Suche nach dem richtigen Stoff als äußerst schwierig. Der Abschluss von Hermann und Dorothea bedeutet deshalb nicht nur eine Zäsur in Goethes epischer Produktivität, ${ }^{101}$ sondern auch eine deutliche Verschiebung der Aufmerksamkeit weg von rein formalistischen Überlegungen hin zu inhaltlichen. Dass die Suche nach einem möglichen Epos zu diesem Zeitpunkt auch forciert auf der Stoffebene stattfindet, offenbart bereits die Frage, ob zwischen Hectors Tod und der Abfahrt der Griechen noch ein episches Gedicht liege. Über seine Achilleis schreibt Goethe zudem:

Die Achilleis ist eine alte Idee, die ich mit mir herumtrage und die besonders durch die letzten Händel über das Alter der Homerischen Gedichte und über die rhapsodische Zusammenstellung derselben neues Leben und Interesse erhalten hat. Ich fange mit dem Schluss der Ilias an, der Tod des Achills ist mein nächster Gegenstand, indessen werde ich wohl noch etwas weiter greifen. Diese Arbeit führt mich auf die wichtigsten Punkte der poetischen Künste, indem ich über das Epische nachzudenken alle Ursache habe. [Hervorhebung M.E.] ${ }^{102}$

Hauptantrieb für Goethes neues Epos ist damit also nicht (mehr) die formale Nachahmung des homerischen Epos, sondern vielmehr ein bestimmter Gegenstand - der Tod des Achilles. Wobei auch über diesen eine gewisse Unklarheit zu herrschen scheint, nimmt er doch durch das Nachdenken über die Form des Epischen überhaupt erst Kontur an. Wie die richtige Stoffwahl für das Epische in der Moderne an herausragender Bedeutung gewinnt, aber gerade auch immer problematischer wird, zeigt sich nun an Goethes Bemühungen um die Achilleis besonders deutlich und soll deshalb im Folgenden ausgestellt werden.

\subsubsection{Vom Suchen und Finden eines geeigneten Gegenstands: Achills' Tod}

Mit dem Motiv aus dem trojanischen Sagenkreis entscheidet sich Goethe ganz gattungskonform für einen bekannten, weitverbreiteten Stoff ${ }^{103}$ - davon scheint er zumindest auszugehen. Gleichwohl stellt der Tod des Achilles in der antiken Tradition eine eigentliche Lücke dar, die weder in der Ilias noch in der Odyssee ausdrücklich behandelt wird. ${ }^{104}$ Zwar wird in der Ilias vielfach darauf

\footnotetext{
101 Vgl. Dreisbach: Goethes Achilleis. S. 10.

102 Goethe an Carl Ludwig von Knebel am 22.3.1799. In: Goethes Werke. Weimarer Ausgabe, IV. Abteilung, Bd. 14. S. $5^{2}$.

103 Vgl. S. 150 in diesem Buch.

104 Zur möglichen Thematisierung von Achilles' Tod in der nicht erhaltenen Aithiopis vgl. Welcker, Friedrich Gottlieb: Der epische Cyclus oder die homerischen Dichter, Bd. 1
} 
hingedeutet (Il. 22, V. 358-36o) ${ }^{105}$, eine konkrete Schilderung bleibt aber aus. An Achilles interessiert Homer nicht dessen Ende, sondern sein unbändiger Zorn, in dem sich wiederum das Hauptmotiv der Ilias, der Krieg, spiegelt. ${ }^{106}$ Und auch die Odyssee erwähnt das Ende des großen Griechenhelden nur in Agamemnons Rückblick in der Unterwelt und konzentriert sich dabei vor allem auf Achills' Begräbnis sowie seinen unsterblichen Ruhm (Od. 24, V. 36-94) ${ }^{107}$. Es sind gerade solche möglichen Lücken im Komplex homerischer Dichtung, zu deren Aufspüren und Ausfüllen Wolfs Thesen angeregt haben. ${ }^{108}$

Dass Homers Epos zweifellos eine wichtige Inspirationsquelle für die Achilleis darstellt, ${ }^{109}$ macht die große inhaltliche und formale Nähe zwar überdeutlich, aber wie der Briefwechsel mit Schiller demonstriert, geht es bei Goethes Achilleis bei weitem nicht nur um ein stoffliches Lückenfüllen. Goethe schließt seine Dichtung wohl explizit an die Ilias an, ${ }^{110}$ der darin vorausgedeuteten Handlung folgt er aber nicht. ${ }^{111}$ Danach sollte Achilles nach Hektors Tod am Skäischen Tor den Pfeilen des Paris und des Apollon zum Opfer fallen. ${ }^{112}$ Davon weicht Goethe nun aber ab und lehnt sich dafür vornehmlich bei Dictys Cretensis spätantikem Troja-Roman an, der Achilles' Tod in den Thymbräischen Tempel verlegt und in engen Zusammenhang mit der Liebe

(zweite Auflage). Bonn:Weber 1865. S. 250-255 und Latacz, Joachim: Ilias mikra. In: Canik, Hubert; Schneider, Helmuth et al. (Hrsg.): Der neue Pauly. Enzyklopädie der Antike, Bd. 5 . Stuttgart: Metzler 1998. S. 934. Sowie Reichel, Michael: Pseudo-Homerica und sonstige Epik der archaischen und klassischen Epoche. In: Zimmermann, Bernhard (Hrsg.): Die Literatur der archaischen und klassischen Zeit (= Handbuch der Altertumswissenschaft. Abt. 7, Bd. 1). München: Beck 2011. S. 66-77, hier S. 68-71.

105 Sämtliche Verweise auf die Ilias beziehen sich auf Homer: Ilias und Odyssee, in der Übertragung von Johann Heinrich Voß, nach dem Text der Erstausgabe (Ilias 1793, Odyssee 1781), mit einem Nachwort von W. H. Friedrich. Stuttgart, Hamburg: Dt. Bücherbund o.J. und werden im Weiteren mit der Verszahl in Klammer direkt im Text angegeben.

106 Vgl. Liggieri: Warum gelingt uns das Epische so selten? Ein Blick hinter Goethes Achilleis. S. 68.

107 Sämtliche Verweise auf die Odyssee beziehen sich auf Homer: Ilias und Odyssee, in der Übertragung von Johann Heinrich Voß, nach dem Text der Erstausgabe (Ilias 1793, Odyssee 1781), mit einem Nachwort von W. H. Friedrich und werden im Weiteren mit der Verszahl in Klammer direkt im Text angegeben.

108 Vgl. Meid: Goethes Achilleis - Versuch eines modernen Epos in der Nachfolge Homers. S. 83-101, hier S. 88.

109 Vgl. ebd. S. 92.

110 Vgl. Goethe an Schiller am 12.5.1798, BW. S. 656.

111 Vgl. Dreisbach: Goethes Achilleis. S. 76.

112 Davon erzählt die an die Ilias anschließende Aithiopis, ein nicht erhaltenes Epos das wahrscheinlich von Arktinos von Milet stammte, vgl. dazu Schadewaldt: Goethes Achilleis. S. 301-395, hier 346 . 
zu Polyxena setzt. ${ }^{113}$ Die tragische Liebeshandlung zwischen Achilles und der Priamos-Tochter hatte Euripides bereits in seiner Hekabe bearbeitet, allerdings nur am Rande. ${ }^{114}$ Dictys schildert dagegen ausführlich, wie Achilles kurz vor dem Ende des trojanischen Krieges in leidenschaftlicher Liebe zu Polyxena entbrennt und diese ihm dann zum Verhängnis wird: Während Achilles mit den Söhnen Priamos' über eine Hochzeit mit Polyxena verhandelt, wird er heimtückisch von Paris und Deiphobus angefallen und getötet (Dict. 4, V. 11). Es sind also vor allem die Liebesthematik und die Lokalitäten, die Goethe dem als Augenzeugenbericht eines trojanischen Priesters konzipierten Roman ${ }^{115}$ für seine Dichtung entnimmt. ${ }^{116}$ Bereits im Winter 1794/1795 hatte Goethe die im Jahr zuvor erschienene Homer-Übersetzung von Johann Heinrich Voß, die als Grundlage der Ilias-Lektüre der im Oktober 1794 restituierten Freitagsgesellschaft gilt, in einem Schema zusammengefasst. ${ }^{117}$ Inwiefern diese summarische, an der originalen Gliederung in 24 Abschnitte orientierte Inhaltsübersicht zu den Paralipomena der Achilleis gezählt werden kann, ist in der Forschung umstritten. ${ }^{118}$ Allerdings zeigt sich daran zum einen, dass den zeitgenössischen Übersetzungsversuchen gerade so viel Bedeutung für Goethes Epos-Projekt zukommt, wie den antiken Vorbildern selbst. Und zum anderen können diese Bemühungen um den Inhalt des homerischen Epos

113 Vgl. Cretensis, Dictys: Ephemeridos belli Troiani libri, hrsg. v. Werner Eisenhut (= Bibliotheca scriptorum Graecorum et Romanorum Teubneriana; Nachdruck der 2. Auflage von 1973). Stuttgart: Teubner 1994. Es handelt sich um einen im 4. Jahrhundert veröffentlichten lateinischen Roman über den trojanischen Krieg in sechs Büchern. Neben der als Gegenentwurf dazu zu verstehenden Bearbeitung des Themas durch Dares Phrygius, gilt Cretensis' Text als bedeutendstes Werk für die mittelalterliche und frühneuzeitliche Rezeption des Troja-Stoffes, vgl. Cretensis, Dictys; Phrygius, Dares: In usum Delphini cum interpretatione Annae Daceriae; accedunt in hac nova editione notae variorum integrae, nec non Josephus Iscanus, cum notis Sam. Dresemii, numismatibus et gemmishistoriam illustrantibus exornavit Lud. Smids, dissertationem de Dictye Cretensi praefixit Jac. Perizonius. Amstelaedam: apud Georgium Gallet 1702.

114 Vgl. Dreisbach: Goethes Achilleis. S. 76.

115 Vgl. Schadewaldt: Goethes Achilleis. S. 301-395, hier S. 348 und Dreisbach: Goethes Achilleis. S. 168.

116 Vgl. Liggieri: Warum gelingt uns das Epische so selten? Ein Blick hinter Goethes Achilleis. S. 88.

117 Vgl. Boyle, Nicholas: Goethe: Der Dichter in seiner Zeit, aus dem Engl. v. Holger Fliessbach, Bd. 2, 1791-1803. München: Beck 1999. S. 329.

118 Während Scheibe davon überzeugt ist, dass Goethe bei der Planung der Achilleis auf diese Zusammenfassung zurückgegriffen hat, meint Dreisbach, dass es dafür keinen Beleg gebe. Sie ist überzeugt, dass diese Materialien nicht als Paralipomena zur Achilleis gezählt werden können, da sie im Jahr 1794/95 entstanden seien und damit eindeutig vor dem Achilleis-Plan, vgl. Scheibe, Siegfried (Hrsg.): Werke Goethes. Akademie-Ausgabe. Epen, Bd. 2. Berlin: Akademie-Verlag 1963. S. 1155 und Dreisbach: Goethes Achilleis. S. 167. 
auch als früher Hinweis auf die Verunsicherung über die epischen Stoffe gedeutet werden.

Im Frühling 1798 ist Goethe gemäß Tagebucheinträgen dann mit einem zweiten Ilias-Schema beschäftigt. ${ }^{119}$ Dieses wird zwar erst 1820 veröffentlicht und ist nur teilweise erhalten, enthält aber zahlreiche Stellen der Achilleis und dient Goethe wohl als ausschlaggebende Grundlage für seine weiteren Überlegungen zum Handlungsgang. ${ }^{120}$ Ähnlich verhält es sich mit einem undatierten Exzerpt aus Dictys' Roman, bei dem sich Goethe ebenfalls an der Originalgliederung orientiert, allerdings mit seiner Bearbeitung nur bis zum Beginn des zweiten Buches vordringt. Diese Auszüge exzerpiert Goethe nun eindeutig mit spezifischem Blick auf seine Achilleis. ${ }^{121}$ Neben Homer und Dictys haben aber auch andere antike Quellen und deren spätere Bearbeitungsstufen Einfluss auf Goethes Konzeption. Seine eingehenden Quellenstudien beschäftigen sich sowohl mit dem lateinischen Troja-Roman von Dares Phrygius - gleichwohl Vorlage wie auch Gegenentwurf zu Dictys' Werk ${ }^{122}$ - Sophokles' AjaxTragödie als auch den Fabeln von Hyginus ${ }^{123}$. Letztere werden um 1800 vor allem auch durch Benjamin Hederichs Gründliches mythologisches Lexikon und Charles Drelincourts Homericus Achilles vermittelt. ${ }^{124}$ Darüber hinaus greift Goethe auf diverse zeitgenössische topographische Schilderungen

119 29. März 1798: „Schema zur Äneis. In der Ilias gelesen. [...].“ 31. März 1798: „Die Ilias. Verschiedne Schriften aus der Bibliothek die sich darauf beziehen. Schemata und Auszüge.“ 1. April 1798: „Fortsetzung der Arbeit an der Ilias. [...].” 2. April 1798: „Wood über Homer. Schema fortgesetzt. [...].“ 3. April 1798: „Le Chevalier Ebene von Troja und dahin einschlagende Betrachtungen. [...] Mittag zu Schiller, wo viel über die neuen epischen und tragischen Unternehmungen gehandelt wurde. [...].“ 11. Mai 1798: „Die Ilias wieder vorgenommen.“ 12. Mai 1798: „Ilias fortgesetzt. [...].“ 13. Mai 1798: „Früh Ilias fortgesetzt. [...]. 14. Mai 1798: „Früh Ilias. [...].“ 15. Mai 1798: „Früh Ilias fortgesetzt. [...]“ 16. Mai 1798: „Ilias fortgesetzt. [...].“ 17. Mai 1798: „Ilias fortgesetzt. [...].” 21. Mai 1798: „Das Schema der Ilias geendigt. Vorbereitung zu andern Arbeiten. Gegen Abend bey Schiller, den Humboldtischen Aufsatz über das Epische Gedicht angefangen. Alsdenn noch viel über die Ilias sowohl im ganzen als in den Theilen."WA III, 2. S. 200-208.

120 Vgl. Dreisbach: Goethes Achilleis. S. 167 f.

121 Auch für Dreisbach besteht kein Zweifel daran, dass weder das zweite Ilias-Schema noch der Dictys-Auszug um ihrer selbst willen verfasst wurden, sondern als eingehende Quellenstudien zur Achilleis zu betrachten sind, vgl. ebd. S. 168.

$122 \mathrm{Zu}$ Dares Phrygius vgl. Rossbach, Otto: Dares. In: Wissowa, Georg (Hrsg.): Paulys Realencyclopädie der classischen Altertumswissenschaft (RE), Bd. IV, 2. Stuttgart: Metzler 1901. S. $2213 \mathrm{f}$.

123 Zu Hyginus vgl. Lebrecht Schmidt, Peter; Schneider, Helmuth: Hyginus, C. Iulius. In: Ders.; Canik; et al. (Hrsg.): Der neue Pauly. Enzyklopädie der Antike, Bd. 5. S. 778 f.

124 Vgl. Meid: Goethes Achilleis - Versuch eines modernen Epos in der Nachfolge Homers. S. 83-101, hier S. 92. 
der trojanischen Ebene ${ }^{125}$ - Reiseberichte von Choiseul-Gouffier ${ }^{126}$ und Le Chevalier ${ }^{127}$ - zurück. ${ }^{128}$ Wenn Goethe also nach ausgedehnten Recherchen im März 1799 endlich an die Ausführung seiner Dichtung geht, verfügt er über breitabgestützte Kenntnisse seines Gegenstands sowie eine ausgeklügelte Handlungskonzeption, die ihm die bevorstehende Arbeit in allen Einzelheiten vor Augen führen. „Ein großer Theil [sic]des Gedichts, dem es noch an innerer Gestalt fehlt, hat sich bis in seine kleinsten Zweige organisiert [... $]^{“ 129}$, schreibt er an Schiller am 9. März voller Zuversicht. Und eine Woche später: „Von der Achilleis sind schon fünf gesänge [sic] motiviert und von dem ersten 180 Hexameter geschrieben. [...] da es mit dem Anfange gelungen ist, so kann man für die Fortsetzung nicht bange seyn [sic]." ${ }^{130}$ Wie weit die Konzeption der Handlung fortgeschritten war - und zwar nicht nur des ersten Gesangs, sonders des ganzen Gedichts - belegen tatsächlich die beiden sehr gründlich ausgearbeiteten Schemata zur Achilleis. ${ }^{131}$

Dieses Sammeln und Zusammenstellen von verschiedenartigen Quellen ist in mehrfacher Hinsicht bemerkemswert: Zum einen wird daran sichtbar, dass Goethe hohen Wert darauf legt, die räumliche Umgebung der Handlung möglichst realistisch zu beschreiben. Die Achilleis soll in der wirklichkeitsgetreuen, genau identifizierbaren Ebene vor Troja stattfinden und nicht in einer idealtypisch stilisierten Lokalität. Die objektivierende Einarbeitung in die zeitgenössischen Debatten der philologischen und geographischen Fachliteratur kann auch dahingehend gedeutet werden, dass Goethe offenbar viel daran liegt, seine epische Dichtung gegen die hier zu erwartenden

125 Durch Tagebucheinträge vom 2., 3., 5. April und 19. Juli 1798 bezeugt. In: WA III, 2. S. $204 \mathrm{ff}$.

126 Lenz, Carl Gotthold: Die Ebene von Troja nach dem Grafen Choiseul Gouffier und andern neuern Reisenden nebst einer Abhandlung des Hrn. Major Müller in Göttingen und Erläuterungen über den Schauplatz der Ilias und die darauf vorgefallnen Begebenheiten; mit Kupfern. Neu-Strelitz: Michaelis 1798. Tagebucheintrag vom 19.7.1798: „Niobe. Theater, Schlossbau. Mittags bey Hofe. Lenz über die Ebne von Troja." WA III, 2. S. 215.

127 Le Chevalier, Jean-Baptiste: Beschreibung der Ebene von Troja mit einer auf der Stelle aufgenommenen Charte mit Anmerkungen und Erläuterungen von Andreas Dalzel, aus dem Engl. mit Anm. und Zus. von C.G. Heyne. Leipzig: Weidmann 1792, vgl. Tagebucheinträge vom 2., 3. und 5.4.1798. In: WA III, 2. S. $204 \mathrm{f}$.

128 Vgl. Meid: Goethes Achilleis - Versuch eines modernen Epos in der Nachfolge Homers. S. 83-101, hier S. 92 und Dreisbach: Goethes Achilleis. S. 78. Zu den Übernahmen Goethes siehe Constantine: Achilleis and Nausikaa. Goethe in Homer's World. S. 95-111.

129 Goethe an Schiller am 9.3.1799, BW. S. 785 .

130 Goethe an Schiller am 16.3.1799, BW. S. 788.

131 Vgl. MA 6.1. S. 1103-1114. 
Kritikpunkte abzusichern. ${ }^{132}$ Den utopisch-entgrenzenden Tendenzen, denen er in Hermann und Dorothea noch stark zuarbeitete, ${ }^{133}$ wirkt er damit auf jeden Fall bewusst entgegen.

Zum anderen verdeutlicht die Quellenakkumulation, dass Homer nicht (mehr) die einzige Autorität ist in Sachen Epos, sondern für die Erneuerung und Transformation des Epischen nun auch auf andere, spätere Darstellungen und sogar die Homer-Rezeption selbst zurückgegriffen werden kann. Auch wenn die Auseinandersetzung mit Homer neben derjenigen mit Shakespeare eine der produktivsten für Goethe war, ${ }^{134}$ zeigt sich hier deutlich, dass es bei seiner Achilleis um sehr viel mehr als bloß um das homerische Epos und dessen Anverwandlung geht. Letztlich führt nämlich ein kollektivierendes Verfahren, wie es oben beschrieben wurde, zu einem historistisch reflektierten Schreiben und damit wiederum in die Aporien moderner Epik.

Drittens verweist der Versuch, alle wesentlichen Aspekte der Motiv- und Gattungsgeschichte sowie der philologischen und geographischen Diskurse integrieren zu wollen, unabhängig davon, als wie charakteristisch die Genese der Achilleis für den Dichter angesehen wird, ${ }^{135}$ auf ein poetologisches Verfahren, das der normativ-klassizistischen Programmatik klar entgegensteht: Goethes ausführliche Quellenarbeit schafft eine breite, heterogene Erfahrungssammlung als Ausgangslage für das Achilleis-Projekt und zeugt gleichzeitig von einer grundlegenden Offenheit gegenüber verschiedensten Wissensgebieten. Dabei erweisen sich gerade die morphologischen Prinzipien der Erweiterung, der Beweglichkeit und der Gleichzeitigkeit ${ }^{136}$ sowohl für die Erkenntnis als auch für die Produktivität als ausschlaggebend. Neues und Bestehendes, Ähnliches und Andersartiges können so ebenbürtig nebeneinandergestellt, mögliche Verbindungen dazwischen gesucht und schließlich gemeinsam

132 Vgl. Meid: Goethes Achilleis - Versuch eines modernen Epos in der Nachfolge Homers. S. 83-101, hier S. 93 .

133 Einzelheiten von Landschaft und Kleinstadt, Markt, Garten, Brunnen sind bewusst keine exakt zu lokalisierenden Größen, sondern generalisierte, unverbindliche Einheiten auch wenn der größere Rahmen der Rheinlandschaft bekannt ist. Vgl. S. 231 ff. in diesem Buch.

134 Vgl. HA 2. S. 762.

135 Meid befindet Goethes umfangreiches Recherchieren, Planen und Organisieren als atypisch für den Dichter und als Ausdruck dafür, dass es ihm immer weniger gelingt, Unzulänglichkeiten und Spannungen produktiv zu machen, vgl. Meid: Goethes Achilleis Versuch eines modernen Epos in der Nachfolge Homers. S. 83-101, hier S. 93. Dagegen betrachtet Schadewaldt dieses Vorgehen gerade als bezeichnend für den reiferen Goethe, vgl. Schadewaldt: Goethes Achilleis. S. 301-395, hier S. 301.

136 Vgl. S. 87 ff. in diesem Buch. 
zur Anschauung gebracht werden. Das ist die fragmentierte Einheit, ${ }^{137}$ die sich hier nicht als Scheitern zeigt, sondern im Gegenteil als moderne Form, in der Brüche und Reibungspunkte gerade sichtbar gemacht werden, anstatt sie klassizistisch zu glätten. Daran, wie Goethe sich den Stoff seiner Dichtung erarbeitet, bestätigt sich erneut, dass seine Antikenaneignung stets auf den Boden der Gegenwart führt.

\subsection{2 „Ob man wohl thue einen tragischen Stoff allenfalls episch zu behandeln?"}

Die Auseinandersetzung mit dem Ende Achills' als Suche nach dem richtigen Stoff führt unwillkürlich in den problematischen Kern der Gattungsfrage. Warum das Epische in der Gegenwart nicht oder nur selten gelingt, erkennt Goethe hier nämlich am deutlichsten: Weder gibt es in der Moderne retrogradierende d.h. rein epische Begebenheiten, ${ }^{138}$ noch geneigte Zuhörer ${ }^{139}$ und alle einigermaßen retardierenden Vorfälle zerstreuen „das Interesse auf mehrere Menschen ${ }^{140}$, was sie zu eigentlichen Privatangelegenheiten mache. Es gilt daher gezwungenermaßen, auf die Antike auszuweichen und den Blick darauf zurückzulenken, was „uns von den Alten noch übrig geblieben “141 ist an epischen Motiven. Diese möglichen Gegenstände benennt Goethe im Brief vom 23.Dezember 1797: Der Tod des Achilles, der Tod des Ajax, die Rückkehr von Philoktes sowie die Schicksale von Hekuba und Polyxena werden weder in der Ilias noch in der Odyssee dargestellt. ${ }^{142}$ Davon ist allerdings einzig das Ende des Griechenhelden Achilles unbehandelt geblieben, während die übrigen Stoffe von den antiken Dramatikern bereits tragisch bearbeitet wurden. Obwohl Goethe zunächst zu dem Schluss kommt, dass aus den genannten Gründen wohl kein Epos mehr zu dichten sei zwischen Ilias und Odyssee, ${ }^{143}$ treibt ihn die Frage weiter um: „Ich habe diese Tage fortgefahren die Ilias zu studieren um zu überlegen ob zwischen ihr und der Odissé [sic] nicht noch eine Epopé [sic] inne liege." Zwischen den großen Epen der Antike findet Goethe allerdings "nur eigentlich tragische Stoffe “. 144

Nicht nur bietet also die moderne Gegenwart keine epischen Begebenheiten, sondern es sind auch aus der Antike keine mehr übrig. Der Tod des

\footnotetext{
137 Vgl. S. 286 f. in diesem Buch.

138 Vgl. Goethe an Schiller, 23.12.1797, BW. S. 537.

139 Vgl. Goethe an Schiller, 27.12.1797, BW. S. 544.

140 Goethe an Schiller, 23.12.1797, BW. S. 537.

141 Ebd.

142 Vgl. ebd.

143 Vgl. ebd.

144 Goethe an Schiller, 27.12.1797, BW. S. 545.
} 
Achilles erweist sich nun Überhaupt als einziger noch episch zu behandelnder Gegenstand $^{145}$ und auch dieser scheint "ein herlich [sic] tragischer Stoff "146 zu sein. Worin für Goethe die eigentliche Tragik des Stoffes besteht, offenbart ein Blick in die überlieferten Paralipomena zur Achilleis. Im Zentrum seiner geplanten Dichtung steht nämlich nicht allein Achilles' Heldentod, sondern vielmehr dessen Verschränkung mit der leidenschaftlichen Liebe zu Polyxena. Mit dieser Motivverbindung entfernt sich Goethe entschieden von der antiken Vorlage: Homer behandelt zwar den Tod des Achilles nicht explizit, aber die Ilias steht unmissverständlich unter der Erwartung seines baldigen Todes ${ }^{147}$ und in der Aithiopis fällt Achill nach dem Tod Hektors am Skäischen Tor durch die Pfeile des Paris und des Apollon. ${ }^{148}$ Das Liebesmotiv entnimmt Goethe hingegen Dictys mittelalterlichem Troja-Roman, Achilles' Leidenschaft für Polyxena ist hier eine verantwortungslose Zügellosigkeit, die direkt zu seiner Ermordung durch Deiphobus und Paris im Thymbräischen Apollon-Tempel führt (Dict. 4, V. 11). Auch Goethes Achilles sollte nach der Begegnung mit der Priamos-Tochter in der Mitte des fünften Gesangs in plötzlicher Liebe zu dieser entbrennen und darüber sein Schiksal vergessen. ${ }^{149}$ Dieses ereilt ihn dann aber umso unerwarteter im siebten Gesang durch den verräterischen Hinterhalt der Trojaner.

Während Dictys' Liebeshandlung den Achilles moralisch diskreditieren soll - sein Tod erscheint nicht nur selbstverschuldet, sondern auch als gerechte Strafe für seine Unbeherrschtheit und das Vergessen seiner Pflichten gegenüber dem Heer ${ }^{150}$ - hat die Situation bei Goethe eine völlig andere Qualität. Nicht nur erscheint sein Achilles von Anfang an als ruhig und nach Innen gekehrt, auch in der Liebesgeschichte sollte der Fokus nur auf Achilles und seiner Befindlichkeit liegen, während Polyxena profillos bleibt. Der jähe Umschwung von Wissen um den eigenen Tod in grenzenlose Leidenschaft

\footnotetext{
145 Vgl. ebd. BW. S. 544 f.

146 Goethe an Schiller, 23.12.1797, BW. S. 537.

147 Im 18. Buch offenbart Thetis ihrem Sohn sein Schicksal - sollte er dem Schlachtfeld nicht den Rücken kehren und nach Hause zurückkehren, würde er dem erschlagenen Hektor in Kürze nachfolgen. Achilles, von Zorn erfüllt und in Trauer um den Tod seines Freundes Patroklos, nimmt dieses Schicksal an und weiß fortan um seinen sicheren Tod. (Il. 18, V. $97-116)$.

148 Vgl. Schadewaldt: Goethes Achilleis. S. 301-395, hier S. 346.

149 „Achilleus weiß, dass er sterben muss, verliebt sich aber in Polyxena und vergisst sein Schicksal rein darüber, nach der Tollheit seiner Natur“ - so gibt Riemer die „Idee des Ganzen“, die ihm Goethe 1806 oder 1807 eröffnet habe, wieder, zitiert nach Martin: Das deutsche Versepos im 18. Jahrhundert. Studien und kommentierte Gattungsbibliographie. S. 398 .

150 Vgl. Dreisbach: Goethes Achilleis. S. 111 f.
} 
wird so als innerer Vorgang vorgestellt, der ganz auf der psychologischen Ebene des Protagonisten spielt. Als sich Achilles in Polyxena verliebt und damit agiert, als ob er nicht sterben müsste, treten rationales Denken und sinnliches Empfinden auseinander oder vielmehr in einen unauflösbaren Konflikt. Diese innere Zerrissenheit führt ihn seinem frühen Tod zu, der gleichfalls als selbstverschuldet erscheint, aber hier insofern tragisch ist, als gerade der Versuch, sich dem Schicksal zu entziehen, zu dessen Erfüllung führt. Das entfernt Goethes Achilles nun allerdings entschieden von den naiven Helden des homerischen Epos. ${ }^{151}$ Der so zentrale Widerstreit zwischen Pflichtgefühl und persönlicher Freiheit als Bewährungsprobe des Einzelnen ist nämlich alles andere als antik, sondern explizit modern, ${ }^{152}$ denn darin erfüllt sich gerade Schillers wirkungsästhetische Programmatik, nach der es das notwendige Ziel der modernen Tragödie ist, das Gemüt eben „erhaben [zu] rühren“. ${ }^{153}$

Der Achilles der Ilias kannte keinen inneren Konflikt, sondern war allein davon angetrieben, ,immer der Beste und den Anderen überlegen [zu] sein“ bzw. „immer der Erste zu sein, und vorzustreben vor andern“ (Il. 11, V. 784), wie es Voß übersetzt. Auch wenn die ganze Bedrohlichkeit und Unberechenbrakeit des antiken Achilles in diesem ewigen Streben ${ }^{154}$ begründet liegt, das dann auch für Faust zum fatalen Charakterzug wird, ${ }^{155}$ erwächst ihm daraus keine Schuld. Entspricht er doch ganz der antiken Konzeption des unreflektierten, nach außen handelnden Helden, dessen Weg nicht durch seine eigenen Entscheidungen, sondern vom Schicksal gelenkt wird. Wo der antike Achilles „strahlend, vital und tätig“ war und ihm der Status eines Übermenschen oder Halbgotts zukam, zeigt ihn Goethe als "wehmütig und passiv“156, wodurch er nun ganz als Mensch erscheint. Goethes Gestaltung und Verquickung von Todes- und Liebesmotiv kommt damit die spezifische Funktion zu, die Dialektik der modernen Subjektkonzeption als Kern der neuzeitlichen Tragödienpoetologie auszustellen.

$15^{1}$ Vgl. ebd. S. 36.

152 Vgl. Jessing: Zwischen Antikisierung und Moderne: Goethes Achilleis. S. 249-264, hier S. 302.

153 Schiller an Professor Johann Wilhelm Süvern, 26.7.18oo. In: Schiller: Werke und Briefe in zwölf Bänden, Bd. 12. S. $5^{22}$.

154 Goethe selbst bezeichnet Achilles am Ende seiner Winckelmann-Schrift als „ewig strebenden Jüngling", MA 6.2. S. 381 .

155 Im 5. Akt des 2. Tragödienteils: „immer strebend sich bemüht“ (V. 11936), vgl. Goethe: Faust. Der Tragödie erster und zweiter Teil. S. 359.

156 Riedel, Volker: Goethe und Homer. In: Ders. (Hrsg.): „Der Beste der Griechen“ - „Achill das Vieh“: Aufsätze und Vorträge zur literarischen Antikenrezeption II (= Jenaer Studien, Bd. 5). Jena: Bussert \& Stadeler 2002. S. 123-143, hier S. 137 und Liggieri: Warum gelingt uns das Epische so selten? Ein Blick hinter Goethes Achilleis. S. 64. 
Dass es in der Achilleis um einen einzelnen Menschen geht, macht allein schon der Titel deutlich. Aber während die gleichfalls nach ihren Helden benannten antiken Epen eben auch „das Interesse der Völker, der Welttheile [sic], der Erde und des Himmels ${ }^{157}$ enthalten, dreht sich Goethes Gedicht tatsächlich exklusiv um das Individuum Achilles. Daran, wie in der ersten Szene Achilles' Innenleben in seiner äußeren Umgebung gespiegelt wird, zeigt sich, dass der Individualisierung und Psychologisierung des Helden von Anfang an zentrale Bedeutung zukommt. Das letzte Aufflammen des Feuers korrespondiert mit Achilles Zorn (V. 11) ${ }^{158}$, der mit dem Erlöschen des Feuers und dem gleichzeitigen Erscheinen der Morgenröte endgültig abflaut (V. 13 f.). Angesichts der Bestattung Hektors gedenkt Achilles jetzt seines eigenen Schicksals (V. 21), „tief bewegt und sanft“ (V. 16) wendet er den Blick nach innen und auf seinen baldigen Tod. Diese absolute Hinwendung auf das bevorstehende Ableben ist das zentrale Hauptmotiv des ersten Gesangs, Achilles scheint des Lebens müde und seinem Schicksal ergeben: „Soll dies also nun sein, wie mir es die Götter entbieten, / Sei es! Gedenken wir nur des Nötigen, was noch zu tun ist" (V. 26-27). In seiner Todessehnsucht richtet sich Achilles ganz darauf aus, ein Grab zu errichten, in dem er wieder mit seinem Freund Patroklos vereint sein wird (V. 28). Der Streit um Troja, das große Ganze, hat für ihn jenseits der Markierung seines eigenen Todes keine Bedeutung mehr. Goethes Achilles erscheint somit als ein sanftmütiges, emotionales und gleichzeitig reflektierendes Subjekt. ${ }^{159}$ Die Achilleis wird von einem Privatinteresse getragen und interessiert sich im Gegensatz zur Ilias kaum für die Welt oder Völkerschicksale ${ }^{160}$ - vom geforderten Ausschluss des Pathologischen und Subjektiven ${ }^{161}$ kann insofern keine Rede sein - der Stoff der Dichtung ist also auch im modernen Sinne tragisch, weil er eben sentimentalisch ist. ${ }^{162}$

Verständlicherweise befürchtet Goethe deshalb im Laufe seiner Arbeit, sich im Stoff zu vergreifen ${ }^{163}$ und fragt sich ganz grundsätzlich, „ob man wohl thue [sic] einen tragischen Stoff allenfalls episch zu behandeln?" ${ }^{164}$ Eine der-

157 Goethe an Schiller am 16.5.1798, BW. S. 66o.

${ }_{15} 8$ Sämtliche Zitate aus Goethes Achilleis folgen im Weiteren der Hamburger-Ausgabe, Bd. 2 und werden mit der Verszahl in Klammern direkt im Text angegeben.

159 Vgl. Dreisbach: Goethes Achilleis. S. 140 ff.

16o Vgl. Liggieri: Warum gelingt uns das Epische so selten? Ein Blick hinter Goethes Achilleis. S. 79 .

161 Vgl. in diesem Buch S. $278 \mathrm{f}$.

162 Vgl. Dreisbach: Goethes Achilleis. S. 36.

163 Goethe an Schiller am 19.5.1798: „Hauptsächlich entstehen diese Bedenklichkeiten aus der Furcht mich im Stoff zu vergreifen, der entweder gar nicht, oder nicht von mir, oder nicht auf diese Weise behandelt werden soll.", BW. S. 663 .

164 Goethe an Schiller am 27.12.1797, BW. S. 545. 
artige Dichtung würde dem Anspruch auf Einheit von Form und Stoff nämlich nicht genügen, sondern sich gerade als prekäres, modernes und dadurch eben auch mangelhaftes Kunstwerk erweisen. Goethe kommt allerdings zu dem Schluss, dass „[d]as Lebensende des Achills mit seinen Umgebungen [...] eine epische Behandlung“ nicht nur zulasse, sondern „wegen der Breite des zu bearbeitenden Stoffs “ ${ }^{\prime 65}$ gewissermaßen forderte. Die mannigfaltigen Umstände des trojanischen Krieges, die den Tod des Helden begleiten und die vom Mythos vorgegebenen, weit gestreuten Handlungsstränge erzeugen eine sinnliche Breite, die der dramatischen Fokussierung auf einen Punkt zuwiderlaufen. ${ }^{166}$ Dem Epischen würden diese Elemente nun aber gerade zugute kommen, wie die Untersuchung des Gattungsdiskurses aufgezeigt hat, ${ }^{167} \mathrm{mehr}$ noch würde der „Effekt" einer solchen Arbeit dem modernen Dichter wohl zum Vorteil gereichen, denn nur ein "pathologisches Interesse“ kann noch den „Beyfall [sic] der Zeit“ erwerben. ${ }^{168}$ Die Stoffwahl würde sich den veränderten Bedürfnissen der neuen Zeit, dem Sehnen des modernen Publikums nach Leidenschaft ${ }^{169}$ also anbieten. Damit benennt Goethe nicht nur genau den Grund, wieso er trotz Skepsis in Betracht zieht, das eigentlich dramatische Sujet episch zu behandeln, sondern führt gleichzeitig auf die Vorteile, die aus dem Missachten der antiken Autorität zu gewinnen sind. ${ }^{170}$ Hier wird bereits deutlich, dass Goethe zu diesem Zeitpunkt dem Vorbild Homer nicht mehr einfach nacheifert, sondern vielmehr nach alternativen Gestaltungsmöglichkeiten, geradezu einer Neubegründung der Form sucht, also mit seiner Achilleis einen höheren Anspruch verfolgt.

Im Verlauf der Konzeptionalisierung führt diese großzügige Annäherung an die Moderne aber in ästhetische Zwiespälte und zu entsprechender Verunsicherung, wie die bereits zitierte Stelle des Briefwechsels über den radikalen Ausschluss des Pathologischen und des Subjektiven ${ }^{171}$ - also die ästhetischen Kategorien der Moderne - und die Forderung nach einer strengen Orientierung an den Alten gezeigt hat. Zwischenzeitlich scheint also das Fortschreiben epischer Dichtung nur noch in der bedingungslosen Nachschöpfung der homerischen Vorlage möglich und deren genaue Kenntnisse unabdingbare Voraussetzung, sowohl für das Erzeugen wie auch das Verstehen

\footnotetext{
165 Ebd.

166 Vgl. Dreisbach: Goethes Achilleis. S. 22.

167 Vgl. S. $115 \mathrm{ff}$. in diesem Buch.

168 Goethe an Schiller am 27.12.1797, BW. S. 545.

169 Vgl. S. 162 in diesem Buch.

170 Vgl. Meid: Goethes Achilleis - Versuch eines modernen Epos in der Nachfolge Homers. S. 83-101, hier S. 89 .

171 Vgl. S. 278 in diesem Buch.
} 
des Epos. Diese innige Vertrautheit mit der Ilias geht den meisten Lesern um 1800 allerdings ab, der Achilles-Stoff ist zu diesem Zeitpunkt bereits im Begriff aus dem kollektiven Gedächtnis zu verschwinden und die Spur der Erinnerung zu den Geschichten des trojanischen Krieges verblasst zunehmend. Die Krise der Kunst betrifft demnach nicht nur die Verfahrensweisen, sondern darüber hinaus auch die Gegenstände, wie Werner Busch anhand der veränderten Hierachien der Bildgattungen des 18. Jahrhunderts bereits aufgezeigt hat. ${ }^{172} \mathrm{Im}$ Gegensatz zu seinen anderen epischen Werken, die die bürgerliche Leserschaft immerhin stofflich an einem ganz persönlichen Punkt erreichten, ${ }^{173}$ muss die Achilleis dem zeitgenössischen Publikum bedeutend fremder, unzeitgemäßer und schließlich auch langweiliger erschienen sein. In Kombination mit der schwer lesbaren Hexameterform wirkt das Fragment deshalb nicht episch im Sinne volksmäßiger Ursprünglichkeit und Natürlichkeit, sondern im Gegenteil geradezu elitär und artifiziell. ${ }^{174}$ Anstatt die aufgespürten Widerstände aufzuheben, bringt die Forderung nach maximaler Annäherung an die Antike also nur neue hervor. Genau hier rührt wohl auch Goethes Unbehagen her. Das bedingungslose Zurücktreten hinter den Stoff im Sinn des antiken Epos bedeutet nämlich den rigorosen Verzicht auf einen eigenen, modernen Standpunkt ${ }^{175}$ und damit eben gerade auf die subjektive Bearbeitung, die das zeitgenössische Publikum verlangt. Das ganze Vorhaben wird damit auf mehreren Ebenen von vorneherein problematisch, ${ }^{176}$ was Goethe dazu zwingt, sich auf die ästhetischen Möglichkeiten zurückzubesinnen, die aus dieser fragilen Prädisposition erwachsen:

Die Achilleis ist ein tragischer Stoff der aber wegen einer gewissen Breite eine epische Behandlung nicht verschmäht. Er ist durchaus sentimental und würde sich in dieser doppelten Eigenschafft zu einer modernen Arbeit qualificiren [sic] und eine ganz realistische Behandlung würde jene beyde inneren Eigenschafften [sic] ins Gleichgewicht setzen. [Hevorhebung M.E.] $]^{177}$

172 Vgl. Busch: Das sentimentalische Bild. Die Krise der Kunst im 18. Jahrhundert und die Geburt der Moderne.

173 Vgl. Liggieri: Warum gelingt uns das Epische so selten? Ein Blick hinter Goethes Achilleis. S. 69 .

174 Auch Sengle sieht darin den Grund für die Ablehnung der Achilleis durch die Leserschaft das Gedicht sei einfach nicht „deutsch genug“ gewesen. Sengle: Goethes Ikarus-Flug. Zur Forcierung des Homerisierens im Achilleis-Plan. S. 69-85, hier S. 81.

175 Vgl. Meid: Goethes Achilleis - Versuch eines modernen Epos in der Nachfolge Homers. S. 83-101, hier S. 9 o.

176 Vgl. ebd. S. 89 .

177 Goethe an Schiller am 16.5.1798, BW. S. 66o. 
Bemerkenswert ist zunächst, wie diese Stelle auf Modernität abzielt, indem hier das Tragische neu mit dem Sentimentalischen gleichgesetzt und der eigentlich antike Achilles-Stoff damit der Moderne zugewiesen wird. Die Neuperspektivierung von aus der Antike übrig gebliebenen, tragischen Stoffen als spezifisch moderne präsentiert sich hier als Lösungsansatz für die oben aufgezeigte Krise der Gegenstände und verweist insofern auf die zunehmende Divergenz zwischen Inhalten und Verfahrensweisen der Kunst. ${ }^{178}$ Schiller bestätigt diese Einsicht in die Sentimentalität des Stoffes, sowie die daraus folgende Eignung zu einer modernen Bearbeitung und beharrt auf derWichtigkeit, oder vielmehr Unhintergehbarkeit eines eigenständigen, zeitgemäßen Standpunkts. Damit lenkt er Goethes Aufmerksamkeit endgültig zurück auf die Gegenwart:

Sie werden sich ganz gewiss Ihren Stoff so bilden, wie er sich zu Ihrer Form qualifiziert und umgekehrt werden Sie die Form zu dem Stoffe nicht verfehlen. Für beides bürgt Ihnen Ihre Natur und Ihre Einsicht und Erfahrung. Die tragische und sentimentale Beschaffenheit des Stoffs werden Sie unfehlbar durch Ihren subjectiven Dichtercharacter [sic] balancieren, und sicher ist es mehr eine Tugend als ein Fehler des Stoffs, dass er den Foderungen [sic] unseres Zeitalters entgegen kommt, denn es ist eben so unmöglich als undankbar für den Dichter, wenn er seinen vaterländischen Boden ganz verlassen und seiner Zeit wirklich entgegensetzen soll. Ihr schöner Beruf ist, ein Zeitgenosse und Bürger beider Dichterwelten zu seyn [sic] [...]. [Hervorhebung M.E. $]^{179}$

Goethes Überlegungen und Schillers Reaktion darauf bestätigen den doppelten Anspruch an das moderne Epos und hier insbesondere die Achilleis, gleichzeitig an die Gegenwart und an die Vergangenheit anzuschließen bzw. dazwischen hin- und herzuschwanken. Dieses pointierte Programm der Hybridisierung von eigentlich entgegengesetzten Formen bzw. von antiker Epen-Form und modernem Tragödien-Stoff macht die Achilleis zu einem ausgewiesenen Sonderfall. ${ }^{180}$ Schillers rückversichernder Zuspruch macht aber gerade auch deutlich, wie schwierig es ist, diesem Anspruch gerecht zu werden. Das Herstellen der heiklen Balance zwischen Naivem und Sentimentalischem, Antike und Moderne traut er Goethe nur zu, weil dieser eben im Gegensatz zum modernen Künstler in beiden Dichterwelten und Zeiten zu Hause ist.

178 Vgl. Busch: Das sentimentalische Bild. Die Krise der Kunst im 18. Jahrhundert und die Geburt der Moderne. S. 477 f.

179 Schiller an Goethe am 18.5.1798, BW. S. 661 f.

18 o Vgl. Dreisbach: Goethes Achilleis. S. 31. 


\subsubsection{Eine andere Verhandlung moderner Subjektivität}

Diese Bemühungen, zwischen den Gegensätzen zu vermitteln, werden im Gespräch zwischen Achilles und Athene auf besondere Weise reflektiert und zwar als prozessuales Herüberleiten von einem antik-naiven Menschenbild zur modern-sentimentalischen Subjektkonzeption. Zu Beginn des ersten Gesangs kennt Achilles zwar sein Schicksal, scheint seiner Bestimmung jedoch ergeben, ohne darin einen tieferen Sinn zu erkennen: „Soll dies also nun sein, wie mir es die Götter entbieten, / Sei es!“ (V. 26 f.). Der Tod seines Gefährten und das Wissen um den eigenen frühen Tod lösen im größten Helden der Griechen deshalb Niedergeschlagenheit und Verbitterung aus. Dieser „Unmut“ (V. 357) ist der eigentliche Grund für Thetis' Erscheinen auf dem Olymp, sie bittet Zeus nämlich nicht um das Leben ihres Sohnes, sondern lediglich um dessen Aufmunterung. ${ }^{181}$ Sinn und Zweck von Athenes Erscheinen auf Erden besteht dann gerade darin, Achilles' trauriges Gemüt zu erheben - ein schönes Leben soll nicht in Unmut enden (V. 357) -, indem sie seine Aufmerksamkeit vom kurz bevorstehenden Tod auf dessen Bedeutung im größeren Zusammenhang hinlenkt. Als Athene am Fuß des Grabmals auf Achilles trifft, ist dieser nur auf das unmittelbar vor ihm Liegende fokussiert - den physischen Bau des Grabmals:

Sieh! wie rings der Damm sich erhebt und schon nach der Mitte

Sich der rollende Schutt, den Kreis verengend, herandrängt.

Solches mag die Menge vollenden, doch dir sei empfohlen,

In der Mitte das Dach, den Schirm der Urne, zu bauen.

Hier! zwei Platten sondert' ich aus, beim Graben gefundne

Ungeheure; gewiss der Erderschüttrer Poseidon

Riss vom hohen Gebirge sie los und schleuderte hierher

Sie, an des Meeres Rand, mit Kies und Erde sie deckend.

Diese bereiteten, stelle sie auf, aneinander sie lehnend,

Baue das feste Gezelt! Darunter möge die Urne

Stehen, heimlich verwahrt, fern bis ans Ende der Tage.

Fülle die Lücken sodann des tiefen Raumes mit Erde,

Immer weiter heran, bis dass der vollendete Kegel,

Auf sich selber gestützt, den künftigen Menschen ein Mal sei. (V. 430-443)

Damit scheint er einer naiven Denkweise verhaftet, ${ }^{182}$ und doch zeigt Achilles nicht die totale Todesbereitschaft der antiken Helden, hat er nicht deren Selbstlosigkeit, weil er sich seiner selbst eben bewusst ist und ihn der eigene

181 Vgl. Liggieri: Warum gelingt uns das Epische so selten? Ein Blick hinter Goethes Achilleis. S. 92.

182 Vgl. Dreisbach: Goethes Achilleis. S. 184. 
Tod ebenso erschreckt und betrübt wie alle Menschen. ${ }^{183}$ Die Göttin nimmt Achilles nun sogleich an die Hand (V. 454 f.) und führt ihn hinaus „aus diesem drängenden Kreise“ (V. 451), hinauf auf den „erhabenen Rücken“ (V. 452) des Walls, wo sich "das Meer und das Land und die Inseln der Ferne“ (V. 453) zeigen. Erst auf dem erhöhten Standpunkt des Hügels beginnt nun das eigentliche Gespräch (V. 457 f.). Diese Heraus- und Hinaufführung beschreibt nicht nur die topographische, sondern gerade auch die geistige Bewegung, die Athene in Achilles anstößt. Im physischen Aufstieg von der Begrenztheit des Grabesbechers auf den oberen Rand des Hügels spiegelt sich im übertragenen Sinn eine regelrechte eductio zur Erkenntnis. ${ }^{184}$ In der Höhe lenkt Athene Achilles' Blick zunächst vom Hügel auf die Weite des Meeres und eröffnet in diesem hellen, heiteren Weitblick einen unbegrenzten Erfahrungs- und Wahrnehmungsraum:
Keinesweges irrte der Mann, der, hier an der Küste
Sich die Warte zu schaffen, die Seinigen sämtlich erregte,
Künftig ins hohe Meer nach kommenden Schiffen zu spähen,
Oder ein Feuer zu zünden, der Steuernden nächtliches Zeichen.
Denn der weiteste Raum eröffnet hier sich den Augen,
Nimmer leer; ein Schiff begnet strebenden Schiffen,
Oder folgt. (V. $472-478$ )

Indem die Göttin nun die Sicht derjenigen beschreibt, die vom Meer her kommen und das Grab des großen Helden sehen werden, vollzieht sie einen Perspektivenwechsel: „Mancher entschlossene Mann“",gelangt [...] hierher und zeigt den Hügel von ferne / Seinen Gesellen und fragt, was hier das Zeichen bedeute“ (V. 491, 493 f.). Durch das Einnehmen der Sicht der Anderen ${ }^{185}$ rückt der Bau des eigenen Grabmals in Distanz und gleichzeitig wird dessen tiefere Bedeutung einsehbar: Es markiert nicht nur Achilles' letzte Ruhestätte, sondern trägt seinen Ruhm in alle Räume und Zeiten.

Die Epitheta des Sehens bilden das semantische Gravitationsfeld des gesamten Dialogs und verbinden sich immer wieder bedeutungsvoll mit Erkennen und Denken. Zum einen erscheint Athene durchweg als sehende,

183 Vgl. Liggieri: Warum gelingt uns das Epische so selten? Ein Blick hinter Goethes Achilleis. S. 111.

184 Vgl. Dreisbach: Goethes Achilleis. S. 215.

185 Inwiefern hier Fremdwahrnehmung als relevante Konstante für moderne Identität und Ich-Konstruktion thematisiert wird siehe bei Liggieri: Warum gelingt uns das Epische so selten? Ein Blick hinter Goethes Achilleis. S. 113-116. 
hellsichtige Göttin, ${ }^{186}$ die Achilles die Zukunft enthüllt. Und zum anderen wird der von ihr angestoßene Erkenntnisprozess als eine zunehmende, sinnlichrezeptive Einsicht Achilles' in sich selbst, sein Schicksal und dessen Bedeutsamkeit gezeigt. Wenn Athene Achilles' Blick in der Höhe über das offene Meer lenkt, steuert sie auch seine Gedanken weg von der gegenwärtigen Befangenheit im eigenen Tod, hin auf das Nachdenken über den größeren Zusammenhang: den unsterblichen Ruhm, den Achilles über alle Zeiten genießen wird. Die reflektierende Betrachtung des Lebens und des Todes werden hier als Methode der Selbstfindung und -positionierung herausgestellt. ${ }^{187}$ Diese Wirklichkeitsbegründung steht darüber hinaus in konstitutiver Verbindung mit der Zeit. In der Gesprächsszene zwischen Athene und Achilles wird der Handlungsfortgang derart verlangsamt, dass dem Schauen die gesamte Aufmerksamkeit zukommt. Durch die geduldige Anschauung dessen, was einen umgibt, kann die Gegenwart räumlich erweitert werden. ${ }^{188}$ Die Ruhe und Entschleunigung, die darin zu gewinnen sind, stellen wiederum die temporalen Voraussetzungen für Reflexion und Erkenntnis dar, ganz entsprechend der epischen Rezeptionsästhetik, wie sie Schiller und Goethe beschrieben haben. ${ }^{189}$ Damit entwirft Goethe in der Achilleis eine spezifisch epische, retardierende Kultur des Anschauens, in der sinnliches Schauen und rationales Reflektieren ineinandergreifen bzw. Naives und Sentimentalisches nebeneinander treten.

Mit Blick auf den ästhetischen und medialen Wandel der Epochenschwelle $^{190}$ lässt sich dieses schwierige Unterfangen als kritische Reaktion auf die Verdrängung sinnlicher Erfahrungs- und Repräsentationsformen durch neue Gattungen wie den Roman begreifen. In der Verbindung mit dem Tragischen gewinnt das Epische hier die Lizenz, vom Leben und Leiden eines Individuums zu erzählen und insofern dem pathologischen Interesse der Zeit zu entsprechen. Das ist auch die primäre Zuständigkeit des modernen Romans. ${ }^{191}$ Im Unterschied zu diesem verbindet die Achilleis aber die Subjektgeschichte mit einer entschleunigten, auf Objektivität abzielenden Darstellung, wodurch der Text ganz entscheidend auf eine Abstraktionsleistung

186 V. 444: „klaräugige“, V. 457: „glänzenden Augen“, V. 471: „bläulich blickende“, V. 51O: „wahrheitsliebender Seher".

187 Vgl. Liggieri: Warum gelingt uns das Epische so selten? Ein Blick hinter Goethes Achilleis. S. 112.

188 Vgl. Osten, Manfred: Homunculus, die beschleunigte Zeit und Max Beckmanns Illustrationen zur Modernität Goethes (= Abhandlungen der Klasse der Literatur / Akademie der Wissenschaften und der Literatur, Nr. 1). Mainz: Akademie der Wissenschaften und der Literatur 2002. S. 16.

189 Vgl. S. 16o ff. in diesem Buch.

190 Vgl. S. 87 ff. in diesem Buch.

191 Vgl. S. 28 f. in diesem Buch. 
ausgerichtet wird, die der Roman als bloße Unterhaltungsform nicht erbringen kann. So werden in der Achilleis die problematischen Aspekte moderner Selbstbestimmung nicht übergangen, sondern vielmehr als Verunsicherung und Isolation fassbar gemacht. Mit der Hybridisierung von Tragischem und Epischem versucht Goethe also, dem doppelten Anspruch an die Kunst, gleichzeitig sinnliche Selbsterfahrung und rationale Erkenntnis zu ermöglichen, der unter den Bedingungen der Moderne immer prekärer wird, noch einmal gerecht zu werden. Dass sich die hier zu erwartenden Spannungen allerdings nicht mehr im Sinne einer klassizistischen Synthese auflösen lassen, ${ }^{192}$ hat sich bisher bereits deutlich abgezeichnet und wird sich im Folgenden auch weiter bestätigen.

\subsubsection{Das Glücksversprechen des epischen Augenblicks: Bemächtigung der Zeit über den Tod hinaus}

Durch Athenes Perspektivierung wird es möglich, gleichzeitig auf das zu blicken, was war, was ist und was erst noch geschehen wird. ${ }^{193}$ Dieses Anfüllen des flüchtigen Hier und Jetzt mit Ewigkeitsbedeutung wird durch Heres Worte an Athene klar vorgezeichnet: „Steige hinab zum Peliden und fülle mit göttlichem Leben / Seinen Busen, damit [...] ihm der Stunde Hand die Fülle des Ewigen reiche“ (V. 394-397). "Stunde“ meint hier deutlich den zeitlichen Moment, den Goethe sonst als Augenblick bezeichnet. ${ }^{194}$ Achilles wird im Moment kurz vor seinem Tod ein Vorblick auf die Zukunft gewährt, so dass er noch zu Lebzeiten persönlich und bewusst an seinem Ruhm teilhaben kann. ${ }^{195}$ Das ist die Idee des prägnanten Moments, wie sie das vorhergehende Kapitel als zentrale Denkfigur für Goethes Formdenken vorgestellt hat. ${ }^{196}$ An dieser Stelle bestätigt sich nun noch einmal die große Bedeutung, die der Vorstellung von Prägnanz bereits in dieser Schaffensphase zukommt und darüber hinaus, wie eng sie mit dem Epischen verbunden ist. Mit einem ersten Blick auf den Faust lässt sich nämlich gerade an der jeweiligen Ausprägungen des Augenblickmotivs der entscheidene Unterschied zwischen dem Epischen und Tragischen bzw. deren wechselseitige Beeinflussung erkennen. Denn auch

\footnotetext{
192 Vgl. Busch: Das sentimentalische Bild. Die Krise der Kunst im 18. Jahrhundert und die Geburt der Moderne. S. 7.

193 Vgl. Liggieri: Warum gelingt uns das Epische so selten? Ein Blick hinter Goethes Achilleis. S. 185 .

194 Vgl. Schadewaldt: Goethes Achilleis. S. 301-395, hier S. 376.

195 Vgl. ebd. S. 376.

196 Vgl. S. 95 f. in diesem Buch und Schneider: „ein strenger Umriß“ - Prägnanz als Leitidee von Goethes Formdenken im Kontext der Weimarer Kunsttheorie. S. 100.
} 
Faust richtet im Moment des Sterbens seine Aufmerksamkeit auf die Zukunft und auf das, was fortdauern wird:

Zum Augenblick dürft' ich sagen:

Verweile doch, du bist so schön!

Es kann die Spur von meinen Erdetagen

Nicht in Äonen untergehn. -

Im Vorgefühl von solchem hohen Glück

Genieß ich jetzt den höchsten Augenblick. (V. 11581-11586) 197

Diese gleichwohl maßlose, ganze Äonen erfassende, wie auch nur nach innen gerichtete Schau („Allein im Innern leuchtet helles Licht“ V. 115oo) ist jedoch kaum mehr als eine Illusion. Nicht ahnend, dass er seinem eigenen Grabbau beiwohnt, ergötzt sich der erblindete Faust am Spatengeklirr (V. 11539) und ist ganz auf den Fortschritt dieses neuen Projekts fokussiert (V. 11551-11556). Noch im Tod drängt er nur begehrend ständig vorwärts und bleibt so, wie in seinem durchgestürmten Leben, ein schrecklich Getäuschter. ${ }^{198}$ Der Aufschwung aus dem Bann der Vergänglichkeit, ${ }^{199}$ das Überdauern des Todes gelingt ihm nämlich nicht - „Die Uhr steht still“ - „Es ist vorbei“ (V. 115593, V. 11595). Damit erweist sich der höchste Augenblick im Faust-Drama nicht als prägnant, sondern vielmehr als höchst problematisch und insofern tragisch, kommt darin doch die ganze Tragik des modernen Menschen zum Ausdruck. In diesem tragischen Augenblick verwirklicht sich die spezifisch romantische Zeitkategorie des Jetzt als plötzliche Wende auf die Zukunft. ${ }^{200}$ Ein grenzenloses, zum Umschlag gesteigertes Beschleunigen verhindert hier gerade jegliche sinnliche Anschauung und deshalb können auch weder Einsicht noch Erkenntnis gewonnen werden, sondern nur Verwirrung und Blindheit. Vergeblich versucht Faust, „[d]en letzten, schlechten, leeren Augenblick“ (V. 11589) festzuhalten bzw. zu genießen, der Moment ist aber ein flüchtiger, er erscheint als verpasst oder versäumt. Nicht nur entzieht sich die Zeit hier der Kontrolle, sondern verfügt sie gerade ihrerseits über das Subjekt: „Die Zeit wird Herr,“ resümiert Mephisto Fausts Tod, „der Greis hier liegt im Sand“ (V. 11592).

Dagegen kommt der Begegnung zwischen Achilles und Athene auf dem Grabhügel tatsächlich der Charakter eines prägnanten, eben spezifisch epischen Augenblicks zu, handelt es sich hier doch eindeutig um einen Moment

197 Goethe: Faust. Der Tragödie erster und zweiter Teil. S. 348. Sämtliche Zitate aus Goethes Faust folgen im Weiteren dieser Ausgabe und werden mit der Verszahl in Klammern direkt im Text angegeben.

198 Vgl. Schadewaldt: Fausts Ende und die Achilleis. S. 283-30o, hier S. 297.

199 Vgl. ebd. S. 297.

200 Vgl. S. 94 in diesem Buch. 
des Innehaltens, des Umsichschauens und Bewusstwerdens. Wenn Athene in ihrer Rede das Grabmal als bereits vollendet darstellt - „Dort ist das herrliche Mal des einzigen großen Peliden“" (V. 508) - hebt sie die lineare Zeitenfolge zugunsten einer verdichteten Gleichzeitigkeit auf: Die flüchtige Gegenwart wird mit Zukunft angefüllt und dadurch über sich hinausgehoben. Damit vermag Athene dem Sterbenden in der gegenwärtigen Situation gleichzeitig einen Vorblick auf seinen unvergänglichen Ruhm zu eröffnen, als auch überhaupt eine Zeitvorstellung von Kontinuität bzw. Ewigkeit zu vermitteln: „[s]o weit nur der Tag und die Nacht reicht“, verspricht sie Achilles, „verbreitet / Sich dein herrlicher Ruhm, und alle Völker verehren / Deine treffende Wahl des kurzen rühmlichen Lebens" (V. 514-516), „[e]wig jung [...], ewig ersehnet" werde er den Künftigen erscheinen (V. 519). Wenn der Tod des Achilles in der Gegenwart erst durch einen Bezug auf die Zukunft Bedeutung erhält, wird damit nicht zuletzt ein reflexives und insofern modernes Zeitverständnis ausgedrückt, in dem die Zukunft bzw. eine Vorstellung von Zukünftigkeit konstitutiv auf die Gegenwart zurückwirkt.

Diese "holde Reden“ (V. 499) der Athene erzeugen „[n]eue Wonne“ (V. 50o) in Achilles' Brust und damit verwirklicht sich für ihn Heres Versprechen, dass er "des künftigen Ruhmes gedenkend“ „[h] $[$ eute der glücklichste sei“ „vor allen sterblichen Menschen“ (V. 395 f.). Das Wissen über die Zukunft versöhnt Achilles mit der Gegenwart und macht ihn zufrieden, davon zeugt der „heitere[...] Ernst“ (V. 619), den sein Gemüt nach der Begegnung mit Athene bestimmt. Die Gewissheit, dass die Menschen in Zukunft sein Mal von weit her sehen und sprechen werden: „Hier liegt keineswegs der Achaier Geringster bestattet“ (V. 503), tröstet Achilles über seinen bevorstehenden Tod hinweg. Anders als Faust, dessen Sehnen sich stets auf ein Unerreichbares richtet und dem weder ein Glück des Schauens noch des Verstehens gegönnt ist, ist Achilles' prägnantem Moment trotz unausweichlichem Tode gerade das Glücksversprechen einer gelungenen Lebensführung eingeschrieben: Ein ausgeglichener Gemütszustand bzw. Glückseligkeit über das gelebte Leben und Einvernehmen mit dem bevorstehenden Tod. ${ }^{201}$

Wenn Achilles nach durchlaufenem Erkenntnisprozess am Ende des ersten Gesangs wieder am Fuße des Grabmals steht, verinnerlicht er gleichsam sein Schicksal und die Freiheit, dieses zu akzeptieren. ${ }^{202}$ Achilles hat nämlich nach der erleuchtenden Begegnung mit Athene seinen Tod auf geistiger Ebene bereits durchlebt ${ }^{203}$ und sich von allen weltlichen Bedürfnissen gelöst:

201 Vgl. Schadewaldt: Goethes Achilleis. S. 301-395, hier S. 377.

202 Vgl. Dreisbach: Goethes Achilleis. S. 206.

203 Vgl. ebd. S. 186. 
„Mich zwar reizet der Hunger nicht mehr, noch der Durst, noch ein anders / Erdgebornes Verlangen zur Feier fröhlicher Stunden“ (V. 621 f.). Damit bringt Goethe an seinem Protagonisten nicht nur die Konzeption des modernen Subjekts zur Darstellung, das nicht mehr in einer selbstverständlichen Einheit von innerer Selbstbestimmung und äußerer Fremdbestimmung verweilt, sondern stellt gleichwohl die geistige Bewegung des Erhabenen als einzigen möglichen Ausgang aus diesem Dilemma vor. Die Verinnerlichung des Schicksals bedeutet die Überwindung des inneren Zwiespalts zwischen Pflicht und Neigung, eigener Entscheidungsfreiheit und Schicksalsbestimmung und macht gleichzeitig die eigentliche Todeserfahrung unwesentlich. Goethes Achilles hat keinen Ausnahmestatus unter den Menschen wie sein antiker Vorgänger, vielmehr erscheint er als Repräsentant einer grundsätzlich gefährdeten Menschheit:

Und wo rastet der Mensch von Müh' und gewaltigem Streben, Der die Meere befährt im hohlen Schiffe? die Erde, Kräftigen Stieren folgend, mit schicklicher Furche durchziehet? Überall sind Gefahren ihm nah', und Tyche, der Moiren Älteste, reget den Boden der Erde so gut als das Meer auf. (V. 6o4-6o8)

Diese Diagnose schließt an die Rede von Dorotheas erstem Verlobten $a^{204}$ und zeigt die tragische conditio humana der Moderne als Kehrseite einer radikal beschleunigten Lebenswelt auf. Die Dynamisierung der Welt und die damit einhergehende Destabilisierung des darin wohnenden Subjekts - das wird im Faust exemplarisch zum Ausdruck kommen - verhindern gerade jene geistige Auseinandersetzung, die das Individuum über sich selbst erheben könnte.

In der Achilleis erzielt Goethe die Wirkung des Erhabenen deshalb durch das dem tragischen entgegengesetzte, retardierende Moment des Epischen. Der prägnante Augenblick hält das lineare Vorwärtsschreiten der Zeit bzw. der Handlung an und leistet so den nötigen Aufschub, um überhaupt Reflexionstätigkeit zuzulassen. Für diesen einen Moment wird fassbar, was sich sonst der Erkenntnis entzieht: die eigene, subjektive Identität und deren Verortung in einer übergeordneten, dauerhaften, kollektiven Ordnung. Beim epischen Augenblick der Achilleis handelt es sich gleichwohl um einen Moment individueller Selbsterkenntnis wie auch der reflexiven Wirklichkeitsbegründung. Das Epische ist in der Moderne zwar darauf angewiesen, auf gattungsfremde, tragische Gegenstände wie das Subjekt auszuweichen, es ist aber gerade das besondere Verdienst der epischen Behandlung, diese überhaupt erkenn- und verstehbar zu machen. Das Epische kann jetzt auch das

204 Vgl. Schadewaldt: Goethes Achilleis. S. 301-395, hier S. 357. 
Individuum verhandeln sowie analysieren und ist nicht länger auf die Darstellung einer ohnehin nicht mehr gültigen objektiven Totalität beschränkt. Insofern offenbart sich an der Achilleis geradezu exemplarisch die von Busch beschriebene Ablösung der Verfahrensweisen von den Gegenständen als Voraussetzung für die moderne Kunst. ${ }^{205}$ In der Achilleis wird das moderne Subjekt in die Lage versetzt, sich der Zeit wieder zu bemächtigen, sich über die Verworrenheit der flüchtigen Gegenwart zu erheben und das Jetzt nutzbar zu machen, in dem es mit den anderen Zeitstufen in Beziehung gebracht wird. In dieser wiederhergestellten Kontinuität der Zeit wird die tragische Selbstentzweiung des modernen Menschen nicht überwunden, aber zumindest ausgestellt und dadurch fassbar gemacht. Der Text stellt nämlich keine idyllisch-utopische Vision der Zukunft vor, in der nach Schiller alle Widerstände zwischen sinnlicher Erfahrung und rationaler Reflexion aufgehoben sind. Vielmehr erweisen sich diese Harmonisierungsbemühungen als ganz und gar sentimentalische, die den ästhetischen Traditionsbruch weder zu verhindern noch darüber hinwegzutäuschen vermögen. Am Ende des ersten Gesanges muss Achilles seinen Tod als endgültig akzeptieren, der Aufschwung aus dem Bann der Vergänglichkeit kann nur auf der psychischen Ebene des kollektiven Gedächtnisses gelingen. Was der Text leistet, ist aber die nötige Einordnung dieses Bruchs, indem er ihn überhaupt erkennbar und dadurch als Teil des großen Ganzen bzw. eben als Moment des kulturhistorischen Kontinuums verstehbar macht: „Mnemosyne“, die Göttin der Erinnerung, und „ihre[...] herrlichen Töchter[...]“ (V. 551), die Musen, werden Achilles' Heldentaten über alle Zeiten hinweg verkünden.

„Immer wird dein Name zuerst von den Lippen des Sängers / Fließen, wenn er voran des Gottes preisend erwähnte. / Allen erhebst du das Herz, als gegenwärtig“ (V. 571-573), verspricht Athene und verweist damit eindeutig auf den Wissenszusammenhang zwischen Erinnerung, Tradition und Erneuerung, der sich gleichwohl in Goethes Kulturbegriff wie auch seinem Epos-Projekt manifestiert. Achilles kann in der Erinnerung der Nachwelt überdauern. Um diese lebendig zu halten, muss die Geschichte seiner Heldentaten jedoch von Generation zu Generation weitergegeben werden. Achilles selbst erscheint als der Begründer dieses Erinnerungskults, wenn er sein Grab als von weither sichtbares Zeichen (V. 465) seines Todes errichtet. ${ }^{206}$ Die letzte Ruhestätte des großen Peliden ist damit zugleich Grab- und Denkmal (V. 28), die daran

205 Vgl. Busch: Das sentimentalische Bild. Die Krise der Kunst im 18. Jahrhundert und die Geburt der Moderne. S. 19-238.

206 Zur semiotischen Deutung der Achilleis vgl. Friedrich: Zeichenbaustellen. Goethes Achillë̈s. S. 65-82. 
geknüpften Bedeutungen von Tod, Ruhm und Gedenken verbinden sich hier zu einem Komplex der Ewigkeit. Das ist eine Kontinuitätsvorstellung, die wesentlich auf Erzählen als zeitenverknüpfende, kulturelle Praxis angewiesen ist und die, wie gesehen, gerade eine besondere Zuständigkeit des Epischen darstellt. ${ }^{207}$ In Athenes Versprechen wird nicht nur das Epos selbst zum Gegenstand der Achilleis erhoben, sondern gerade auch diese modernespezifische Funktion als Erinnerungsspur besonders herausgestellt. An dieser Stelle wird die ganze Achilleis rückwirkend als metaphorische Erzählung über das Epische und sein Schicksal in der Moderne lesbar und erweist sich insofern als höchst selbstreflexive Dichtung. Wenn in der ersten Szene „die mächtige Lohe noch einmal“ (V. 1) entbrennt und das Feuer dann "zuletzt“ (V. 5) erlischt, wird damit auch eine Aussage über das vorliegende Epos gemacht: Es ist das letzte seiner Art. Hektors Leichenfeuer gemahnt nicht nur Achilles an seinen eigenen Tod, sondern auch an den Tod des Epos. Überhaupt manifestiert sich am zentralen Themenkomplex von Tod, Bestattung und Grabmal gerade die unausweichliche Gefährdung epischen Erzählens in der Moderne. ${ }^{208}$

So wie Achilles' Grab schließlich zum Zeichen seines ewigen Ruhmes wird, wird die Achilleis zum Denkmal für die Gattung des Epischen. Um in die Erinnerung einzugehen und darin über alle Zeiten hinweg zu bestehen, muss das Leben allerdings erst zu einem Ende kommen. Das gilt gleichermaßen für Achilles, dessen Größe gerade in der Kürze seines Lebens besteht (V. $5^{24}-526$ ), wie auch für das Epos. Wenn es also über Achilles' Grab heißt, dass darin „keineswegs der Achaier Geringster bestattet [liegt], [d] enen zurück den Weg der Moiren Strenge versagt hat; / [d]enn nicht wenige trugen den türmenden Hügel zusammen" (V. 503 ff.), dann wird damit auch die Problematik des Epischen um 1800 beschrieben: Hier liegt die hohe Kunst der Alten bestattet, an der sich nicht wenige Dichter verdient gemacht haben, deren Restitution in der Gegenwart aber nicht mehr gelingen kann - zumindest nicht in der alten Form. An der Achilleis wird insofern bereits die erneuernde Energie erahnbar, die Hegels späterer Rhetorik vom Ende der Kunst und des Epos unterschwellig eingeschrieben ist. Denn wie Geulen deutlich gemacht hat, ${ }^{209}$ hat jede Rede vom Ende der Kunst - und damit auch die Behauptung vom Ende des Epos - ein gespaltenes Verhältnis zu ihrem Gegenstand. Sie ist entweder verfrüht oder zu spät, sie widerspricht sich jedenfalls stets selbst, denn solang noch bzw. wenn wieder darüber geredet wird, kann das Epos gar nicht tot sein. Wie das Eposkonzept der Moderne gerade das eigene Ableben, oder

207 Vgl. S. $145 \mathrm{ff}$. in diesem Buch.

208 Vgl. Friedrich: Zeichenbaustellen. Goethes Achilleïs. S. 65-82, hier S. 75 .

209 Vgl. S. 36 in diesem Buch. 
zumindest die Rede davon, zum produktiven Antrieb macht, wird auch für Achilles die Auseinandersetzung mit dem eigenen Tod zum Antrieb, zur Energie der Erneuerung, der Metamorphose. Insofern versucht Goethe mit seinem Fragment, wenn schon nicht an Homer anzuschließen, so zumindest an ihn zu erinnern und sein Vermächtnis dadurch lebendig zu halten. Im Zusammenspiel von Erinnerung und literarischem Artefakt entwickelt sich so die an den Artefakten hängende Historizität ihrer selbst und des kulturellen, sozialen Geflechts, in welchem sie entstanden sind. ${ }^{210}$ Goethe benutzt die Formensprache des Epischen nicht, um im klassizistischen Sinn an die darin gespeicherten, antiken Vorstellungen anzuschließen, sondern gerade um aus der Spannung von antiker Form und neuzeitlichem Gegenstand - epischer Behandlung und tragischem Stoff - die Aufhebung des Klassischen in der Moderne resultieren zu lassen. ${ }^{211}$ Das ist nicht mehr die versuchte Rettung der Antike bzw. die Restitution des Epos, sondern eine Überführung ins kollektive Gedächtnis der Traditionsgeschichte und gleichzeitig das Herausbilden einer neuen epischen Formensprache auf der Folie der klassischen Vorlage. Die Antike fungiert hier nicht mehr als vergangener Sehnsuchtsort, sondern als Spiegel der Moderne, in den die gegenwärtigen Destabilisierungserfahrungen hineinprojiziert werden und aus dem die Vorstellungen von Stabilität und Kontinuität zurückgewonnen werden können.

Daraus spricht nicht zuletzt ein spezifisch zeitliches Bewusstsein für das Ende einer Epoche bzw. das Ende des klassizistischen Gattungsverständnis auf der einen Seite und auf der anderen für den Anbruch einer neuen Zeit sowie das damit einhergehende Bedürfnis für neue Gegenstände und Verfahrensweisen bzw. deren gegenseitige Unabhängigkeit. In der Achilleis geht es daher, anders als in Hermann und Dorotea, nicht darum, trotz aller Prekarität die mögliche Wiederherstellung eines Idealzustands vorzustellen, sondern vielmehr um das Sichtbarmachen von historischer Verfasstheit und dem Gedenken der Vergangenheit. Der Gründungsprozess einer neuen Form des epischen Erzählens in und für die Moderne wird so in der Achilleis noch einmal in zugespitzter Weise reflektiert.

210 Vgl. Böhme: Fetisch und Idol. Die Temporalität von Erinnerungsformen in Goethes Wilhelm Meister, Faust und Der Sammler und die Seinigen. S. 178-201, hier S. 196 f.

211 Vgl. Busch: Das sentimentalische Bild. Die Krise der Kunst im 18. Jahrhundert und die Geburt der Moderne. S. 15 . 


\subsection{Die ästhetischen Eigenzeitlichkeiten des Tragischen und die Lizenzen des Epischen}

In den bisherigen Ausführungen wurde die Hybridisierung des Epischen und des Tragischen als ein Versuch beschrieben, das Epische auf der Ebene des Dargestellten über die Thematisierung moderner Subjektivität an die Gegenwart anzuschließen. Dabei geht es nicht mehr darum, einen sentimentalischmodernen Stoff in einer naiv-antiken, also zeitlosen und mustergültigen Behandlung zu vermitteln, vielmehr werden Gegenstand und Form in ein ebenso anspruchsvolles wie prekäres Spannungsverhältnis gesetzt. Daran wird deutlich, dass die Erneuerung des Epischen mit der Achilleis eine entschieden andere Ausprägung annimmt, als die Verbindung von Idylle und Epos, die mit Hermann und Dorothea vorgestellt wurde. Und zwar insofern, als das epische Erzählen nun radikal auf eine kritische Betrachtung nicht nur der modernen Zeit und dem darin isolierten Individuum, sondern vor allem auch der eigenen Verfahrensweisen und Leistungspotenziale ausgerichtet wird.

Dass Goethe damit weit über die Erkenntnisse des theoretischen Gattungsdiskurses hinaus geht und eine neue Form des Erzählens hervorbringt, die im Kern darauf abzielt, ihre eigene Gefährdung auszustellen, soll im Folgenden entlang der Spannungen nachverfolgt werden, die sich jenseits des Verhältnisses von Gegenstand und Behandlung auch auf der Ebene der poetolgischen Darstellung selbst, genauer ihrer ästhetischen Eigenzeitlichkeit ergeben. Inwiefern gerade auch der zeitlichen Verfasstheit des Tragischen in der Moderne besondere Bedeutung zukommt, soll zunächst an Goethes Faust exemplarisch sichtbar gemacht werden, bevor die prekäre Zeitorganisation der Achilleis als Ausweis ihrer Modernität dargestellt werden kann.

\subsubsection{Faust und das Veloziferische}

Der Kern der tragischen Form ist für Goethe zeitlich bestimmt, das zeigt das Gattungsgespräch mit Schiller unmissverständlich, und zwar als vorwärts gerichtetes Streben. ${ }^{212}$ Inwiefern der Bewegung des unaufhaltsamen Vorwärtsstrebens eine tragische Qualität innwohnt und sich dieser Zusammenhang in der Moderne als Zeitsignatur akzentuiert, bringt Goethe mit seiner Formel des Veloziferischen prägnant auf den Punkt:

Für das größte Unheil unserer Zeit, die nichts reif werden lässt, muss ich halten, dass man im nächsten Augenblick den vorhergehenden verspeist, den Tag im Tage vertut und so immer aus der Hand in den Mund lebt, ohne irgend etwas

212 Vgl. S. $120 \mathrm{ff}$. in diesem Buch. 
vor sich zu bringen. Haben wir doch schon Blätter für sämtliche Tageszeiten! ein guter Kopf könnte wohl noch eins und das andere interkalieren. Dadurch wird alles, was ein jeder tut, treibt, dichtet, ja was er vorhat, ins Öffentliche geschleppt. Niemand darf sich freuen oder leiden als zum Zeitvertreib der übrigen; und so springt's von Haus zu Haus, von Stadt zu Stadt, von Reich zu Reich und zuletzt von Weltteil zu Weltteil, alles veloziferisch. [Hervorhebung M.E.] ${ }^{213}$

Dieser tragischen Verschränkung von Velocitas (Eile) und Lucifer (Teufel) kommt nun gerade in der Faust-Tragödie und dem dafür so zentralen Pakt mit dem Teufel besondere Bedeutung zu. Auf der Ebene des Dargestellten personifiziert Mephistopheles das Veloziferische geradezu prototypisch, während Faust für das moderne Individuum steht, das sich dem teuflischen Beschleunigungsgesetz nur allzu breitwillig unterwirft. Sein unaufhaltsames Streben nach Wissen und Macht setzt Faust einem rasant beschleunigenden Lebenstempo aus, dessen entgrenzende Kräfte ihn zunächst erblinden lassen (V. 11498) und schließlich zu Chaos, Irrtum, Gewalt und Tod führen. Zu Recht sieht Manfred Osten in der Faust-Tragödie die Beschleunigung bereits im modernen Sinne mit quantitativer Produktionssteigerung und fortwährender Erschütterung sämtlicher gesellschaftlicher Zustände verknüpft. ${ }^{214}$ Nicht nur offenbart sich hier die kaum zu überschätzende Bedeutung ästhetischer Eigenzeiten für die ganze moderne Gattungspoetologie, sondern auch, wie darüber antike Formen an die Moderne angeschlossen werden können.

Dass in der Ungeduld der Teufel steckt, wird in der Faust-Dichtung aber gerade auch auf der Ebene der Darstellung prominent reflektiert. In immer schneller wechselnden Bildsequenzen rauschen Mephisto und Faust vom Himmel durch die Welt zur Hölle - vorbei an Auerbachs Keller, Hexenküche, Walpurgisnacht, heraufbeschworener Helena und längst vergangenen Schlachtfeldern. Gegen Ende springt die Handlung in immer kürzeren Sequenzen vorwärts in der Zeit und von Ort zu Ort. Die Zeit der Darstellung, also die Abfolge der sprachlichen Zeichen, bleibt in dieser Raffung deutlich hinter der dargestellten Zeit zurück - ganz veloziferisch - und diese drängende Entfaltung des Geschehens erzeugt einen wirkungsästhetischen Sog, der den Rezipienten unwillkürlich mitreißt. Damit steigert die moderne Tragödie die dramatische Zeitorganisation des unaufhaltsamen, linearen Fortschreitens zu einer radikalen und fatalen Form der Übereilung. In der Achilleis ist dagegen bezeichnenderweise ein geradezu gemächliches Erzähltempo vorherrschend, welches sie zumindest in dieser Hinsicht eindeutig dem Epischen zuweist.

213 Goethe nennt den Begriff in einem Brief an Nicolovius, vgl. FA, II, 10. S. 333 f.

214 Vgl. Osten, Manfred: „Alles veloziferisch“ oder Goethes Entdeckung der Langsamkeit. Zur Modernität eines Klassikers im 21. Jahrhundert. Leipzig: Insel 2003. S. 29. 
Die 651 Verse des ersten Gesangs umfassen einen Zeitraum von höchstens ein paar Stunden - von der Morgenfrühe vor Sonnenaufgang ${ }^{215}$ bis zu einem nicht näher bestimmten Zeitpunkt am Vormittag, zu dem die Arbeitenden das Frühmal einnehmen. Zudem geben die Paralipomena zur Achilleis Aufschluss darüber, dass Goethe wohl gesamthaft eine ausgedehnte Dichtung im Sinn hatte, in der fast alle Figuren, die am Ende der Ilias noch bestehen, zu einem Auftritt kommen und in der die Darstellungszeit die dargestellte Zeit bei weitem übertroffen hätte. ${ }^{216}$

Um die tragische Form und damit auch die Erfahrung des Tragischen hervorzubringen, reicht der dramatische Transport, ${ }^{217}$ wie er oben beschrieben wurde, jedoch nicht aus. Gerade in der Moderne bedeutet die eigentliche Verwirklichung tragischer Form ja nicht mehr unreflektierte Ergebenheit, sondern das Erlangen von Freiheit und Selbstbestimmung durch Selbstentzweiung. ${ }^{218}$ Um diese dialektische Dynamik freizusetzten, muss die einseitig mitreißende Handlung unterbrochen werden, denn nur durch den Bruch der Ereigniskette kann die nötig Distanz zur Reflexion überhaupt geschaffen werden, die das Hervortreten struktureller Gesetzmäßigkeiten ermöglicht. So kann ein ästhetisches Bewusstsein entstehen, nicht zuletzt auch beim Rezipienten, welches die spezifischen Beziehungen zwischen Form und Inhalt der Tragödienform zu reflektieren vermag und den eigentlichen Kern der tragischen Affekttheorie bildet. ${ }^{219}$ Die Unterbrechung der vorantreibenden Handlung, die Peripetie der aristotelischen Tragödie, ist demnach auch für das tragische Formgesetz der Neuzeit ein äußerst entscheidendes Moment. Hölderlin hat dafür den der Verslehre entlehnten Begriff der Zäsur fruchtbar gemacht $\mathrm{t}^{220}$ und damit auf die für die Peripetie so zentrale Dimension der Zeitorganisation hingewiesen. Die Zäsur unterbricht nämlich nicht nur die Abfolge der vorgestellten Ereignisse, sondern sie bricht überhaupt die rhythmische Struktur poetischer Darstellung auf. Die zeitliche Sequenzierung wird maximal verkürzt auf einen plötzlichen Umschlagspunkt - der beschleunigte Transport wird in eine Trennung überführt, ${ }^{221}$ wobei die lineare Ausrichtung allerdings

215 Das Achilleis-Fragment selbst gibt weder Aufschluss über genauen Ort noch genaue Zeit aber das Schema vom 31. März 1798 enthält eine exakte Zeitangabe: 1. Morgen nach der Verbrennung des Hectors, vgl. FA I, 8. S. 1212.

216 Vgl. Dreisbach: Goethes Achilleis. S. 81.

217 Vgl. Wellbery, David E.: Goethes Faust I. Reflexion der tragischen Form (= Reihe „Themen“, Bd. 102). München: Carl Friedrich von Siemens Stiftung 2016. S. 31.

218 Vgl. S. 275 f. in diesem Buch.

219 Vgl. Galle: Tragisch/Tragik. S. 117-171.

220 Vgl. Wellbery: Goethes Faust I. Reflexion der tragischen Form. S. 30-34.

221 Vgl. ebd. S. 32. 
erhalten bleibt. Die tragische Prozessgestalt formt sich damit um eine eigentlich Lücke im Zeitgefüge, womit die Tragödie in ihrem Kern auf Diskontinuität ausgerichtet wird.

Die zentrale strukturelle Bedeutung, die der Zäsur für die Entfaltung des Tragischen zukommt, zeigt sich in der Faust-Dichtung immer wieder sinnfällig. In Wald und Höhle erreicht der erste Tragödienteil seinen Höhepunkt, die Szene unterbricht den bisherigen Handlungsgang und gibt Hinweise auf die weitere Entwicklung. Fausts anfängliches Glücksgefühl kippt in Erkenntnis, er ahnt die tragische Entwicklung voraus, kann sich aber aus dem Verhältnis zu Mephisto, das sich von nun an als unfreiwillige Abhängigkeit zeigt, nicht mehr befreien. Auf diesen inneren Umschlag folgt dann unweigerlich der äußere: Faust verschwindet nach der Liebesnacht, lässt Gretchen allein mit der toten Mutter zurück und überlässt schließlich auch sie ihrem Schicksal. 222 Inwiefern für Goethe der Bruch der Zeitenfolge aber nicht nur das Alleinstellungsmerkmal des Tragischen ist, sondern sich darin gerade auch die eigentliche Tragödie der Moderne offenbart, findet seinen radikalsten Ausdruck im fünften Akt des zweiten Teils, wenn Faust Philemon und Baucis gewaltsam tötet. ${ }^{223}$ Mit der Ermordung der beiden Alten und der Vernichtung ihrer Behausung zerstört Faust die ganze Lebenswelt der Antike, die sie repräsentieren. ${ }^{224}$ Und mit dem Altertum wird auch die alte mythische Weltordnung „weggeräumt“ (V. 11361) - Zeus, der "alte Gott“ (V. 11142), der als Wanderer verkleidet bei Philemon und Baucis eingekehrt war und sich gegen den Angriff zur Wehr setzt, wird von Fausts Gesellen unerkannt mitbeseitigt. Die rücksichtslose Vernichtung der Antike, diese „ungeduld'ge Tat“ (V. 11341), "geboten schnell, zu schnell getan!" (V. 11382), wirkt um so brutaler, weil Haus und Umgebung der Alten in der vorherigen Szene mit allen Zeichen der Idylle erscheinen:225 Schon ein Mal hatte Zeus bei den Alten Zuflucht gefunden, wo Glockenklang ertönt und der Duft der Linden in die Luft steigt, als wär „das Leben ein verschollner Traum“ (V. 11268). ${ }^{226}$ Die Hütte und das „Gärtchen“

222 Vgl. dazu ausführlicher ebd. S. 34-47.

223 Dazu vgl. zum Beispiel Goethe: Faust. Der Tragödie erster und zweiter Teil. S. 712-715; Henkel, Arthur: Erwägungen zur Philemon-und-Baucis-Szene im fünften Akt von Goethes Faust (Zweiter Teil). In: Études Germaniques 38 (1983). S. 128-137; Härtling, Peter: Die beiden Alten. Über Philemon und Baucis in Goethes Faust. Eine literarische Reflexion. In: Ders. (Hrsg.): Zwischen Untergang und Aufbruch. Aufsätze, Reden, Gespräche. Berlin: Aufbau 199o. S. 238-246.

224 Vgl. Osten: „Alles veloziferisch“ oder Goethes Entdeckung der Langsamkeit. Zur Modernität eines Klassikers im 21. Jahrhundert. S. 32 .

225 Vgl. Goethe: Faust. Der Tragödie erster und zweiter Teil. S. 712.

226 Damit wird auf die idyllische Philemon und Baucis-Erzählung in Ovids Metamorphosen verwiesen, vgl. ebd. S. $713 \mathrm{f}$. 
(V. 11080) unter alten Linden (V. 11044 f.) erinnern an die Idyllen von Voß, die im oberen Kapitel vorgestellt wurden, ${ }^{227}$ und geben ein ebenso „paradiesisch Bild“ (V. 11086) ab. Hier herrschen Begrenztheit, Ruhe und eine natürlichgewachsene Lebensordnung. Es ändert sich nichts, alles ist alt und war es bereits zuvor - die ganze Szene Offene Gegend steht so exemplarisch für das alte, zyklische Zeitregime. ${ }^{228}$ Nicht zuletzt spiegelt sich diese Zueignung zur antiken Welt- und Zeitordnung in der schlichten, redundanten Sprache sowie in den kurzen vier-hebigen Trochäen, die Ruhe, Stille und Stetigkeit auch auf prosodischer Ebene implementieren. ${ }^{229}$ Mit der Beseitigung der Alten wird also nicht nur die Vergangenheit abgeschafft, sondern auch das ganze tradierte Zeitgefüge aufgelöst und in die Temporalstrukturen der Moderne überführt. An der "wildentbrannte[n] Hölle“ (V. 11323), die Faust entfacht, offenbart sich die ungeheure Zerstörungsgewalt, die gleichwohl der tragischen Peripetie als auch dem irreversiblen Bruch der Zeit innewohnt. Das Abbrechen der Gegenwart von der Vergangenheit und die daraus resultierende Verunsicherung über die Zukunft zeigt Goethe hier deutlich als die Schattenseite des modernen Freiheitsgewinns auf.

Diese radikale Zurichtung der Zeit in der Tragödie verbindet Goethe nun aber gerade mit der epischen Lizenz zur zeitlichen Entgrenzung und erzeugt so ein komplexes, vielschichtiges Zeitgefüge, welches insbesondere Schillers moderner Tragödienpoetologie entgegensteht. Die Faust-Szene Vor dem Tor (V. 808-1177), in der die Handlung des ersten Teils ihren Anfang nimmt und die insofern als Eröffnungsszene gekennzeichnet ist, führt das geradezu musterhaft vor. Hier wird der einzige Rückblick auf Fausts Vergangenheit gegeben und ein prägendes Erlebnis aus der Jugend des Protagonisten wiedergegeben - gemeinsam mit seinem Vater, einem Alchimisten, verabreichte Faust angesichts der Pest ein unwirksames, tödliches Medikament, an dem Tausende starben (V. 1020-1055). Bei genauer Betrachtung ist die ganze Vor dem Tor-Szene eng an Sophokles' Öpipus angelehnt - beide finden vor dem Tor bzw. der Tür statt, beide zeigen auf dem Hintergrund von Festlichkeiten eine Begegnung zwischen dem Protagonisten und einer Volksmasse, aus der ein Alter als Sprecher hervorgeht. Sowohl Ödpipus' als auch Fausts Status wird durch die Lobpreisung des Volkes überhöht. Aus gattungspoetologischer Sicht wird so der Eingang in die tragische Handlung bewerkstelligt - gerade

227 Vgl. S. $215 \mathrm{ff}$. in diesem Buch.

228 Vgl. Schmidt, Jochen: Goethes Faust. Erster und Zweiter Teil. Grundlagen - Werk Wirkung (= Arbeitsbücher zur Literaturgeschichte). München: Beck 1999. S. 274 f.

229 Zur metrischen Gestaltung des Fausts vgl. May, Kurt: Faust II. Teil in der Sprachform gedeutet (= Literatur als Kunst - May). München: Hanser 1962. S. 25 o. 
die Erhebung durch das Volk wird in beiden Fällen tragische Konsequenzen haben und liefert aber auch einen großen Anreiz zur Selbstüberhöhung bzw. tragischer Überschreitung. ${ }^{230}$

Im Faust wird der Dialog zwischen dem alten Bauern und Faust durch den Bezug auf Gegenwart und Vergangenheit strukturiert und gleichwohl wird gerade dadurch auch die Zukunft bzw. der tragische Ausgang antizipiert: die Offenbarung von Mord und Tod. Der Alte sieht in Faust einen Retter, jemanden, der durch seine früheren Taten die Gegenwart gesichert hat und holt in seiner Rede die Vergangenheit in die Jetzt-Zeit hinein - er erinnert an die Pest und deren vermeintliche Bekämpfung durch die Fausts. Diese Rettung war allerdings nur eine scheinbare, da tatsächlich Faust und sein Vater die eigentlichen Täter, „freche[...] Mörder“ (V. 1055), waren. Nicht nur fallen damit Retter und Täter auf ähnliche Weise zusammen wie in Sophokles Ödipus, ${ }^{231}$ sondern erscheint zum einen in der Figur des mörderischen Vaters auch Fausts Ende vorausgedeutet und zum anderen wird sich die gewaltsame Paarung alchimistischer Ingridienzen im Brautgemach in Gretchens Zimmer wiederholen. Fausts spätere Abwendung von der Religion und Hinwendung zur Magie - beide von großer tragischer Bedeutsamkeit - haben ihren Ursprung hier im erinnerten, aus der Vergangenheit in die gegenwärtige Handlung hineingeholten Jugenderlebnis. Durch diese Verschränkung der Zeitschichten wird der chronologische Handlungsverlauf mit Vorausdeutungen und Rückbezügen derart überlagert, dass sich neben der linearen Zeitorganisation auch eine andere, zyklische Zeitlichkeit bemerkbar macht, die einen mythischen Kreislauf von Verbrechen und Schuld, Leid und Sühne aufzeigt.

Gemäß Wellbery ist diese „mythische Zeit- und Schiksalsverschlingung“232 ein wesentliches Strukturelement der antiken Tragödie, ${ }^{233}$ das Goethe erfolgreich in sein modernes Faust-Drama hinträgt. Wie die bisherigen Ausführungen allerdings gezeigt haben, ist das Herstellen von übergeordneten und komplexen Zeitbezügen durch Vor- und Rückgriffe eine Zuständigkeit, die in der Moderne explizit dem Epischen zukommt. ${ }^{234}$ Durch das Produktiv-

230 Vgl. Wellbery: Goethes Faust I. Reflexion der tragischen Form. S. 11 f.

231 Theben erhofft sich eine erneute Rettung vor der Pest durch Ödipus - die erinnerte Rettung vor dem Bann der Spinx ist aber nur scheinbar, denn ihr ging Ödipus Mord an Laios voraus, der die Ursache für die gegenwärtige Seuche ist. Der Zeitbezug zwischen Vergangenheit und Gegenwart ist hier allerdings umgekehrt - die Pest bestimmt die Gegenwart, während die Rettung in der Vergangenheit verortet ist.

232 Wellbery: Goethes Faust I. Reflexion der tragischen Form. S. 13.

233 Vgl. ebd. S. 12.

234 Vgl. Kap. 4.1: Gattungspoetologie als Gegenwartskritik: Zwischen Epos und Roman und 4.2: Von der Krise der Kunst und der Verzeitlichung der Zeit. 
machen dieser epischen Lizenz zur zeitlichen Entgrezung für das moderne Drama gelingt Goethe die Übertragung der mythischen Wirkungsmacht der antiken Tragödie in die Neuzeit und gleichzeitig eine entscheidende Öffnung und Erweiterung der streng normierten Tragödienform. Trotz tragisch konzentrierter Handlung und Diskontinuität erlangt Goethes Faust-Dichtung so eine episch-sinnliche Breite, die ihr wiederum zu umfassender, allgemeiner Bedeutung gereicht und den Blick auf ein großes Ganzes - Fausts gesamtes Leben - eröffnet.

\subsubsection{Das komplexe Zeitregime der Achilleis}

Die gestaltgebende Kraft der tragischen Peripetie macht sich Goethe auch in der Achilleis zunutze, ${ }^{235}$ oder zumindest hatte er den Plan dazu gefasst, wie die Paralipomena erkennen lassen. In der ersten Episode des fünften Gesangs sollte Achilles' Blick in der Heeresversammlung der Griechen auf die stumme Polyxena fallen, worauf er in plötzlicher Leidenschaft entflammen würde danach wäre alles anders. ${ }^{236}$ „Achilleus weiß, dass er sterben muss, verliebt sich aber in Polyxena und vergisst sein Schicksal rein darüber, nach der Tollheit seiner Natur ${ }^{\text {"237 }}$ - so beschreibt Goethe die alles entscheidende Szene in einem Brief an Riemer und landet damit im eigentlichen Zentrum der Tragödienform: Zwei durch eine Zäsur geschiedene Hauptlinien - Achilles' Weg in den Tod zum einen und die Liebe zu Polyxena zum anderen bestimmen die Grundstruktur der Achilleis. ${ }^{238}$ Um diesen Wendepunkt, der genau in die Mitte der geplanten acht Gesänge fallen sollte, legt Goethe seine ganze Dichtung an. Während die anderen Gesänge durch klare Zäsuren voneinander getrennt sind, verbindet Goethe nun aber den vierten und fünften Gesang in der Mitte der Dichtung, indem er die Heeresversammlung der Griechen bereits in der zweitletzen Szene des vierten Gesangs beginnen lässt, dann aber zwischen diesen ersten und den im fünften Gesang folgenden, zweiten Teil der Versammlung eine olympische Szene einschiebt. Mit dieser dreiteiligen Verdichtung - Versammlung, Olymp, Versammlung - inmitten des Gedichts werden der vierte und der fünfte Gesang zusammengefügt und die dazwischenliegende Zäsur überbrückt. Durch die formale Struktur dieser Verdichtung und ihre mittige Position im Gesamttext wird die zentrale Bedeutung

235 Vgl. Dietrich: Die Geheimnisse, Achilleis, Das Tagebuch. S. 268-29o, hier S. 276.

236 Zu sämtlichen Äusserungen zu den Schemata vgl. MA 6.1. S. 1105 f. und 1112.

237 Zitiert nach Schadewaldt: Goethes Achilleis. S. 301-395, hier S. 348.

238 Vgl. Jessing: Zwischen Antikisierung und Moderne: Goethes Achilleis. S. 249-264, hier S. 254 . 
der Peripetie, der plötzliche Umschlag von Todes- zu Liebeshandlung, gerade besonders akzentuiert. ${ }^{239}$

Anders als im Faust oder auch im Ödipus funktioniert die Peripetie in der Achilleis allerdings nicht einfach als Scheidepunkt in einer Ereignisskette, die insgesamt eine lineare und konsekutive Abfolge vorgibt. Während beide Handlungslinien der Faust-Tragödie in die gleiche Richtung weisen - nämlich unaufhaltsam vorwärts in die Katastrophe - und dadurch das tragische Moment verstärken, weisen die Hauptlinien der Achilleis vielmehr in entgegengesetzte Richtungen: Der Todesbefangenheit kommt eine tragisch vorwärtsstrebende Funktion zu - Achilles ist ganz auf sein baldiges Ende fokussiert - während die Liebeshandlung dagegen in der Zeit zurückweist - in der Beziehung zu Polyxena scheint sich Achilles seinem Schicksal entziehen zu können. Auch wenn dieser plötzliche Umschwung - von Todes- zu Liebesthematik und wieder zurück - nicht ausgeführt wurde, wird er im ersten Gesang bereits vielfach vorausgedeutet und vorbereitet. ${ }^{240}$ Mit dem Beginn des Gedichts setzt zunächst die Todeslinie ein, Achilles weiß nicht nur, dass er noch vor dem Fall Trojas sterben wird - „So wird kommen der Tag, da bald von Ilios' Trümmern / Rauch und Qualm sich erhebt, [...] Aber ich werd' ihn nicht sehen!" (V.18-21)-, sondern er hat sich mit diesem Schicksal auch abgefunden: „Soll dies also nun sein, wie mir es die Götter entbieten; Sei es!“ (V. 26 f.). In vollem Einverständnis mit dem eigenen Tod richtet Achilles seine ganze Aufmerksamkeit auf die Errichtung seines Grabes. Diese Todesbefangenheit wäre über den ersten Gesang hinaus bis zur Begegnung mit Polyxena Achilles' Hauptcharakteristik geblieben.

Die Gegenbewegung, die Achilles von seinem Tod zu entfernen und ihn dafür auf Liebe und Hochzeit hinzuführen scheint, setzt nun mit jenem Aufruf des Zeus in der ersten olympischen Szene ein: „noch drängt nicht Verderben / Unaufhaltsam heran, die Mauern Trojas zu stürzen, / Auf denn! wer Troja beschützt, beschütze zugleich den Achilleus“ (V. 296-298). Damit zieht ausgerechnet der mächtigste aller Götter nicht nur die Unausweichlichkeit von Achilles' baldigem Tod in Zweifel, sondern stellt auch dessen Zusammenhang mit dem Fall Trojas in Frage: ${ }^{241}$ Weshalb Troja nicht erobert werden und Achilles dennoch nach Hause zurückkehren kann, scheint auf einmal nicht mehr unmittelbar einsichtig zu sein. Bei Goethe entzieht sich damit die menschliche Wirklichkeit grundsätzlich der göttlichen Wirkungsmacht

239 Vgl. Schadewaldt: Goethes Achilleis. S. 301-395, hier S. 349.

240 Vgl. Reinhardt: Tod und Held in Goethes Achilleis (Vortrag vor der Leipziger GoetheGesellschaft, Okt. 1944). S. 283-308, hier S. 293.

241 Vgl. Dreisbach: Goethes Achilleis. S. 205. 
und das Verhältnis der Menschen zum Schicksal erscheint als ein zutiefst problematisches und beeinflussbares (V. 236-241). In allen Beispielen, die Zeus hier zitiert, haben Menschen ihr vorbestimmtes Schicksal verändert und sich dem sicheren Tod entzogen (V. 242-248). Schiksalsbestimmung und eigene Entscheidungsmöglichkeit sind hier nicht mehr eine selbstverständliche Einheit, vielmehr stehen sich innere Freiheit und äußere Verpflichtung als Widerspruch gegenüber. Der freien Selbstbestimmung kommt in Zeus' Antwort nun besondere Bedeutung zu, beschreibt er sie doch als die Kraft, welche die eigentliche Ordnung herstellt: „Ja, es treibet der Mensch sie zurück, die Keren des Todes [Hervorhebung M.E.]“ (V. 252). Unter diesem Gesichtspunkt wird auch Heres Beharren auf der Themis - „Denn so hoch wir auch stehn, so ist der ewigen Götter / Ewigste Themis allein, und diese muss dauern und walten" (V. 283 f.) - als ein Bestehen auf dem Gesetz nur um des Gesetzes willen erkennbar, ohne Einsicht in dessen Sinn oder kritische Betrachtung. ${ }^{242}$ Somit verhandelt die Achilleis in der Rede des Zeus ganz zentral die modernen Prinzipien von persönlicher Autonomie, Freiheit und privatem Glück. Wie Goethe darin das Prinzip der Hoffnung ${ }^{243}$ exemplarsich gegen die Unausweichlichkeit des Schicksal in Stellung bringt, steht der antiken Tradition, in der Götter und Schicksal eine geschlossene Einheit bilden, klar entgegen.

Allerdings geht es hier bei weitem nicht um die Selbstversicherung im modernen Kosmos, sondern vielmehr darum, auf die Unzulänglichkeiten seiner Dichotomien hinzuweisen. Die in der Moderne grundsätzlich positiv besetzten Prinzipien von Hoffnung und Freiheit werden in Goethes Epos nämlich durchwegs kritisch beleuchtet - dem mit der griechischen Mythologie wohl vertrauten Leser entgeht nicht, dass Zeus in seiner Aufzählung jeweils unterschlägt, dass am Ende all dieser Begebenheit dann doch der Tod steht: Die aufopfernde Alkestis wird aus dem Reich der Toten gerettet, bleibt danach der Welt der Lebenden und damit auch ihrem Geliebten Admetos aber entrückt. Protesilaos kehrt nach seinem Tod zwar für kurze Zeit in die Oberwelt zurück, aber als er wieder in den Hades hinab muss, folgt ihm seine Gemahlin aus lauter Verzweiflung nach. Auch Orpheus erhält seine verstorbene Geliebte zwar zurück, allerdings nur für kurze Zeit. Und der Totenerwecker Asklepios bezahlt seine Freveltat mit dem eigenen Tod. ${ }^{244}$ Die moderne, auf dem Fort-

\footnotetext{
242 Vgl. ebd. S. 205 f.

243 Zur besonderen Bedeutung der Hoffnung als christlichem Prinzip in der Achilleis vgl. Gärtner: Das Motiv der Hoffnung in Goethes Achilleisfragment. S. 174-181 und Dreisbach: Goethes Achilleis. S. 94-106 sowie Reinhardt: Tod und Held in Goethes Achilleis (Vortrag vor der Leipziger Goethe-Gesellschaft, Okt. 1944). S. 283-308, hier S. 302.

244 Asklepios. In: Der Neue Pauly Online. https://referenceworks.brillonline.com/entries/ der-neue-pauly/asklepios-e2038oo [abgerufen am 8.10.2019].
} 
schrittsglauben der Neuzeit gründende Konzeption von Hoffnung ${ }^{245}$ wird dadurch unterschwellig als Verblendung, als etwas trügerisches vorgeführt.

Entsprechend vielfältig sind die Folgen von Zeus' Ausspruch, aufgrund dessen die Götter nun jeweils für die eine oder andere Konfliktpartei in Aktion treten und versuchen, den Ausgang zu ihren Gunsten zu beeinflussen: Ares wird die Amazonen und Memnon zum Schutze Trojas herbeirufen (V. 327 ff.); Hera schickt Pallas Athene, um Achilles' Gemüt aufzuheitern (V. 386-397), Apollon ruft die Priamiden zum Widerstand gegen die Griechen auf (V. 345 ff.) und Kypris wird versuchen, ihn davon abzubringen (V. 352 f.). Auch die Wirkung, die Polyxena auf Achilles hat und welche die Liebeshandlung initiiert, ist schließlich Aphrodites Werk, die hofft, die Trojaner dadurch auszustechen. ${ }^{246}$ Und wenn Kypris dem sich nach Thymbra begebenden Apollon nachblickt (V. 344 f.), wird damit bereits der künftige Ort von Achilles' Tod zitiert und in ein Spannungsverhältnis gesetzt mit seinem momentanen Aufenthaltsort, dem Grabhügel. ${ }^{247}$ Noch wird der thymbräische Tempel nicht geschildert, sondern nur genannt, noch steht er wie verdeckt von der Beschreibung des sich immer höher türmenden Grabhügels: So hält sich Achilles' zukünftiges Schicksal gleichzeitig verborgen hinter seiner Gegenwart und ist dieser dennoch bereits eingeschrieben. Daraus lässt sich deutlich erkennen, dass die einführende, linear verlaufende Todeshandlung durch die hier vorbereitete Liebeslinie einen retardierenden Aufschub erfährt ${ }^{248}$ und die ganze Dichtung insofern zentral um ein Verzögerungsmoment angelegt wird.

Der Liebe zu Polyxena kommt damit eine ähnliche Funktion für die Achilleis zu, wie der Zorn des Achilles für die Ilias. ${ }^{249}$ Es handelt sich dabei zweifellos um eine Bemühung Goethes, den grundsätzlichen Mangel an für das Epische ausschlaggebender Retrogradation durch retardierende Vorfälle zu beheben. ${ }^{250}$ Achilles' Weg zu seinem Tod sollte weder gradlinig verlaufen noch durch Hindernisse gestört werden, die überwunden werden müssen, wie etwa im Ödipus auf Kolonos. Die tragische Handlung soll nicht aufgehalten, aber doch entschieden verzögert werden. Anders als im Faust, wo die disruptive Kraft des Tragischen zur vollen Entfaltung gebracht wird, bemüht sich Goethe also in der Achilleis besonders darum, einen abrupten Bruch zu vermeiden und verbindet

\footnotetext{
245 Vgl. Dreisbach: Goethes Achilleis. S. 95.

246 Vgl. Schadewaldt: Goethes Achilleis. S. 301-395, hier 353 f.

247 Vgl. Reinhardt: Tod und Held in Goethes Achilleis (Vortrag vor der Leipziger GoetheGesellschaft, Okt. 1944). S. 283-308, hier S. 294.

248 Vgl. Friedrich: Zeichenbaustellen. Goethes Achilleïs. S. 65-82, hier S. 72.

249 Vgl. Liggieri: Warum gelingt uns das Epische so selten? Ein Blick hinter Goethes Achilleis. S. $56 \mathrm{f}$.

250 Vgl. WA IV, 12. S. 384.
} 
dafür die tragische Zäsur mit der epischen Retardation. Die Handlung stellt so einen ambivalenten, vor- und wieder zurückschreitenden Prozess vor, in dem sich das Tragische und das Epische in einem diffizilen Gleichgewicht halten. Paradoxerweise trägt das Liebesmotiv gleichwohl zum tragischen Umschwung bei, als es gerade auch wieder der epischen Entschleunigung dient. So scheint sich Achilles durch die Liebe zu Polyxena zwar von seinem Tod zu entfernen würde er sich vom Krieg abwenden, könnte er mit Polyxena glücklich werden und Troja könnte dennoch fallen - aber auch diese scheinbare Gegenbewegung führt mit unentrinnbarer Notwendigkeit zu seinem vorbestimmten Tod. ${ }^{251}$ Die Erfahrung der Retardation eröffnet so zwar andere Wege - Achilles' Schicksal erfüllt sich schließlich anders als erwartet - aber trägt gerade auch zur Erfüllung der tragischer Form bei: Achilles' plötzliche Ermordung kann gerade deshalb die tragische Wirkung der jähen Peripetie entfalten, weil die Handlung zuvor retardiert wurde und einen möglichen glücklichen Ausgang vorstellte. ${ }^{252}$

Damit stehen die Linien der Todesbefangenheit und der Leidenschaft sowie die ihnen eingeschriebenen Eigenzeiten weder in einem Abfolge- noch in einem Ausschlussverhältnis, sondern überkreuzen sich vielmehr in tiefsinniger Verbindung. ${ }^{253}$ Das Etablieren von Oppositionen, deren Durchkreuzen und wieder Auflösen spielt sich in der Achilleis besonders prominent auf der Ebene der Zeitorganisation ab und erzeugt hier ein komplexes, zutiefst uneindeutiges Gefüge: „Nicht ist fest umzäunt die Grenze des Lebens“ (V. 251), stellt Zeus fest und zieht damit nicht nur den vorherbestimmten Tod des Achilles in Zweifel, sondern überhaupt die Macht des Schicksals. Trotz Prophezeiung besteht für Achilles bis zuletzt die Hoffnung auf Leben und Liebe, denn „[s]o auch weiß, mich dünkt, kein Gott noch Göttinnen erste, / Wem vom Ilios' Feld Rückkehr nach Hause bestimmt sei.“ (V. 262 f.). Damit rührt der Streit um Achilles' Tod unmittelbar an die Grundfesten nicht nur der olympischen, sondern überhaupt der tradierten Weltordnung. Die Zeitdimensionen stehen nicht mehr in einer verbindlich-zuverlässigen Beziehung zueinander - obwohl Achilles' Tod in der Vergangenheit beschlossen wurde, zweifelt Zeus daran, dass dieses Ereignis in Zukunft auch eintreffen muss. Auch wenn Zeus' Aussage sich als einmalig und situationsbedingt erweist - das ganze folgende Gespräch zwischen

251 Vgl. Schadewaldt: Goethes Achilleis. S. 301-395, hier S. $35^{2}$.

252 Vgl. Reinhardt: Tod und Held in Goethes Achilleis (Vortrag vor der Leipziger GoetheGesellschaft, Okt. 1944). S. 283-308, hier S. 301.

253 Vgl. Jessing: Zwischen Antikisierung und Moderne: Goethes Achilleis. S. 249-264, hier S. 254 und Friedrich: Zeichenbaustellen. Goethes Achilleïs. S. 65-82, hier S. 72. 
Achilles und Athene ist schließlich allein durch Achilles' bevorstehenden Tod motiviert - zerbricht darin die mythische Einheit von Zeit und Schicksal.

Dass Goethe hier nicht nur deutlich, sondern ganz bewusst vom homerischen Vorbild abfällt, zeigt sich auch an der göttlichen Auseinandersetzung zwischen Zeus und Here. In den Worten des Göttervaters erscheint die antike Vorstellung einer aus der Vergangenheit verbürgten Zukunft keine Gültigkeit mehr zu haben. Anstatt eines umfassenden Gesamtzusammenhangs ergibt sich hier vielmehr der Eindruck von Unberechenbarkeit und Kontingenz nicht einmal die Götter kennen die Zukunft. Diesen Autoritätsverlust, nicht nur der Götter, sondern eben auch der Zeit selbst, verbindet Zeus nun aber im modernen Sinn mit den Vorstellungen von Freiheit und Hoffnung. Heres Beharren auf dem ewigen Gesetz der Themis, auf Ordnung und Verlässlichkeit (V. 275-286), steht Zeus' Idee einer offenen Zukunft nicht nur radikal entgegen, sondern wird in dessen Vergleich mit den Titanen auch als zerstörerisch ausgewiesen (V. $293 \mathrm{ff}$.). Here schimpft Zeus wohl einen „Schrekliche[n], wankende[n] Gesinnte[n]" (V. 268) und bezichtigt ihn der Willkür (V. 281), deckt aber mit ihren eigenen Worten gerade die unbarmherzige Brutalität ihres Zeitmodells auf:

Denn wer im Wege steht dem Geschick, das dem endlichen Ziele Fruchtbar zueilt, stürzt in den Staub, ihn zerstampfen die Rosse, Ihn zerquetschet das Rad des ehernen heiligen Wagens. (V. 275-277 ff.)

Nicht nur ist das Bild des Schicksalswagens unhomerisch, ${ }^{254}$ mehr noch scheinen sich darin anstatt eines antiken Zeitbegriffs gerade die problematischen Aspekte der modernen Vorstellung von Zeit als unaufhaltsamer, linearer Beschleunigung zu manifestieren. In der Achilleis wird also die tradierte Vorstellung einer gesicherten, kontinuierlichen Zeitenfolge, wenn nicht abgelöst, so zumindest ins Spiel gebracht mit dem disparaten, reflexiven Zeitgefüge der Moderne. Das Hin- und Herschwanken zwischen Kontinuität und Kontingenz erzeugt zwar ein gleichwohl unlösbares wie auch besonders reizvolles Spannungsverhältnis, ${ }^{255}$ es erweisen sich aber auch der Bruch im Zeitgefüge als unhintergehbar und das Herstellen von Kontinuität als von vorneherein gefährdete Unternehmung: Während Hephaistos im antiken Epos Zeus und Here miteinander versöhnen kann, erscheinen ihre entgegengesetzten Positionen sowie die damit in Beziehung stehenden Zeithorizonte der Antike und der Moderne in Goethes Achilleis unvermittelbar.

254 Vgl. Dreisbach: Goethes Achilleis. S. 191.

255 Vgl. Meid: Goethes Achilleis - Versuch eines modernen Epos in der Nachfolge Homers. S. 83-101, hier S. 84 . 


\subsubsection{Formale Überstrukturierung der Komposition}

Dieser grundsätzlichen Diskontinuität auf der Ebene des Dargestellten versucht Goethe auf der Darstellungsebene mit extremer kompositorischer Gefügtheit zu begegnen. Zunächst schreibt er sein ganzes Gedicht unauflösbar in die Ilias ein, indem er nicht einfach an deren letzten Vers anschließt, wie das Morris ${ }^{256}$, Regenbogen ${ }^{257}$, Gerhard ${ }^{258}$ und auch Constantine ${ }^{259}$ behauptet haben, sondern den Anfang der Achilleis und das Ende der Ilias vielmehr übereinander legt. ${ }^{260}$ Am Ende der Ilias handeln Achilles und Priamos einen elftägigen Waffenstillstand zur Bestattung Hektors aus, am zwölften sollte der Kampf wieder aufgenommen werden (Il. 24, V. 657-667). Geschildert werden dann neun Tage der Trauer, die Verbrennung am zehnten und die Errichtung des Grabhügels am elften Tag - der zwölfte bleibt allein angekündigt. ${ }^{261}$ Goethes Achilleis setzt jedoch nach der Verbrennung Hectors und damit kurz vor dem Ende der Ilias ein - diese erwähnt bereits die Morgenröte, die den zehnten Tag ankündigt (Il. 24, V. 785). Der erste Gesang der Achilleis beginnt nun aber nicht mit dem neuen Tag, sondern noch in der Nacht mit dem letzten Aufflammen von Hektors Scheiterhaufen:

Hoch zu Flammen entbrannte die mächtige Lohe noch einmal,

Strebend gegen den Himmel, und Ilios' Mauern erschienen

Rot, durch die finstere Nacht; der aufgeschichteten Waldung

Ungeheures Gerüst, zusammenstürzend, erregte

Mächtige Glut zuletzt. Da senkten sich Hektors Gebeine

Nieder, und Asche lag der edelste Troer am Boden. [Hervorhebungen M.E. (V. 1-6)

Damit leistet Goethe eine zeitliche Überlagerung der Ereignisse, ${ }^{262}$ ohne allerdings an einen konkreten Vers der Ilias anzuschließen. Gleichzeitig nimmt er nämlich einen Schauplatzwechsel vor, wenn er die Verbrennung Hektors nun aus der Perspektive des Achilles schildert, der im Lager der Griechen weilt. Diese Art des Anknüpfens an das homerische Ende der Ilias erzeugt gleichzeitig Nähe wie auch Distanz - Goethes Gedicht bezieht sich sowohl inhaltlich

256 Morris: Goethes Achilleis. S. 26.

257 Regenbogen: Über Goethes Achilleis (1942). S. 495-520, hier S. 506.

258 Gerhard, Melitta: Götter-Kosmos und Gesetzessuche: Zu Goethes Versuch seines Achilleis-Epos. In: Monatshefte 4 (1964). S. 145-159, hier S. 145.

259 Constantine: Achilleis and Nausikaa. Goethe in Homer's World. S. 107.

26o Vgl. Meid: Goethes Achilleis - Versuch eines modernen Epos in der Nachfolge Homers. S. 83-101, hier S. 93 .

261 Vgl. Dreisbach: Goethes Achilleis. S. 79.

262 Vgl. Meid: Goethes Achilleis - Versuch eines modernen Epos in der Nachfolge Homers. S. 83-101, hier S. 93 und Dreisbach: Goethes Achilleis. S. 174. 
wie auch formal klar auf das antike Epos, ${ }^{263}$ es handelt sich dabei aber bei weitem nicht um ein Weitererzählen der Ilias, sondern um einen klar davon getrennten, eigenständigen Versuch epischer Dichtung für die Neuzeit. ${ }^{264}$ Damit erhalten die temporalen Wendungen der ersten sechs Verse, „Noch einmal“ und „zuletzt", überragende Bedeutung, denn sie verweisen nicht nur auf etwas unmittelbar vorhergegangenes, sondern auch spezifisch auf den Übergang zwischen Antike und Moderne. ${ }^{265}$

Darüber hinaus leiten sie vom Schauplatz am Ende der Ilias zum Griechenlager und Ort der nun folgenden Begebenheiten über und führen gleichzeitig vom zentralen Motiv der Ilias hinüber zum neuen Thema der Achilleis, wodurch ihre Vermittlungsfunktion zusätzlich akzentuiert wird. Im Anschluss an die ersten Verse wird in weiteren sechs Versen Achilles geschildert, der sich erhebt, nachdem er den Flammen aus der Ferne zugeschaut und in diesem Anblick noch einmal seinen Hass auf Hektor aufleben gespürt hat. Dabei stehen die Formulierungen „die Stunde durchwachte“ (V. 8) und „ihm den Freund erschlug" (V.12) im Präteritum nebeneinander, die beiden vergangenen Ereignisse werden so auf die gleiche Zeitstufe gehoben und gleichzeitig dem gegenwärtigen Moment - dem letzten Aufflammen und Achilles' in Bewegung geraten - eingeschrieben. Mit dem 13. Vers kommen nun die Nacht, das Feuer des Scheiterhaufens und das alte Thema der Ilias, Achilles' Zorn, gleichsam zu einem Ende:
Aber als nun die Wut nachließ des fressenden Feuers Allgemach und zugleich mit Rosenfingern die Göttin Schmückete Land und Meer, dass der Flammen Schrecknisse bleichten, Wandte sich, tief bewegt und sanft, der große Pelide Gegen Antilochos hin und sprach die gewichtigen Worte:
„So wird kommen der Tag, da bald von Ilios' Trümmern Rauch und Qualm sich erhebt, von thrakischen Lüften getrieben, Idas langes Gebirg' und Gargaros' Höhe verdunkelt; Aber ich werd' ihn nicht sehen! [...]" (V. 13-21)

Erst in dieser Rede des Achilles wird an das neue Hauptthema, den bevorstehenden Tod, herangeführt. Die eigentliche Einleitung in die Achilleis als etwas völlig Neues - „der große Pelide“ und "die gewichtigen Worte" unterstreichen die große Bedeutung, die dieser Stelle zukommt - erfolgt also erst

263 Vgl. Martin: Das deutsche Versepos im 18. Jahrhundert. Studien und kommentierte Gattungsbibliographie. S. 292.

264 Vgl. Meid: Goethes Achilleis - Versuch eines modernen Epos in der Nachfolge Homers. S. 83-101, hier S. 94.

265 Vgl. Dreisbach: Goethes Achilleis. S. 174. 
nach zwölf Versen. Bemerkenswerterweise wollte Goethe wohl auch das Ende der Achilleis in dieser Art eines gleichzeitigen Anknüpfens und Abschließens gestalten. Gemäß den Schemata sollte nämlich Achilles bereits gegen Ende des siebten Gesangs zu Tode kommen ${ }^{266}$ und im Anschluss noch die Folgen seines Todes geschildert werden: Im achten Gesang wäre es unter den Griechen zu Machtkämpfen und Rivalitäten gekommen, um Achilles' Waffe würde gestritten, Odysseus würde losgeschickt, um Achilles' Sohn herbeizuholen, Achilles' Leichnam würde an Thetis übergeben und neue Verbündete im Kampf gegen Troja würden erscheinen. Die letzte Notiz lautet: „102. Ajax Raserei und Tod“, womit die Achilleis mit dem Tod Ajax', anstatt mit dem Tod ihres Titelhelden beendet würde. ${ }^{267}$ Zunächst hätte Goethe damit einen bereits tragisch behandelten Stoff einer epischen Neubearbeitung unterzogen. ${ }^{268}$ Darüber hinaus erzeugen die Verknüpfung von Achilles' und Ajax' Schicksal die Rahmung der Achilleis-Handlung mit dem Tod zweier homerischer Helden ${ }^{269}$ epische Breite ${ }^{270}$ und Kontinuität. In Ajax' tödlicher Raserei wird der Tod des Achilles wieder aufgenommen und gleichwohl übersteigert - durch diesen Parallelismus besingt die Achilleis nicht einfach das Ende eines Individuums, sondern eines ganzes Helden- und Weltbildes. ${ }^{271}$ Mit dem Tod Hektors am Anfang und dem Tod des Ajax am Ende erscheint die Achilleis als Teil einer übergreifenden, kontinuierlichen Geschichte. Das Gedicht hätte nicht nur aus der Antike in die Moderne, sondern auch wieder zurückgeführt und so als Ganzes eine vermittelnde Funktion zwischen den Zeiten erlangt.

Den Weg zurück in die Antike und zu antiker Totalität scheint Goethe allerdings nicht mehr gefunden zu haben, davon zeugt gerade der massive narrative Aufwand, den er betreibt, um jeglichen Bruch zu vermeiden. Der erste Gesang umfasst drei inhaltlich voneinander getrennte Teile: Auf dem Grabhügel (V. 1-6o), von hier aus schaut Achilles auf sein Leben zurück und denkt über sein Schicksal nach. Im Olymp (V. 61-397), wo die Götter um Achilles' Schicksal streiten. Und wieder auf dem Grabhügel (V. 398-651), wo sich im Gespräch zwischen Achilles und Athene die Sphären des Irdischen und des Göttlichen begegnen. Die Schemata skizzierten den Wechsel zwischen der Handlung auf Erden und der Götterversammlung noch nach homerischer Art

\footnotetext{
266 Vgl. MA 6.1. S. 1106.

267 MA 6.1. S. 1107.

268 Vgl. Friedrich: Zeichenbaustellen. Goethes Achilleïs. S. 65-82, hier S. 72.

269 Vgl. Meid: Goethes Achilleis - Versuch eines modernen Epos in der Nachfolge Homers. S. 83-101, hier S. 91.

270 Vgl. Reinhardt: Tod und Held in Goethes Achilleis (Vortrag vor der Leipziger GoetheGesellschaft, Okt. 1944). S. 283-308, hier S. 295.

271 Vgl. Dreisbach: Goethes Achilleis. S. 105.
} 
als plötzliche Verlagerung des Schauplatzes. ${ }^{272}$ In der Ausführung gestaltet Goethe dann aber diesen Szenenwechsel mit größter Umsicht als ein langsames, graduelles und sinnvoll strukturiertes Nacheinander. Der narrative Aufstieg von der Erde zum Olymp beginnt mit Eos, der Göttin der Morgenröte, die Achilles' Myrmidonen freundlich anblickt (V. 54) und mit ihrem Licht zur Arbeit animiert (V. 56). Goethes Eos ist eine „Völkerweckerin“ (V. 21), sie wirkt nur auf die Menschen erfreulich und erquickend, während ihr Licht die Lebenssphäre der Götter nicht zu erreichen vermag. Nach Eos erscheint Helios mit seinem Gespann (V. 62-68), das nun die ganze Erde beleuchtet, also die räumliche Perspektive erweitert und dessen Heraufziehen die Götter- und Menschenwelt als einen eng miteinanderverbundenen Kosmos zeigt. Darauf folgen die Horen, die das letzte Stück zum Olymp hinaufführen (V. 67) und hier Hephaistos begegnen (V. 69). Dieser trifft seinerseits auf Here und Pallas Athene (V. 95), worauf dann der Rest der Götter den Saal betritt. Dieser Einzug wird einerseits summarisch geschildert und dennoch erhält jede Gottheit eine Charakterisierung ihrer Persönlichkeit, wie auch ihrer Beziehung zu den übrigen Göttern (V. 123-134). Hier stellen sowohl Artemis' als auch Aphrodites Auftritte wiederum eine Verbindung zum irdischen Geschehen her - beide kehren sie in den Morgenstunden (V. 132) direkt von der Erde zurück, wodurch die Handlungen im Olymp und auf Erden als gleichzeitig stattfindend markiert werden. ${ }^{273}$ Als zweitletzter Gott erscheint Zeus bzw. Kronion, mit seinem Eintreffen wird ein kompositorischer Höhepunkt erreicht - der Wechsel von irdischem zu olympischem Geschehen ist vollzogen - nach ihm tritt nur noch Thetis in ihrer Rolle als Bittstellerin auf.

Diese extreme formale Gefügtheit wiederholt sich als gespiegelte Symmetrie im Abtreten der Götter - Zeus geht als Erster, ihm folgt Thetis, dann Ares, Phöbos und schließlich Athene - so wie im erneuten Schauplatzwechsel zum Grabhügel. Athene eilt zwar durch den Himmel hinab auf die trojanische Ebene, die Darstellung dehnt sich aber aus, indem alles geschildert wird, was Athene in ihrer Eile nicht sieht (V. 398-411). Und auch die Beschreibung des olympischen Lokals selbst folgt einer klaren kompositorischen Logik. Schritt für Schritt wird hier von außen immer mehr ins Innere geführt, von der Himmelspforte (V. 61) zu Zeus' Haus (V. 68), über dessen Schwelle (V. 93) zum Göttersaal (V. 123) und schließlich auf den Thron (V. 139). In Goethes Dichtung geschieht nichts unvorbereitet, nichts steht isoliert oder zusammenhangslos, die ganze Komposition ist vielmehr dezidiert auf das Herstellen von Ganzheit und Geschlossenheit ausgerichtet. Diese tatsächlich unhomerischen

272 Vgl. ebd. S. 196.

273 Vgl. ebd. S. 197. 
Modernisierungen ${ }^{274}$ versucht Goethe auf der sprachlichen Ebene auszugleichen, indem er sich der antiken Metrik und Wortbildung bedeutend stärker annähert als noch in Hermann und Dorothea. ${ }^{275}$ Die Hexameter der Achilleis folgen mehr den strengen theoretischen Regeln der Versbildung als einer sinnlich-intuitiven Versifikation, die Sprache ist komplizierter, weniger verspielt und wirkt dadurch auch um einiges artifizieller. Die ursprünglichen Trochäen der Verse 15 („Schmückte“) und $5^{2}$ („wellenbespülten“) erscheinen in der Erstausgabe zu reinen Daktylen umgebildet („Schmückete“, „wellenbespületen“). Aus „sprechend untereinander" wird „sprechend wechselndes Wort" (V. 96) und damit eine direkte Referenz auf die Odyssee (3, V. 148). ${ }^{276}$ Zudem setzt Goethe im Gegensatz zu Hermann und Dorothea in der Achilleis zahlreiche der von Voß vorgeschlagenen Korrekturen um. Den ersten Vers stellt er von „Hoch zu Flammen entbrannte noch einmal die mächtige Lohe“ zu „Hoch zu Flammen entbrannte die mächtige Lohe noch einmal“ um, wodurch die verpönte Zäsur nach dem Trochäus im vierten Fuß vermieden und stattdessen eine Diärese ${ }^{277}$ eingeführt wird. ${ }^{278}$ Für den fünften Vers schlägt Voß vor, „Es“ durch den stärkeren Partikel „Nun“ zu ersetzen, darüber geht Goethe dann sogar hinaus und setzt neu „Da“ an den Beginn des dritten Versfußes. „Achilles“ ersetzt Voß wenn immer möglich durch die volle griechische Namensform „Achilleus“ (V. 7, 346, 359, 512). „[N] och Harnisch, noch aber des Schildes/Umfang“ korrigiert er zu: „noch der Harnisch, noch auch des Schildes / Umfang“ - der Artikel stellt einen Daktylus anstelle des Trochäus her. Auch diese Korrektur übernimmt Goethe, lässt aber die Formulierung „noch auch“ weg, so dass der Vers am Ende heißt: „noch der Harnisch, auch nicht des Schildes / Umfang“ (V. 103 f.). In der gleichen Manier schlägt Voß vor, „ein Wunder staunenden Augen“ zu „ein Wunder dem staunenden Anblick“ umzuformulieren - auch hier führt der Artikel zum Daktylus - Goethe entscheidet sich dann für „ein Wunder staunendem Anblick“. ${ }^{279}$

Diese Korrekturen der Handschrift zeigen, dass Goethe den sprachlichen Ausdruck an zahlreichen Stellen stark dem homerischen annähert. Damit

274 Vgl. ebd. S. 177.

275 Vgl. ebd. S. 39 wie auch Liggieri: Warum gelingt uns das Epische so selten? Ein Blick hinter Goethes Achilleis. S. 164.

276 Analog dazu V. 131: statt „die reizende Göttin“: „die äugelnde Göttin“, V. 148: statt „Trauer im Blick“: „trauernden Blickes“, V. 312: statt „Achill“: „Achilleus“.

277 Einschnitt nach dem 4. Versfuß.

278 Analog dazu V. 105, 292, 364-149: aus „die erste der Neriden“ wird: „die lieblichste Tochter des Nereus".

279 Vgl. dazu auch Liggieri:Warum gelingt uns das Epische so selten? Ein Blick hinter Goethes Achilleis. S. 156-16o. 
zielt der Text allerdings nicht auf ein klassizistisches Kunstideal ab - dieses wird in der Eröffnungsszene der Götterversammlung mit Hephaistos und den Horen nämlich gerade einer scharfen Kritik unterzogen. Hephaistos' Saal ist wohl nach "dem göttlichen Maß des herrlichsten Musengesanges" erbaut und steht „vollendet“ und „vollkommen“ da, „[u]ngekränkt von der Zeit“ (V. 72-76). „Doch alles ist leblos!" (V. 84) und erst die Horen, Göttinnen der Zeit, der Anmut und des Reizes verhelfen durch ihr bewegliches „Leben und Licht“ (V. 91) dem toten Gebilde zu wahrer Schönheit. ${ }^{280}$ Nicht nur verbindet Hephaistos über das göttliche Maß des Musengangs - damit ist der Hexameter gemeint - die unvergänglich-vollkommenen Werke des Saals mit den traditionellen, aber im Ablösen begriffenen gattungspoetologischen Forderungen an das Epos, darüber hinaus verweist er auch auf das grundsätzliche Defizit an Lebendigkeit, Beweglichkeit und Ursprünglichkeit der normativ-regulierten Kunst. Die Kräfte der Zeit bringen zwar Destabilisierung und Vergänglichkeit, indem sie die Werte des Todes und des Lebens ${ }^{281}$ miteinander in Verbindung bringen, aber eben auch wahre Bedeutung - das ist die Erkenntnis der Morphologie, die Goethe seiner epischen Dichtung an dieser Stelle gleichwohl auf der Darstellungs- wie auch der Anschauungsebene einschreibt.

Darin zeigt sich nicht zuletzt auch Goethes Aneignung des Epischen als äußerst schwieriger Prozess zwischen Annäherung an das Ideal in sich geschlossener Ganzheit und bewusster Entfernung davon. Die große Mühe, die Goethe auf das Gestalten von gleitenden Übergängen verwendet, deutet deshalb vielmehr auf die fraktale Disposition der Achilleis und die für das Epos-Projekt überhaupt symptomatischen Brüche hin, als auf eine klassizistische Ästhetik der Einheit. ${ }^{282}$ Die letztlich unauflöslichen formalen Spannungen zwischen Tragischem und Epischem, Antikem und Modernem, Partialem und Ganzen prägen den ganzen Gesang und sind gerade das, was die Achilleis relevant macht. Der Text fordert dadurch immer wieder neu zur Auseinanderstzung mit ihm und zur Bewältigung seiner Bruchstellen auf, das macht ihn schließlich interessant für die Moderne. In der prekären Verbindung mit dem Tragischen wird so erneut deutlich, wie grundsätzlich gefährdet und unsicher die Form des Epischen in der Moderne ist. Die Achilleis verabschiedet mit der antiken Zeitordnung auch die veralteten Gattungsmerkmale der Ganzheit und der Geschlossenheit sowie das daran haftende Versprechen

280 Vgl. dazu Dreisbach: Goethes Achilleis. S. 193-196 und Schadewaldt: Goethes Achilleis. S. 301-395, hier S. 371 .

281 Vgl. Friedrich: Zeichenbaustellen. Goethes Achilleïs. S. 65-82, hier S. 77.

282 Vgl. Meid: Goethes Achilleis - Versuch eines modernen Epos in der Nachfolge Homers. S. 83-101, hier S. 99 . 
kultureller Kontinuität endgültig aus der Poetologie des Epischen und überführt es der Moderne. Nicht nur kann über den Bruch im Zeitgefüge und seine Konsequenzen nicht mehr hinweggetäuscht werden, sondern scheint überhaupt die Vorstellung eines Kontinuums, von verlässlichen Beziehungen zwischen den Zeiten obsolet geworden zu sein bzw. dienen sie hier nur noch als Folie. 